\title{
Side-by-Side Field Evaluation of Highly Insulating Windows in the PNNL Lab Homes
}

\section{FINAL REPORT}

SW Widder

GB Parker
MC Baechler

NN Bauman

August 2012

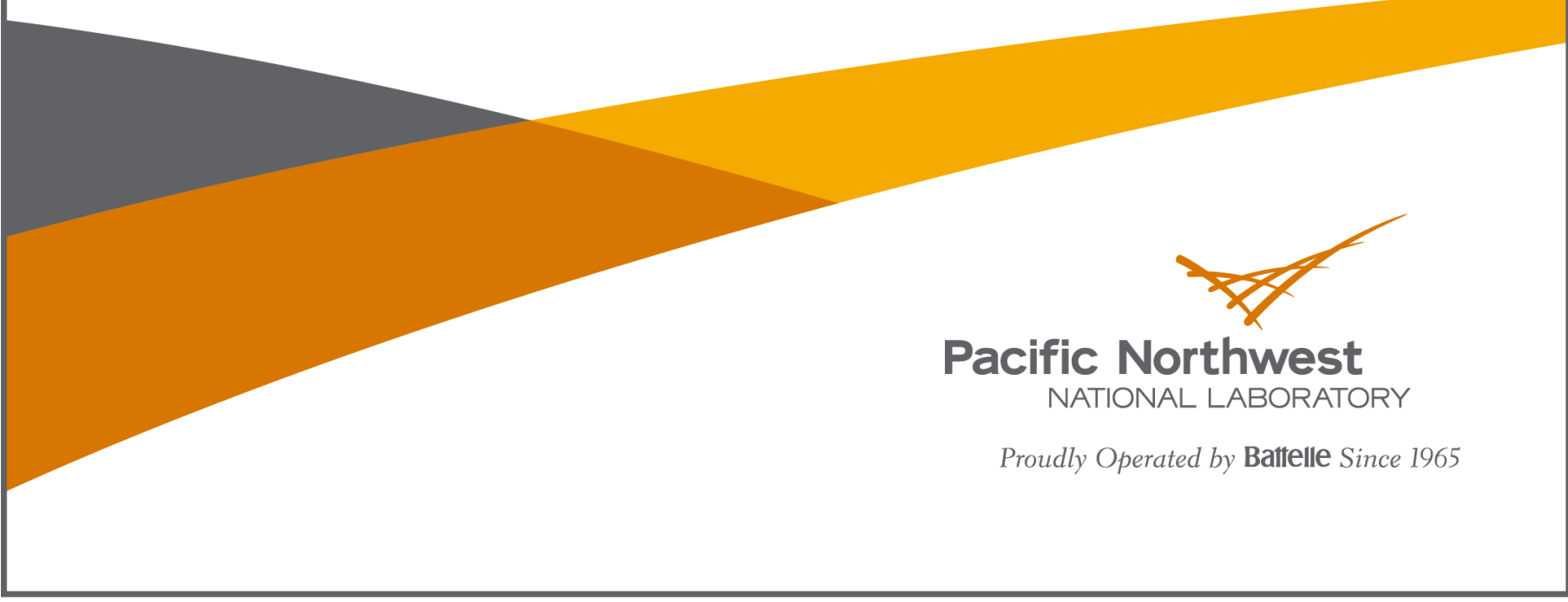




\title{
DISCLAIMER
}

This report was prepared as an account of work sponsored by an agency of the United States Government. Neither the United States Government nor any agency thereof, nor Battelle Memorial Institute, nor any of their employees, makes any warranty, express or implied, or assumes any legal liability or responsibility for the accuracy, completeness, or usefulness of any information, apparatus, product, or process disclosed, or represents that its use would not infringe privately owned rights. Reference herein to any specific commercial product, process, or service by trade name, trademark, manufacturer, or otherwise does not necessarily constitute or imply its endorsement, recommendation, or favoring by the United States Government or any agency thereof, or Battelle Memorial Institute. The views and opinions of authors expressed herein do not necessarily state or reflect those of the United States Government or any agency thereof.

\author{
PACIFIC NORTHWEST NATIONAL LABORATORY \\ operated by \\ BATTELLE \\ for the \\ UNITED STATES DEPARTMENT OF ENERGY \\ under Contract DE-AC05-76RL01830
}

Printed in the United States of America
Available to DOE and DOE contractors from the Office of Scientific and Technical Information,
P.O. Box 62, Oak Ridge, TN 37831-0062;
ph: (865) 576-8401
fax: $(865)$ 576-5728
email: reports@adonis.osti.gov
Available to the public from the National Technical Information Service
5301 Shawnee Rd., Alexandria, VA 22312 ph: (800) 553-NTIS (6847)
email: orders@ntis.gov $<$ http://www.ntis.gov/about/form.aspx $>$
Online ordering: http://www.ntis.gov

This document was printed on recycled paper. 


\section{Side-by-Side Field Evaluation of Highly Insulating Windows in the PNNL Lab Homes}

FINAL REPORT

SH Widder

MC Baechler

GB Parker

NN Bauman

August 2012

Prepared for

the U.S. Department of Energy

under Contract DE-AC05-76RL01830

Pacific Northwest National Laboratory

Richland, Washington 99352 



\begin{abstract}
To examine the energy, air leakage, and thermal comfort performance of highly insulating windows, a field evaluation was undertaken in a matched pair of all-electric, factory-built "Lab Homes" located on the Pacific Northwest National Laboratory (PNNL) campus in Richland, Washington. The "baseline" Lab Home A was retrofitted with "standard" double-pane clear aluminum-frame slider windows and patio doors, while the "experimental" Lab Home B was retrofitted with Jeld-Wen ${ }^{\circledR}$ triple-pane vinyl-frame slider windows and patio doors with a U-factor of 0.2 and solar heat gain coefficient of 0.19 . To assess the window, the building shell air leakage, energy use, and interior temperatures of each home were compared during the 2012 winter heating and summer cooling seasons. The measured energy savings in Lab Home B averaged 5,821 watt-hours per day (Wh/day) during the heating season and 6,518 Wh/day during the cooling season. The overall whole-house energy savings of Lab Home B compared to Lab Home A are $11.6 \% \pm 1.53 \%$ for the heating season and $18.4 \% \pm 2.06 \%$ for the cooling season for identical occupancy conditions with no window coverings deployed. Extrapolating these energy savings numbers based on typical average heating degree days and cooling degree days per year yields an estimated annual energy savings of $12.2 \%$, or $1,784 \mathrm{kWh} / \mathrm{yr}$. The data show that highly insulating windows are an effective energy-saving measure that should be considered for high-performance new homes and in existing retrofits. However, the cost effectiveness of the measure, as determined by the simple payback period, suggests that highly insulating window costs continue to make windows difficult to justify on a cost basis alone. Additional reductions in costs via improvements in manufacturing and/or market penetration that continue to drive down costs will make highly insulating windows much more viable as a cost-effective energy efficiency measure. This study also illustrates that highly insulating windows have important impacts on peak load, occupant comfort, and condensation potential, which are not captured in the energy savings calculation. More consistent and uniform interior temperature distributions suggest that highly insulated windows, as part of a high performance building envelope, may enable more centralized duct design and downsized HVAC systems. Shorter, more centralized duct systems and smaller HVAC systems could yield additional cost savings, making highly insulating windows more cost effective as part of a package of new construction or retrofit measures which achieve significant reductions in home energy use.
\end{abstract}





\section{Executive Summary}

Improving the insulation and solar heat gain characteristics of a home's windows has the potential to significantly improve the home's overall thermal performance by reducing heat loss (in the winter), and cooling loss and solar heat gain (in the summer) through the windows. A high-quality installation will also minimize or reduce air leakage through the building envelope, decreasing infiltration and thus contributing to reduced heat loss in the winter and cooling loss in the summer. These improvements all contribute to decreasing overall annual home energy use. In addition to improvements in energy efficiency, highly insulating windows can have important impacts on occupant comfort by minimizing or eliminating the cold draft many residents experience at or near window surfaces that are at a noticeably lower temperature than the room air temperature. Although not measured in this experiment, highly insulating windows (triple-pane in this experiment) also have the potential to significantly reduce the noise transmittance through windows compared to standard double-pane windows. Energy efficiency measures, such as highly insulating windows, also have the potential to decrease peak energy use in a home, which can lead to measurable peak load decreases for a utility service territory if implemented on a large scale.

High-performance windows now feature triple-pane glass, double low-e coatings, and vinyl insulated frames to achieve U-factors as low as $0.2^{1}$, as compared to double-pane clear glass windows with a Ufactor of 0.67 , which are common in existing homes across the United States. The highly insulating windows (as they will be referred to in this document) are now available from several manufacturers and show promise to yield considerable energy savings and thermal comfort improvements in homes.

To examine the energy, air leakage, and thermal comfort performance of highly insulating windows, a field evaluation was undertaken in a matched pair of "Lab Homes" located on the Pacific Northwest National Laboratory (PNNL) campus in Richland, Washington, during the winter heating and summer cooling seasons in 2012. The heating season data were taken from February 3 to April 13, 2012, and the cooling season data was taken from July 6, 2012 to August 18, 2012. In this field test, the energy savings from highly insulating windows in the experimental home (Lab Home B) were compared to those of the standard double-pane clear glass windows in the baseline home (Lab Home A).

In addition to the improved energy and thermal comfort performance, highly insulating windows must prove to be cost-effective compared to baseline, clear glass, windows to enable significant market penetration. Based on measured and modeled energy savings, as well as installed cost data from window manufacturers, the cost-effectiveness of windows in new construction and retrofit scenarios was examined.

\section{The PNNL Lab Homes}

The Lab Homes are factory-built, ${ }^{2}$ all-electric, and nearly $1,500 \mathrm{ft}^{2}$ with 3 bedrooms/2 bathrooms and have approximately $196 \mathrm{ft}^{2}$ of window area. The homes were fully instrumented to collect energy enduse and environmental data. One of the homes (Lab Home A - the baseline home) was retrofit with "standard" double-pane clear aluminum-frame slider windows and patio doors typically found in many

\footnotetext{
${ }^{1}$ The $\mathrm{U}$ factor is the inverse of $\mathrm{R}$ value, with units of $\mathrm{Btu} / \mathrm{ft}^{2} \cdot{ }^{\circ} \mathrm{F} \cdot \mathrm{h}$, a represents the rate of heat transfer through a material.

${ }^{2}$ The homes were built at the Marlette Industries factory in Hermiston, Oregon.
} 
existing homes built in the decades of the 1960s through 1980s throughout the Pacific Northwest (PNW) region and across the country. 1 The other home (Lab Home B - the experimental home) was retrofit with Jeld-Wen ${ }^{\circledR}$ triple-pane vinyl-frame slider windows and patio doors. The retrofit windows' characteristics are given in Table S.1. The homes are identical in every way except for the windows, including simulated occupancy and weather variations. Thus, all variations in energy use and temperature distributions are directly a result of the difference in window performance. This type of side-by-side experiment provides a degree of accuracy and precision in the results that pre-/post-assessments do not afford.

Table S.1. Window Performance Characteristics of the Windows in Lab Home A (Standard Retrofit Windows and Patio Doors), and Lab Home B (Highly Insulating Windows and Patio Doors) Retrofit in the Lab Homes

\begin{tabular}{lcccc}
\hline & \multicolumn{2}{c}{ Lab Home A } & \multicolumn{2}{c}{ Lab Home B } \\
& \multicolumn{2}{c}{ Standard Retrofit Windows } & Highly Insulating Retrofit Windows \\
\cline { 2 - 5 } Value & Windows & Patio Doors & Windows & Patio Doors \\
\hline U-factor & 0.68 & 0.66 & 0.20 & 0.20 \\
SHGC $^{(a)}$ & 0.7 & 0.66 & 0.19 & 0.19 \\
VT $^{(\text {b) }}$ & 0.73 & 0.71 & 0.36 & 0.37 \\
\hline (a) Solar heat gain coefficient & & & \\
(b) Visible transmittance & & & \\
\hline
\end{tabular}

\section{Results}

To assess the performance of the retrofit highly insulating windows compared to the retrofit baseline windows, the building shell air leakage, energy use and interior temperatures of the homes were compared. A 95\% confidence interval is calculated to quantify error about each measured value, assuming a normal distribution and based on a two-tailed student's t-statistic. Statistical significance of measured differences is determined using a t-test, based on the calculated $95 \%$ confidence intervals.

\section{Building Shell Air Leakage}

Building shell air leakage was measured prior to and after the windows retrofit to determine whether there was any difference in the windows or installation techniques. Prior to the windows retrofit and after the metering equipment and sensors were installed in the homes, the blower door test results show the air leakage of the two homes to be statistically the same, with $95 \%$ confidence. The homes are both fairly tight, which is typical of the manufactured housing industry in the PNW. Lab Home A has leakage of $657.6 \pm 27.8 \mathrm{cubic}$ feet/minute (cfm) at 50 Pascals depressurization (cfm50) and Lab Home B has an air leakage of $701.4 \pm 26.7 \mathrm{cfm} 50$. These values correspond to $0.15 \pm 0.01$ natural air changes per hour $\left(\mathrm{ACH}_{\mathrm{n}}\right)$ in Lab Home A and $0.16 \pm 0.01 \mathrm{ACH}_{\mathrm{n}}$ in Lab Home B.

The windows in Lab Home B were retrofitted by the general contractor (GC) with technical assistance and materials (foam sealant and window drain mat material) provided by Jeld-Wen® Inc. The Jeld-Wen ${ }^{\circledR}$ Inc staff ensured installation was in accordance with the documented recommendations by

\footnotetext{
${ }^{1}$ These double-pane clear windows are typical of many windows installed in homes across the country in the late 60s through the late 90s. They were also the 2006-2012 Federal Housing and Urban Development (HUD)-mandated nationwide minimum code for manufactured housing (see http://www.gpo.gov/fdsys/pkg/CFR-2003-title24vol1/content-detail.html).
} 
Jeld-Wen® Inc for their windows. The windows in Lab Home A were retrofitted by the same GC staff using standard caulking technique and no special flashing or additional materials.

In Lab Home B, air leakage, as characterized by the cfm50 depressurization with respect to the outside, decreased $46.4 \pm 34.9 \mathrm{cfm} 50$ or $6.9 \%$. Conversely, air leakage in Lab Home A increased $50.3 \pm$ $34.1 \mathrm{cfm} 50$. While the error is large in comparison to the magnitude of the change, the overall impact of these changes was statistically significant. This decrease in air leakage in Lab Home B is attributed primarily to the quality of the retrofit given that the air leakage (AL) rating of the highly insulating windows and patio doors $\left(\mathrm{AL}=0.3 \mathrm{cfm} / \mathrm{ft}^{2}\right)$ is greater than the factory-supplied windows and patio doors $\left(\mathrm{AL}=0.1 \mathrm{cfm} / \mathrm{ft}^{2}\right) .{ }^{1}$ This is therefore compelling evidence of the positive impact of the installation of the retrofit windows on home air leakage.

Prior to initiating the summer cooling season experiment, the air leakage in both homes was retested to determine the persistence of improved air leakage resulting from the windows installation. The measured air leakage was $660.1 \pm 21.2 \mathrm{cfm} 50$ in Lab Home A and $622.9 \pm 21.9 \mathrm{cfm} 50$ in Lab Home B. These numbers show that the statistically significant difference in air leakage between Lab Home A and Lab Home B was maintained, with the leakage in Lab Home B being less than Lab Home A. However, the values have decreased slightly in both homes, as shown in Table S.2.

Table S.2. Building Shell Leakage in the Baseline and Experimental Homes Before Window Retrofits, After Window Retrofits, and Prior to Initiation of the Summer Experiment

\begin{tabular}{lrrrr}
\hline & Baseline Home & \pm Error & Experimental Home & \multicolumn{1}{c}{ \pm Error } \\
\hline Null Data & & & & \\
cfm25 & 477.4 & 30.4 & 478.5 & 30.5 \\
cfm50 & 638.5 & 27.8 & 681.1 & 26.7 \\
ACH50 & 3.07 & 0.13 & 3.28 & 0.13 \\
ACHn & 0.14 & 0.01 & 0.15 & 0.01 \\
Post-Windows Install & & & & \\
cfm25 & 446.9 & 19.0 & 372.8 & 15.7 \\
cfm50 & 690.8 & 24.6 & 639.3 & 22.5 \\
ACH50 & 3.32 & 0.12 & 3.08 & 0.11 \\
ACHn & 0.15 & 0.01 & 0.14 & 0.01 \\
Prior to Summer Experiment & & & \\
cfm25 & 432.8 & 17.7 & 401.8 & 26.3 \\
cfm50 & 660.1 & 21.2 & 622.9 & 21.9 \\
ACH50 & 3.18 & 0.10 & 3.00 & 0.11 \\
ACHn & 0.15 & 0.005 & 0.14 & 0.005 \\
\hline
\end{tabular}

\section{Whole-House Energy Savings}

The measured energy savings in Lab Home B averaged 5,821 watt-hours per day (Wh/day) during the heating season and $6,518 \mathrm{Wh} /$ day during the cooling season. The overall whole-house energy savings of

\footnotetext{
${ }^{1}$ The AL rating of the retrofit windows in Lab Home A is unknown because this attribute was not included in the windows certification data the manufacturer provided to PNNL.
} 
Lab Home B compared to Lab Home A are $11.6 \% \pm 1.53 \%$ for the heating season and $18.4 \pm 2.06 \%$ for the cooling season. Extrapolating these energy savings numbers based typical average heating degree days (HDD) and cooling degree days (CDD) for Pasco, Washington per year yields an estimated annual energy savings of $12.2 \%$, or $1,784 \mathrm{kWh} / \mathrm{yr}$.

Table S.3. Average Daily Energy Use and Energy Savings in the Heating Season and Cooling Season

\begin{tabular}{|c|c|c|c|c|}
\hline & & $\begin{array}{c}\text { Average Daily } \\
\text { Energy Use (Wh) }\end{array}$ & $\begin{array}{c}\text { Average Daily } \\
\text { Energy Savings (Wh) }\end{array}$ & $\begin{array}{c}\text { Average Daily } \\
\text { Energy Savings }(\%)\end{array}$ \\
\hline $\begin{array}{l}\text { Heating } \\
\text { Season }\end{array}$ & $\begin{array}{l}\text { Lab Home A (Baseline) } \\
\text { Lab Home B (Experimental) }\end{array}$ & $\begin{array}{l}47,599 \\
41,896\end{array}$ & $5,821 \pm 1,054$ & $11.6 \pm 1.53$ \\
\hline $\begin{array}{l}\text { Cooling } \\
\text { Season }\end{array}$ & $\begin{array}{l}\text { Lab Home A (Baseline) } \\
\text { Lab Home B (Experimental) }\end{array}$ & $\begin{array}{l}35,572 \\
29,055\end{array}$ & $6,518 \pm 842$ & $18.4 \pm 2.06$ \\
\hline
\end{tabular}

In addition to increasing the thermal performance windows, low-e coatings ${ }^{1}$ also affect the solar heat gain through the windows. The highly insulating windows installed in Lab Home B have a very low solar heat gain coefficient (SHGC) compared to the clear glass windows in Lab Home A, as shown in Table S.1, which was found to decrease the solar insolation measured on the inside of window by $83.2 \%$ in Lab Home B compared to Lab Home A. An analysis of the whole-house energy use in watt-hours (Wh) versus solar insolation in watts per square meter $\left(\mathrm{W} / \mathrm{m}^{2}\right)$ for Lab Home A and Lab Home B revealed that increased solar insolation decreased whole-house energy use in the winter and increased whole-house energy use in the summer. The difference in solar heat gain also affects the whole-house energy savings. Data analysis of whole-house energy savings on overcast days showed energy savings for Lab Home B compared to Lab Home A of $14.6 \% \pm 1.86 \%$, while the energy savings on clear days are $8.9 \% \pm 1.42 \%$. In the summer, days are much more consistently sunny in Richland, Washington, so the impact of solar insolation cannot be as clearly observed. However, the energy savings appear to be more correlated to outdoor air temperatures, with higher temperatures yielding higher savings. Also, the high savings observed in the cooling season $(18.4 \% \pm 2.06 \%)$ indicate that both the low U-factor and low SHGC are contributing to savings during the hot summer days.

\section{Energy Modeling}

A representative EnergyPlus model was created for the Lab Homes to compare modeled savings from the highly insulating windows to measured results. The EnergyPlus analysis run with typical weather data for the nearby Pasco, Washington, airport station shows average whole-building energy savings in Lab Home B from the highly insulating windows to be $13.9 \%$ during the heating and cooling season experimental periods (February 2012 to April 2012 and July to August 2012). These results agree fairly well with measured data, which indicated savings of $11.6 \pm 1.53 \%$ in Lab Home B compared to Lab Home $\mathrm{A}$ in the heating season and $18.4 \% \pm 2.06 \%$ in the cooling season. The EnergyPlus model was also used to predict annual savings from the highly insulating windows using typical occupancy patterns and thermostat set points. The EnergyPlus model predicts $13.2 \%$ annual savings, or 1,370 kWh/yr.

\footnotetext{
${ }^{1}$ Low-emittance (low-e) coatings are microscopically thin, virtually invisible, metal or metallic oxide layers deposited on a window surface primarily to reduce the heat loss through the glass by suppressing radiative heat flow. The principal mechanism of heat transfer in multilayer glazing is thermal radiation from a warm pane of glass to a cooler pane. Coating a glass surface with a low-e material and facing that coating into the gap between the glass layers of multi-pane windows blocks a significant amount of this radiant heat transfer, thus lowering the total heat flow through the window.
} 


\section{Peak Load Reduction}

Another impact of reduced energy use that is important to mention from a utility and resource planning perspective is the ability to reduce peak load. In the heating season, the daily peak power observed in Lab Home B was 33.9\% $\pm 0.6 \%$ less than the peak power observed in Lab Home A. During the heating season, the peak load in both homes occurred during the evening hours after sunset. In the cooling season, the peak power use occurred in the afternoon and early evening hours each day, which corresponds with typical utility peaks. The peak power measured in Lab Home B was $24.7 \% \pm 0.1 \%$ less than Lab Home A in the cooling season. Although there is no direct financial benefit to most residential customers of a utility for peak reduction (customers with time-of-use rates notwithstanding), this significant reduction in peak power can be of benefit to the utility depending upon the time of the utility or system peak.

\section{Thermal Comfort}

In addition to yielding energy savings, the highly insulating windows in Lab Home B exhibited much more consistent indoor temperatures than Lab Home A. For example, on a sunny day in February, the average indoor temperatures in the kitchen of Lab Home A reached a balmy $84^{\circ} \mathrm{F}$, while Lab Home $\mathrm{B}$ reached only $78^{\circ} \mathrm{F}$, within $3^{\circ} \mathrm{F}$ of the $75^{\circ} \mathrm{F}$ thermostat set point. The average outside temperature on this day was $39^{\circ} \mathrm{F}$. This could cause a comfort problem for any occupants at home during this time, even during these cold winter months.

In the summer, comfort problems also were observed. Measured indoor temperatures reached $73^{\circ} \mathrm{F}$ on several days in Lab Home A, indicating that the heat pump is undersized for the load on this home with clear glass windows and no window coverings, while the heat pump in Lab Home B (also with no window coverings) was able to maintain a temperature of $70^{\circ} \mathrm{F}$ on most days, which was consistent with the $70^{\circ} \mathrm{F}$ thermostat set point. Also, the temperature rise in Lab Home A caused increased overcooling in some rooms with the shortest duct runs, where temperatures as cool as $63^{\circ} \mathrm{F}$ were observed. The outdoor temperature typically reached 90 to $100^{\circ} \mathrm{F}$ during the cooling season experimental period.

The window surface temperatures also affect comfort in the home felt by occupants, particularly in the winter. A window with a colder surface temperature is noticeable to an occupant (near the window area) even though the room dry bulb temperature may be at a comfortable level, due to convective and radiative heat transfer from the occupant to the cooler air near the window or cooler window surface temperatures. This effect is apparent in the Lab Homes, as illustrated by the dramatically cooler window surface temperatures observed in Lab Home A (baseline home) of as low as $50^{\circ} \mathrm{F}$ recorded on the westfacing living room window. In the Lab Home B (experimental home), the highly insulating window's surface temperature never dropped below $60^{\circ} \mathrm{F}$ - the lowest temperature measured on the same window. When considering the average interior glass surface temperature measurement of all the windows over this period, a difference of $7^{\circ} \mathrm{F}$ is observed, with an average interior glass surface temperature of $68.7 \pm$ $0.05^{\circ} \mathrm{F}$ in the baseline home compared to $75.7 \pm 0.04^{\circ} \mathrm{F}$ (almost exactly the interior thermostat set point) in the experimental home.

Mean radiant temperature (MRT) is also a measured proxy for thermal comfort/discomfort resulting from the radiant heat exchange between an occupant (a body) and surrounding surface temperatures such as the surface temperature of a window or a wall. Each Lab Home has two MRT sensors: one located in the master bedroom and one in the northwest corner of the living room. The average indoor MRT in Lab 
Home A and Lab Home B was determined after the windows retrofit over a 1-week time period when the outside temperature averaged $49^{\circ} \mathrm{F}$, with a maximum of $65^{\circ} \mathrm{F}$ and a minimum of $35^{\circ} \mathrm{F}$.

The average MRT in Lab Home A during the nighttime period during the week when radiant heat loss was most extreme was $79.0 \pm 0.02^{\circ} \mathrm{F}$ in both the master bedroom and the living room compared to an average room temperature of $80.2 \pm 0.11^{\circ} \mathrm{F}$. The average MRT of both the living room and master bedroom was $1.63 \pm 0.01^{\circ} \mathrm{F}$ lower than the average interior room temperature in Lab Home $\mathrm{A}$. The maximum MRT recorded in Lab Home A was $86.3^{\circ} \mathrm{F}$ and the minimum MRT was $77.0^{\circ} \mathrm{F}$.

In contrast, in Lab Home B the average MRT in the living room and master bedroom was $1.64 \pm$ $0.01^{\circ} \mathrm{F}$ lower than the average room temperature of $80.4 \pm 0.01^{\circ} \mathrm{F}$ in the living room and master bedroom. The maximum MRT recorded in Lab Home B was $81.7^{\circ} \mathrm{F}$ and the minimum MRT was $77.7^{\circ} \mathrm{F}$. Overall, the average nighttime MRT in Lab Home B was slightly warmer than the average MRT in Lab Home A during the nighttime periods when radiant heat loss is most extreme, but the difference was small. The very small temperature differences between the room temperature and MRT in Lab Home B compared to the larger difference in Lab Home A, as well as the higher average MRT in Lab Home B, suggest the highly insulating windows can provide a noticeably greater comfort level for occupants. Also, the MRT in Lab Home B was much more consistent, varying only $4.9^{\circ} \mathrm{F}$, while Lab Home A varied $9.2^{\circ} \mathrm{F}$.

\section{Condensation/Moisture on Windows}

Condensation on windows is of concern to homeowners and can be a health issue because moisture can lead to mold growth. A direct measurement was not made of condensation or moisture on windows in either Lab Home A or Lab Home B. ${ }^{1}$ However, using the windows' inside surface temperature measurements allowed a calculation of the potential for condensation to form on the windows. An interior window temperature as low as $50^{\circ} \mathrm{F}$ was recorded in Lab Home A, while the lowest interior window temperature was $60^{\circ} \mathrm{F}$ in Lab Home B. With these temperatures and an average interior room temperature of $75^{\circ} \mathrm{F}$, the relative humidity of the air in Lab Home B would have to exceed $70 \%$ to cause condensation on the highly insulating windows, while a relative humidity of $40 \%$ or more would cause condensation on the double-pane windows in Lab Home A. However, condensation was not a concern due to the dry climate in Richland. The average measured relative humidity in the heating season was $20.7 \%$, with a maximum of $31.7 \%$, in Lab Home A, and it was $21.7 \%$, with a maximum of $28.1 \%$ in Lab Home B. During the cooling season, similarly low indoor relative humidities were observed. In addition, the warm interior glass temperature measurements do not cause concerns related to the potential for condensation.

\section{Analysis of Window Cost}

While the highly insulating windows show significant energy savings compared to the baseline windows, the capital cost of windows must also be considered to determine the cost-effectiveness of highly insulating windows as an energy efficiency measure. The capital cost of highly insulating windows, as delivered, was used to determine the cost effectiveness of windows in a retrofit scenario. An incremental cost, compared to code minimum windows ${ }^{2}$, was also considered for new construction or if windows are being replaced for another reason (e.g., safety, functionality, aesthetics). In the incremental

\footnotetext{
${ }^{1}$ Humidity to represent occupants and occupant activity was not generated in the Lab Homes for this experiment.

${ }^{2}$ Minimum code for the State of Washington Climate Zone 1 is 0.32 U-factor and 0.40 SHGC.
} 
cost scenario, installation cost is not included and only the cost difference between code minimum and highly insulating (triple-pane) windows is used.

Windows cost data for highly insulating windows and sliding glass doors in small quantities for retrofit were obtained from the U.S. Department of Energy (DOE) Windows Volume Purchase Program. ${ }^{1}$ These costs ranged from $\$ 25 / \mathrm{ft}^{2}$ to $\$ 46 / \mathrm{ft}^{2}$, with an average cost of $\$ 34 / \mathrm{ft}^{2}$. This agrees well with the quoted cost of the windows $-\$ 25 / \mathrm{ft}^{2}$ - that were installed in the Lab Homes. These numbers include installation and materials costs, which were estimated at $\$ 3 / \mathrm{ft}^{2}$ based on observed retrofit of the windows at the Lab Homes. Therefore, the total installed cost for the highly insulating windows and sliding glass doors in Lab Home B was estimated to be $\$ 4,900$ to $\$ 9,000$. Based on these costs and the modeled annual savings of $1,370 \mathrm{kWh} / \mathrm{yr}$, the payback period (PBP) for highly insulating windows ranges from 30 to 55 years. Using the extrapolated measured data to estimate annual savings, a savings of $1,784 \mathrm{kWh} / \mathrm{yr}$, the PBP ranges from 23 to 42 years.

If the highly insulating windows were installed in a new home or windows are already being replaced for another reason (i.e., safety, operability, aesthetics), the incremental cost of the windows over a code minimum window should be considered and installation costs can be ignored. The incremental cost of highly insulating windows is estimated to be approximately $\$ 3.87 / \mathrm{ft}^{2}$ and ranges from $\$ 1.59 / \mathrm{ft}^{2}$ to $\$ 5.85 / \mathrm{ft}^{2}$. Using the average value, the total incremental cost for highly insulating windows is estimated to be $\$ 1,372$ for a home with the same window area as the Lab Homes $\left(195.7 \mathrm{ft}^{2}\right)$. Based on the modeled incremental annual energy savings of highly insulating windows over code minimum windows of 363 $\mathrm{kWh}$, the PBP is 32 years.

\section{Conclusion}

The side-by-side assessment in the PNNL Lab Homes demonstrates that highly insulating windows show considerable energy savings when compared to double-pane clear glass windows. These energy savings may also contribute to reduced peak energy load, especially in the cooling season, if implemented on a large scale. Highly insulating windows show more consistent interior temperature distributions and improved thermal comfort because interior glass surface temperatures are much closer to interior dry bulb temperatures. Increased glass surface temperatures in the winter could also decrease the risk of condensation and mold issues in regions where high humidity exists. Based on windows cost data available from manufacturers via the Windows Volume Purchase Program and a local cost of electricity, highly insulating windows have a simple PBP of 23 to 55 years. The range is primarily due to the large variability in primary window costs.

These data suggest that highly insulating windows are an effective energy-saving measure that should be considered for high-performance new homes and in existing retrofits. However, the cost effectiveness of the measure, as determined by the simple PBP, suggests that highly insulating window costs continue to make windows difficult to justify on a cost effectiveness basis alone. Additional reductions in costs via improvements in manufacturing and/or market penetration that continue to drive down costs will make highly insulating windows much more viable as a cost-effective energy efficiency measure. This study also illustrates that highly insulating windows have important impacts on peak load, occupant comfort,

\footnotetext{
${ }^{1}$ The window vendors selected for estimating costs from the qualified vendors in the DOE High Performance Windows Volume Purchase Program were vendors who offered both sliders and patio doors and who sold products in the PNW. An average cost per square foot across the multiple sizes of highly insulating windows for Lab Home B was determined from these windows suppliers.
} 
and condensation potential, which are not captured in the energy savings calculation. In addition, more consistent and uniform interior temperature distributions suggest that highly insulated windows, as part of a high performance building envelope, may enable more centralized duct design and downsized HVAC systems. Shorter, more centralized duct systems and smaller HVAC systems could yield additional cost savings, making highly insulating windows more cost effective as part of a package of new construction or retrofit measures which achieve significant reductions in home energy use. 


\section{Acknowledgments}

This project was funded by the U.S. Department of Energy, Energy Efficiency and Renewable Energy Building America Program (Eric Werling/David Lee, Program Managers) and Emerging Technology Windows R\&D Program (Marc LaFrance, Program Manager); the Bonneville Power Administration (Kacie Bedney, Project Manager); and the U.S. Department of Energy, Office of Electricity Delivery and Energy Reliability (Dan Ton, Program Manager). Additional support was provided by Battelle Memorial Institute; Northwest Energy Works (Tom Hews/Brady Peeks); Washington State University Extension Energy Program (Ken Eklund/Emily Salzberg); GE Appliances (Dave Najewicz); Tri Cities Research District (Diahann Howard); the City of Richland, Washington (Bob Hammond); and Jeld Wen®, Inc. (Ray Garris/Mike Westfall).

Other stakeholders on this project include the U.S. Department of Energy Pacific Northwest Site Office, Northwest Energy Efficiency Alliance, the Energy Trust of Oregon, and Marlette Industries.

PNNL staff significantly contributing to this project include facilities, operations, contracting, and financial staff: Raul Carreno, Garret Hyatt, Sheena Kanyid, David Koontz, Bob Turner, Ray Sadesky, T.R. Hensyel, Jim Bixler, Vicki Stephens, Sam Martinez and Jamie Spangle; media relations staff: Annie Haas, Franny White, Dawn Zimmerman, Megan Neer, Tim Ledbetter, and Kevin Kautzky; editor: Susan Ennor; management staff: Evan Jones, Sean McDonald, Mark Morgan, Todd Samuel, Sriram Somasundaram, Terry Brog, Rob Pratt and Gary Spanner; and technical staff: Vrushali Mendon, Susan Sande, Jeremy Blanchard, Eric Richman, Susan Loper, Michael Kintner-Meyer, Michael Baechler, and Laura Van Kolck (student intern).

The authors also acknowledge the technical support provided by Greg Sullivan, Principal, Efficiency Solutions, LLC, Richland, Washington, for specification development, occupancy simulation development, metering, and data collection. 



\title{
Acronyms and Abbreviations
}

\author{
${ }^{\circ} \mathrm{C}$ \\ ${ }^{\circ} \mathrm{F}$ \\ A \\ ACH50 \\ $\mathrm{ACHn}$ \\ AL \\ AML \\ ARRA \\ ASTM \\ BPA \\ BTP \\ Btu \\ $\mathrm{Btu} /\left(\mathrm{h} \cdot{ }^{\circ} \mathrm{F} \cdot \mathrm{ft}^{2}\right)$ \\ CDD \\ $\mathrm{cfm}$ \\ $\operatorname{cfm} 25$ \\ cfm50 \\ $\mathrm{COM}$ \\ CT \\ DAC \\ DNP3 \\ DOE \\ DOE/OE \\ ELA \\ EMC \\ ER \\ fc \\ $\mathrm{ft}$ \\ $\mathrm{ft} 2$ \\ GC \\ GFI \\ HDD \\ HP \\ $\mathrm{hr}$ \\ HSPF \\ HUD \\ HVAC \\ degree(s) Centigrade or Celsius \\ degree(s) Fahrenheit \\ ampere(s) \\ air changes per hour at 50 Pascals depressurization \\ natural air changes per hour \\ air leakage \\ Atmospheric Measurement Lab \\ American Recovery and Reinvestment Act of 2009 \\ ASTM International, formerly the American Society for Testing and Materials \\ Bonneville Power Administration \\ Buildings Technology Program \\ British thermal unit(s) \\ British thermal unit per hour, degree Farenheit, square foot (feet) \\ cooling degree days \\ cubic feet per minute \\ cubic feet per minute at 25 Pascals depressurization \\ cubic feet per minute at 50 Pascals depressurization \\ common \\ current transformers \\ digital-to-analog converter \\ Distributed Network Protocol 3 \\ U.S. Department of Energy \\ DOE Office of Electricity Delivery \& Energy Reliability \\ effective leakage area \\ electromagnetic compatibility \\ electric resistance \\ footcandle(s) \\ foot(feet) \\ square foot(feet) \\ general contractor \\ Ground Fault Interrupter \\ heating degree days \\ heat pump \\ hour(s) \\ Heating Seasonal Performance Factor \\ U.S. Department of Housing and Urban Development \\ heating, ventilating and air conditioning
}




\begin{tabular}{|c|c|}
\hline IEC & International Electrotechnical Commission \\
\hline IECC & International Energy Conservation Code \\
\hline in. or" & inch(es) \\
\hline IP & internet protocol \\
\hline IR & infrared \\
\hline IT & information technology \\
\hline $\mathrm{kW}$ & kilowatt(s) \\
\hline $\mathrm{lb}$ & pound(s) \\
\hline low-e & low-emisivity \\
\hline $\mathrm{mA}$ & milliampere(s) \\
\hline MRT & mean radiant temperature \\
\hline MW & megawatt \\
\hline $\mathrm{NE}$ & northeast \\
\hline NEC & National Electric Code \\
\hline NEW & Northwest Energy Works \\
\hline NFRC & National Fenestration Rating Council \\
\hline NREL & National Renewable Energy Laboratory \\
\hline $\mathrm{Pa}$ & $\operatorname{pascal}(\mathrm{s})$ \\
\hline PBP & payback period \\
\hline PNNL & Pacific Northwest National Laboratory \\
\hline PNW & Pacific Northwest \\
\hline $\mathrm{R}$ & thermal resistance $\left(\mathrm{ft}^{2} \cdot{ }^{\circ} \mathrm{F} \cdot \mathrm{h} / \mathrm{Btu}\right)$ \\
\hline $\mathrm{R} \& \mathrm{D}$ & research and development \\
\hline RH & relative humidity \\
\hline RTU & remote terminal unit \\
\hline S & second(s) \\
\hline SEER & Seasonal Energy Efficiency Ratio \\
\hline SHGC & solar heat gain coefficient \\
\hline SMTP & Simple Mail Transfer Protocol \\
\hline SRAM & static random access memory \\
\hline TCP/IP & Transmission Control Protocol/Internet Protocol \\
\hline $\mathrm{TI} / \mathrm{C}$ & Technology Innovation Council \\
\hline TMY & typical meteorological year \\
\hline $\mathrm{U}$ & overall heat transfer coefficient $\left(\mathrm{Btu} /\left(\mathrm{h} \cdot{ }^{\circ} \mathrm{F} \cdot \mathrm{ft}^{2}\right)\right)$ \\
\hline VT & visible transmittance \\
\hline $\mathrm{W}$ & watt(s) \\
\hline Wh & watt-hour(s) \\
\hline $\mathrm{W} / \mathrm{m} 2$ & watt(s) per square meter \\
\hline WSU & Washington State University \\
\hline
\end{tabular}




\section{Contents}

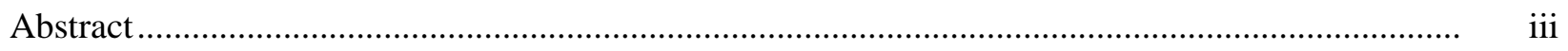

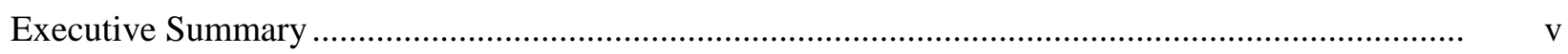

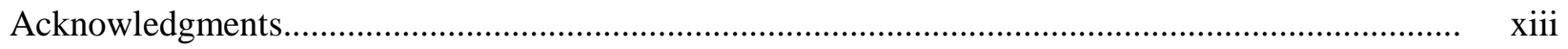

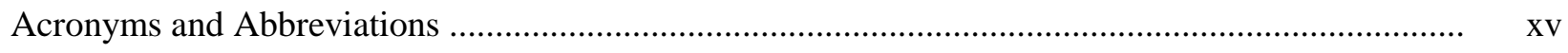

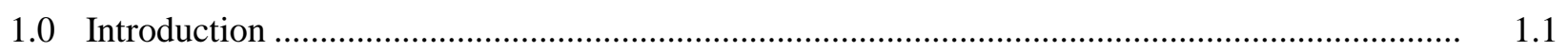

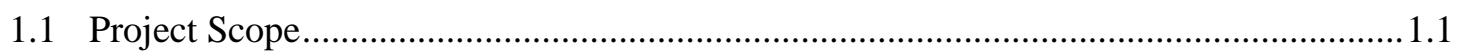

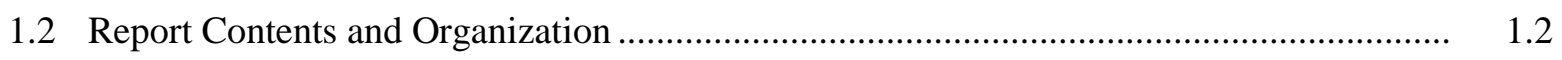

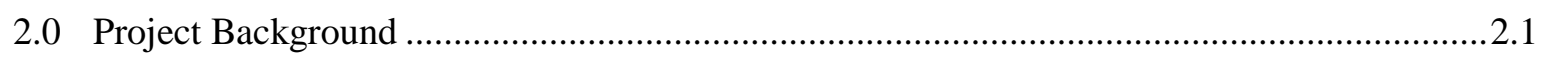

2.1 Development, Expansion, and Relevance of the Field Evaluation Project ........................ $\quad 2.1$

2.2 Background and History of Building Research in Manufactured Housing....................2.3

3.0 The PNNL Lab Homes ................................................................................................

3.1 Construction Features and Siting of the Lab Homes .................................................... 3.1

3.2 Metering, Monitoring, and Experimental Plan........................................................... 3.4

3.2.1 Metering and Monitoring Approach............................................................. 3.4

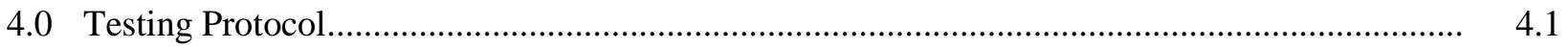

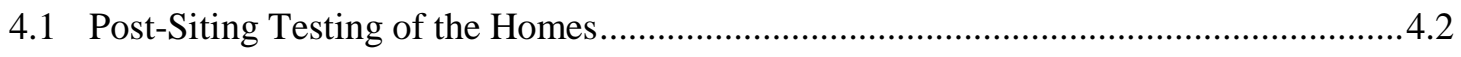

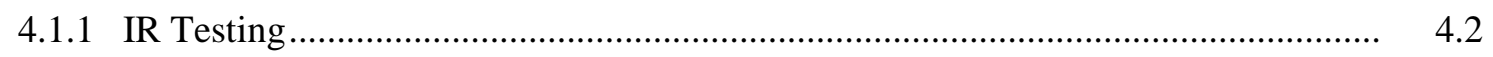

4.1.2 Building Shell Air Leakage .............................................................................. 4.2

4.1.3 Duct Leakage and Pressure Mapping ................................................................ 4.2

4.1.4 Ventilation Fan Flow Rate ............................................................................ 4.3

4.1.5 Heat Pump Performance................................................................................ 4.3

4.2 Post-Siting Instrumentation Installation and Data Collection Protocols ..........................3

4.3 Float, HVAC, and Full-System Null Testing ................................................................. 4.3

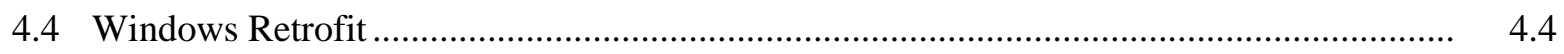

4.5 Initiation of Windows Field Evaluation ...................................................................... 4.6

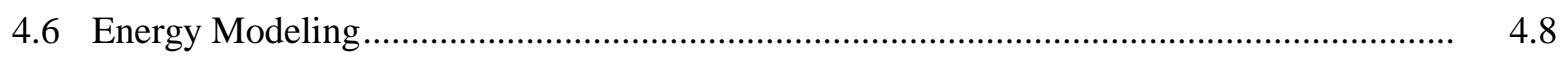

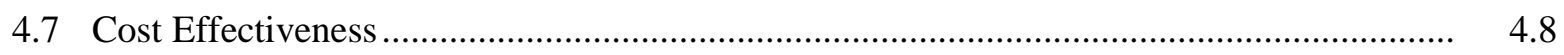

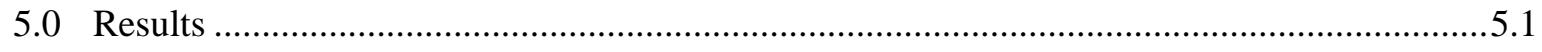

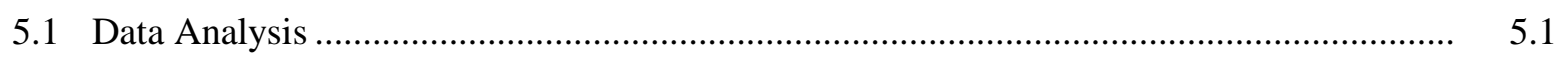

5.2 Lab Homes Thermal Characteristics ….................................................................... 5.1

5.2.1 Infrared Testing ...................................................................................... 5.1

5.2.2 Pre-Windows-Retrofit Building Shell Air Leakage ........................................... 5.3

5.2.3 Duct Leakage and Pressure Mapping .................................................................5.4

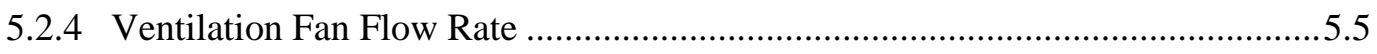

5.3 Heat Pump and Air Handler Performance.................................................................. 5.5

5.4 Pre-Windows-Retrofit Null Testing ....................................................................... 5.6 
5.5 Post-Windows-Retrofit Building Shell Air Leakage..................................................... 5.7

5.6 Post-Windows Retrofit HVAC and Whole-House Energy Performance ........................... 5.8

5.6.1 Thermostat Set Points..................................................................................... 5.9

5.6.2 Winter Heating Season Results .................................................................. 5.9

5.6.3 Summer Cooling Season Results ..................................................................... 5.9

5.6.4 Dependence on Outdoor Air Temperature and Solar Insolation ............................. 5.11

5.6.5 Average Annual Savings .......................................................................... 5.22

5.7 Interior Temperature Distributions........................................................................ 5.23

5.8 Thermal Comfort and Condensation ......................................................................... 5.25

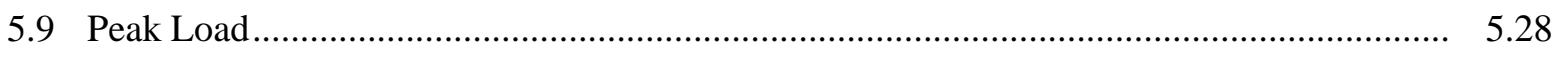

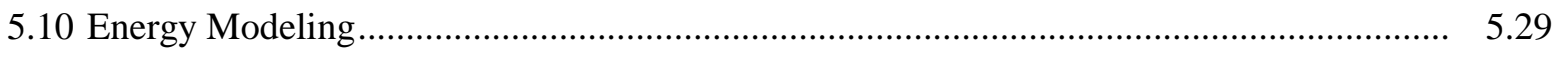

5.11 Cost Effectiveness of Highly Insulating Windows ...................................................... 5.31

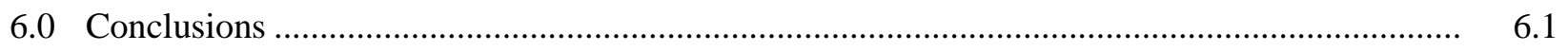

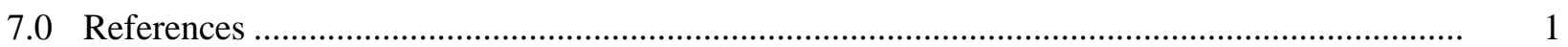




\section{Figures}

3.1 Floor Plan of the Lab Homes as Constructed...................................................................... 3.1

3.2 Lab Home B and Lab Home A after Setup During Final Site Preparation .............................. 3.3

3.3 North Side and North and West Sides of Lab Home A........................................................... 3.3

3.4 West and South Sides of Lab Home B ......................................................................... 3.4

3.5 South Side of Lab Home B .......................................................................................

4.1 NFRC Certification Label for Jeld-Wen® Highly Insulating Windows Installed in Lab

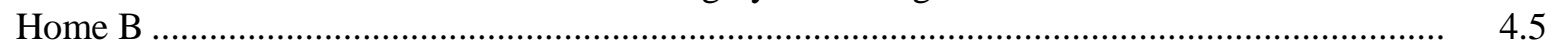

5.1 Baseline and Experimental Homes Exterior Side/Endwall Corner Thermal Images ................. 5.2

5.2 Thermal Image of Experimental Home East End Wall from the Master Bedroom.................. 5.2

5.3 Comparison of Cumulative HVAC Energy Use of Lab Home A Versus Lab Home B ............ $\quad 5.7$

5.4 Relative Daily Whole House Energy Consumption of Lab Home A and Lab Home B Scaled Based on CDD for Each Day During the Summer Experiment ...............................5.11

5.5 Whole-House Energy Use and Whole-House Energy Savings Versus Outdoor Air

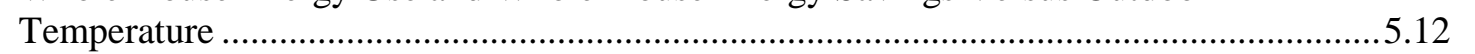

5.6 Daily Whole-House Energy Savings Due to Highly Insulating Windows for Overcast, Clear, Partly Cloudy, and Dusty Conditions ...

5.7 Whole-House Energy Use and Indoor Temperature for the Experimental Home and the Baseline Home on a Sunny Day......

5.8 Cumulative Energy Use of Lab Home B Versus Lab Home A on a Sunny Day ...................... 5.15

5.9 Whole-House Energy Use and Indoor Temperature for the Experimental Home and the Baseline Home on a Cloudy Day ....................................................................................... 5.16

5.10 Cumulative Energy Use of Lab Home B Versus Lab Home A on a Cloudy Day .................... 5.16

5.11 Whole-House Energy Use in Lab Home A Versus Solar Insolation for the Heating Season .... 5.17

5.12 Whole-House Energy Use in Lab Home B Versus Solar Insolation for the Heating Season5.17

5.13 Whole-House Energy Use in Lab Home A and Lab Home B Versus Solar Insolation for the Cooling Season.

5.14 Whole-House Energy Savings in Lab Home B as Compared to Lab Home A in the Cooling Season Versus Solar Insolation Through the Window in Lab Home A.

5.15 Whole House Energy Savings in Lab Home B as Compared to Lab Home A in the Cooling Season Versus Outdoor Air Temperature .....

5.16 Hourly Average Whole-House Energy Use and Indoor Temperature for Lab Home B and Lab Home A and Outdoor Air Temperature on a Hot Day...

5.17 Cumulative Energy Use of Lab Home B Versus Lab Home A on a Hot Day .......................... 5.20

5.18 Cumulative Energy Use of Lab Home B Versus Lab Home A on a Milder Day ..................... 5.21

5.19 Hourly Average Whole-House Energy Use and Indoor Temperature for the Experimental Home and the Baseline Home and Outdoor Air Temperature on a Mild Day .....................5.22

5.20 Interior Temperature Distribution for Lab Home A and Lab Home B on a Sunny Day............ 5. 5.23

5.21 Whole House Energy Use in Lab Home A on a Hot Day with HVAC, Occupancy, and Lighting Loads Disaggregated. 
5.22 Interior Temperature Distribution for Lab Home A and Lab Home B on a Hot Day

5.23 Interior Window Temperatures and Dew Point Temperatures Based on a $75^{\circ} \mathrm{F}$ Interior Air Temperature in the Baseline Home from March 11 Through 17, $2012 .$.

5.24 Interior Window Temperatures and Dew Point Temperatures Based on a $75^{\circ} \mathrm{F}$ Interior Air Temperature in the Experimental Home from March 11 Through 17, 2012.

5.25 Average Indoor Air Temperature and Mean Radiant Temperature in Lab Home A and Lab Home B

5.26 Average Hourly Power Use for Lab Home A and Lab Home B and the Bonneville Power Administration Load Curve During a 1-Week Period from July 6 to July 13, 2012

5.27 Modeled and Measured HVAC Energy Use for Lab Home A

5.28 Modeled and Measured HVAC Energy Use for Lab Home B ........................................5.30

5.29 Modeled and Measured Energy Savings

5.30 Window Cost Data for R-5 Sliders, Casements, and Double-Hung from the DOE Windows Volume Purchase Program.

5.31 Cost Data, Excluding Outliers, for All Window Types from the Windows Volume Purchase Program......

5.32 Simple PBP for R-5 Windows for a Retrofit or in an Incremental Cost Scenario

\section{Tables}

2.1 2009 International Energy Conservation Code (IECC) Requirements for Climate Zone 5 ........

3.1 Electrical Points Monitored.

3.2 Temperature and Environmental Points Monitored

4.1 Window Performance Characteristics of the Factory-Installed, Baseline Retrofit, and Highly Insulating Retrofit Windows and Patio Doors Installed in the Lab Homes

4.2 Timeline and Summary of Operating Parameters During the Data Collection Period

4.3 2009 Washington State Energy Requirements for Climate Zone 1

5.1 Building Envelope Air Leakage of Baseline and Experimental Home As-Received and Sited

5.2 Building Envelope Leakage as Measured by Blower Door Tests in the Baseline and Experimental Home with Metering Equipment Installed..

5.3 Duct Leakage Measurements in Lab Home A and Lab Home B

5.4 Duct Distribution System Performance, Static Pressure and Flows in Baseline Lab Home A and Experimental Lab Home B ....

5.5 Flow Rate of Bath and Whole-House Ventilation Exhaust Fans Measured in the Baseline and Experimental Homes

5.6 Heat Pump Temperature Differential Across the Coil .....

5.7 Air Handler Flow and Static Operating Pressure

5.8 Building Shell Leakage in the Baseline and Experimental Homes After Window Retrofits...... 
5.9 Building Envelope Leakage as Measured by Blower Door Tests in the Baseline and Experimental Home Prior to Initiation of Summer Cooling Season Experiments.

5.10 Average Heating Season Energy Savings and 95\% Confidence Interval from Highly Insulating Windows in Different Operating Scenarios: With and Without Occupancy Simulation and in HP Versus ER Heating Modes.

5.11 Average Energy Savings and 95\% Confidence Interval from Highly Insulating Windows in Different Operating Scenarios: With and Without Simulated Equipment Loads and With Blinds 



\subsection{Introduction}

As utility and governmental programs and regulations continue to drive reduced energy use in new and existing site-built and manufactured homes, new energy efficient technologies and measures are necessary to cost-effectively achieve energy-reduction goals. The Bonneville Power Administration (BPA) and the U.S. Department of Energy (DOE) have identified highly insulating windows, with Ufactors around 0.2 , as a key technology that could play an important role in the next phase of energy efficiency improvements in the residential sector.

Pacific Northwest National Laboratory (PNNL) proposed a joint-funded research project to the BPA Request for Offers 1515 in the spring of 2010. Under the PNNL proposal, joint funding was provided by the DOE Buildings Technology Program (BTP) Envelope and Windows research and development (R\&D). The initial $\$ 200 \mathrm{~K}$ proposal was to demonstrate the energy performance of highly insulating windows retrofitted in a matched pair of single-wide manufactured homes leased/rented for approximately 1 year. With additional joint funding (see additional background in Section 2.0) and the agreement of BPA and DOE/BTP, the windows demonstration experiment was re-scoped to take place in a matched pair of double-wide manufactured "Lab Homes" located side-by-side on the PNNL campus in Richland, Washington ${ }^{1}$ - one served as the baseline, the other as the experimental home. After arriving on the PNNL campus, the homes were null tested for a short time period to verify similar construction and energy use before retrofitting the baseline home with double-pane, clear, metal-frame windows typical of existing homes and the other experimental home with highly insulating (U-factor ${ }^{2}$ of 0.22 or lower, equivalent to $\sim \mathrm{R}-5$ ) triple-pane windows. The highly insulating windows were selected from a window manufacturer that is participating in the DOE volume purchase program for highly insulating windows. ${ }^{3}$

\subsection{Project Scope}

The field evaluation included winter and summer experiments; the former was conducted for a period of 70 days from February 3 to April 13, 2012, during the heating season, and the latter was conducted for a period 43 days from July 6 to August 18, 2012, during the cooling season. The evaluation compared the energy and comfort performance of highly insulating windows to those of baseline windows in the two identical (except for the windows), all electric, side-by-side Lab Homes. Occupancy in each home was simulated to represent loads from inhabitants and associated lighting loads. No window coverings were installed or used for the heating season experiment or the majority of the cooling season experiment. Measured data obtained with simulated occupancy and lighting loads, with no window coverings, represents the primary data that are used for comparison of heating and cooling seasons and for comparison with the EnergyPlus model (see Section 5.10) used to predict annual savings. For the final weeks of the summer study period, sensitivity experiments were conducted; they included the impact of equipment loads and blinds on window performance.

\footnotetext{
${ }^{1}$ http://labhomes.pnnl.gov

2 The rate of heat loss through a window assembly is indicated in terms of the U-factor. The lower the U-factor, the greater a window's resistance to heat flow and the better its insulating properties.

${ }^{3}$ www.windowsvolumepurchase.org
} 


\subsection{Report Contents and Organization}

This report describes the results of testing highly insulating, triple-pane, R-5 windows in the experimental home and double-pane, clear glass windows in the baseline home for a period of 70 days during the heating season and 39 days during the cooling season in 2012. The impact of highly insulating windows and quality installation was investigated based on measured air leakage of the home before and after installation of the windows for the experiment. The whole-house and heating, ventilation, and air conditioning (HVAC) electrical energy savings derived from the installation of highly insulating windows are presented, including impacts on peak load energy reductions. The ensuing sections provide project background relative to the development, expansion, and relevance of the Lab Homes field evaluation project and an overview of the history of building research in manufactured homes (Section 2.0). An overview of the PNNL Lab Homes - their construction features and siting and the associated metering, monitoring, and experimental plan - is provided in Section 3.0. The testing protocol is described in Section 4.0, followed by results, conclusions, and recommendations in Sections 5.0, 6.0, and 7.0, respectively. Section 8.0 contains the reference list and appendixes contain information that supplements the main text. 


\subsection{Project Background}

The field research documented in this report developed beyond its initially proposed field evaluation, expanding its scope and relevance and building upon the history of building research in manufactured housing, as described below.

\subsection{Development, Expansion, and Relevance of the Field Evaluation Project}

After the project was awarded, additional joint funding became available from DOE to expand the capabilities of undertaking residential retrofit research and smart grid-enabled residential technologies beyond the highly insulating windows demonstration. The additional funding was provided through the American Recovery and Reinvestment Act (ARRA) funds allocated to DOE's Building America Program and from DOE's Office of Electricity Delivery and Energy Reliability (OE) smart grid appliances R\&D program. The scope of the ARRA project is to undertake field demonstrations of a portfolio of new and emerging retrofit technologies in the residential building sector. ${ }^{1}$ The scope of the DOE/OE smart grid $\mathrm{R} \& \mathrm{D}$ program is to undertake a demonstration of smart grid-enabled appliances and technologies.

As indicated previously, with the additional joint funding and agreement of BPA and DOE/BTP, the windows demonstration experiment was re-scoped to take place in a matched pair of double-wide manufactured "Lab Homes" located side-by-side on the PNNL campus in Richland, Washington. ${ }^{2}$ As the expanded project was developed, it became a joint effort among many agencies and partners contributing more than $\$ 1 \mathrm{M}$ to the establishment of the Lab Homes at PNNL. The partners include the following:

- DOE/BTP (ARRA, Building America, Envelope and Windows R\&D)

- BPA

- $\mathrm{DOE} / \mathrm{OE}$

- PNNL Facilities

- Battelle Memorial Institute

- GE Appliances

- Tri Cities Research District

- City of Richland, Washington, Energy Services

- Northwest Energy Works (NEW)

- Washington State University Extension Energy Program

- Jeld-Wen®, Inc.

\footnotetext{
${ }^{1}$ Additional retrofit technologies will be evaluated in the Lab Homes under a broad-based R\&D demonstration program in these homes at the conclusion of the highly insulating windows demonstration project. Therefore, the pair of homes will remain at the PNNL campus for these experiments for an additional 5 to 7 years beyond the end of the highly insulating windows demonstration project.

${ }^{2}$ http://labhomes.pnnl.gov
} 
Improving the insulation and solar heat gain characteristics of a home's windows has the potential to significantly improve the home's building envelope and overall thermal performance by reducing heat loss (in the winter) and cooling loss and solar heat gain (in the summer) through the windows. A highquality installation will also minimize or reduce air leakage through the window cavity, thereby contributing to reduced heat loss in the winter and reduced cooling loss in the summer. These changes decrease overall yearly home energy use and increase occupant comfort.

The outcome of this field evaluation has relevance to the recent activity by BPA to develop new specifications for high-performance manufactured homes that go beyond today's ENERGY STAR specifications. This activity is designed to obtain deep energy savings in the manufactured housing sector in the Pacific Northwest (PNW). The approach is designed to 1) develop a set of specifications for the construction of manufactured homes that address all aspects of home energy use,2) develop a new market for high-performance manufactured homes, and 3) provide large, cost-effective electric savings to the region. The draft specifications were presented to the Regional Technical Forum in April 2012. ${ }^{1}$ The proposed specifications included a recommendation for $\mathrm{U}$-factor $=0.22$ windows, the same $\mathrm{U}$-factor as that of the windows being evaluated under this project, and a maximum air infiltration of 0.21 air changes/hour (natural) (ACHn). Therefore, the data from the field evaluation can be of value to the ongoing regional dialog and analysis required for the adoption of the high-performance manufactured home specifications.

The results are also relevant to residential retrofit programs being implemented across the nation. Windows are a key aspect of the building envelope, accounting for approximately 10 to $13 \%$ of an average home's energy use (EIA 2009; DOE 2011). This is because of the low thermal resistance of typical windows found in existing home or installed in most new homes today. Table 2.1 lists the typical insulation characteristics of several building envelope components in climate zone 5 , which is where the Lab Homes are located, and illustrates the dramatic difference between the isolative qualities of windows versus other building envelope components, such as walls.

Table 2.1. 2009 International Energy Conservation Code (IECC) Requirements for Climate Zone 5

\begin{tabular}{lc}
\hline Building Component & R-Value \\
\hline Wall Insulation & R-20 \\
Ceiling Insulation & R-38 \\
Window Insulation & $\sim$ R-3 \\
\hline
\end{tabular}

Windows are also an area with high potential for significant improvements in energy efficiency. The U.S. Energy Information Administration estimates there are more than 100 million homes in the United States with single- or double-pane clear glass (2009). High-performance windows decrease heat transfer through the window by as much as $70 \%$ over double-pane clear glass windows. ${ }^{2}$

\footnotetext{
${ }^{1}$ See http://www.nwcouncil.org/energy/rtf/meetings/2012/04/.

${ }^{2}$ Based on an assumed U-factor of 0.67 for double-pane clear glass and 0.2 for triple-pane, low-e (highperformance) windows.
} 


\subsection{Background and History of Building Research in Manufactured Housing}

In 2002, the BPA demonstrated multiple technologies in a zero-energy manufactured home. The 2002 project involved the demonstration, promotion, and monitoring of two manufactured homes: a zeroenergy manufactured home, and a base (Housing and Urban Development [HUD]-code) home. The BPA partnered with the Nez Perce Tribe, the Washington State University (WSU) Extension Energy Program, and the DOE's Building America Industrialized Housing Partnership as well as a number of industry partners.

The zero-energy manufactured home used innovative energy-saving technologies and building practices, such as ENERGY STAR lighting, appliances, and windows; a heat-recovery, whole-house ventilation system; Icynene ${ }^{\circledR}$ wall insulation; a solar water heating system; and a heat pump that extracts heat from the crawlspace. It also incorporated a renewable energy system $-4.2 \mathrm{~kW}$ of photovoltaic panels on the roof - that converts the sun's energy into electricity. The base home is a typical manufactured home built to Super Good Cents and ENERGY STAR standards.

In addition, there is a nationwide ENERGY STAR qualified manufactured home program. ${ }^{1}$ To qualify as an ENERGY STAR home, a manufactured home is required to be substantially more energy efficient than a comparable HUD-code home. This includes not only the thermal envelope, but also the estimate of total energy use for space heating, space cooling, and water heating. ENERGY STAR has developed pre-approved design packages of energy features that meet or exceed the ENERGY STAR requirements. For each climate region, pre-approved ENERGY STAR design packages are provided. The variety of packages gives the manufacturer fairly wide latitude in deciding how to design an ENERGY STAR qualified home. A package contains requirements for several features that must be used together to qualify as an ENERGY STAR qualified manufactured home. All the packages are roughly equivalent in energy terms. That is, applied to the same home, each package will result in approximately the same total energy use.

The federal government is currently undertaking rulemaking to improve the energy efficiency of current HUD-code manufactured homes. ${ }^{2}$ As part of that rulemaking, multiple scenarios are being evaluated for cost-effectively improving the building shell of the manufactured home. Among the measures being analyzed are highly insulating windows. These analyses are being done across multiple climate zones.

The DOE/BTP is undertaking a number of R\&D and demonstration projects on envelopes and windows focused almost exclusively on site-built homes. ${ }^{3}$ The focal point for all subprogram elements is the goal of advancing technologies that contribute to net zero-energy buildings. Specifically, DOE's Residential and Commercial Buildings Integration subprograms have identified the building shell and window needs for reducing home energy use by 30 to $50 \%$ (compared to the 2009 energy codes for new homes and pre-retrofit energy use for existing homes). Overall, highly insulating windows can become one of the key technologies in the building shell and contribute to DOE's goals for reduced energy use.

\footnotetext{
${ }^{1}$ See http://www.energystar.gov/index.cfm?c=bldrs lenders raters.pt builder_manufactured.

${ }^{2}$ See http://www.energycodes.gov/status/mfg_housing.stm

${ }^{3}$ See http://www1.eere.energy.gov/buildings/building_america/index.html
} 
In fact, studies suggest that advanced highly insulating windows have the technical potential to just about completely offset the current 4 quads of net energy use attributed to windows. In any given building energy simulation, results show that improved windows and shell measures are key to achieving DOE's whole-building energy goals.

Equipment loads and humidity were not simulated during the winter or most of the summer study period. The impact of the windows on interior dry bulb temperature distributions, glass surface temperature, and mean radiant temperature are presented to characterize thermal comfort impacts.

In this final report, PNNL evaluates the cost effectiveness of highly insulating windows as an energy efficiency measure for new and existing homes and makes recommendations for integrating highly insulating windows into the manufactured homes industry, utilities, and the retrofit industry. 


\subsection{The PNNL Lab Homes}

The project began with specification of the homes and procurement of the homes on the PNNL campus. The construction features and siting of the PNNL Lab Homes is described in Section 3.1. After arriving at PNNL, the double-wide homes were sited and alterations began. The most significant alterations included rewiring to accommodate 42 independent and controllable circuits in each home and installation of electrical, temperature, and environmental sensors throughout each home. The final specifications to which the two homes were constructed and altered are given in Appendix A and the specification process is described in more detail in the report that documents the winter experiment (Parker et al. 2012). After the homes were procured, PNNL procured highly insulating (U-factor $=0.20$ 0.22) windows and sliding glass doors for retrofit in Lab Home B (the experimental home), and standard windows and sliding glass doors for retrofit in Lab Home A (the baseline home). The highly insulating windows were specified by Jeld-Wen ${ }^{\circledR}$, a window manufacturer that is a participant in the DOE Windows Volume Purchase Program for high-performance windows and is based in Portland, Oregon. The standard windows (double-pane clear with aluminum frame) were specified and installed in Lab Home B to represent windows commonly found in existing homes.

\subsection{Construction Features and Siting of the Lab Homes}

The matched pair of Lab Homes were constructed at a Marlette ${ }^{\circledR}$ Homes manufacturing plant in Hermiston, Oregon, during the time period from August 11 through August 23, 2011. The homes are both HUD-code Marlette Value Edition Model \#2856B with the options identified in the specifications given in Appendix A. The thermal calculations provided by the manufacturer show a heat transfer coefficient of $345.36 \mathrm{Btu} / \mathrm{hr} \mathrm{ft}^{2}{ }^{\circ} \mathrm{F}$. The floor plan of the homes as constructed is shown in Figure 3.1.

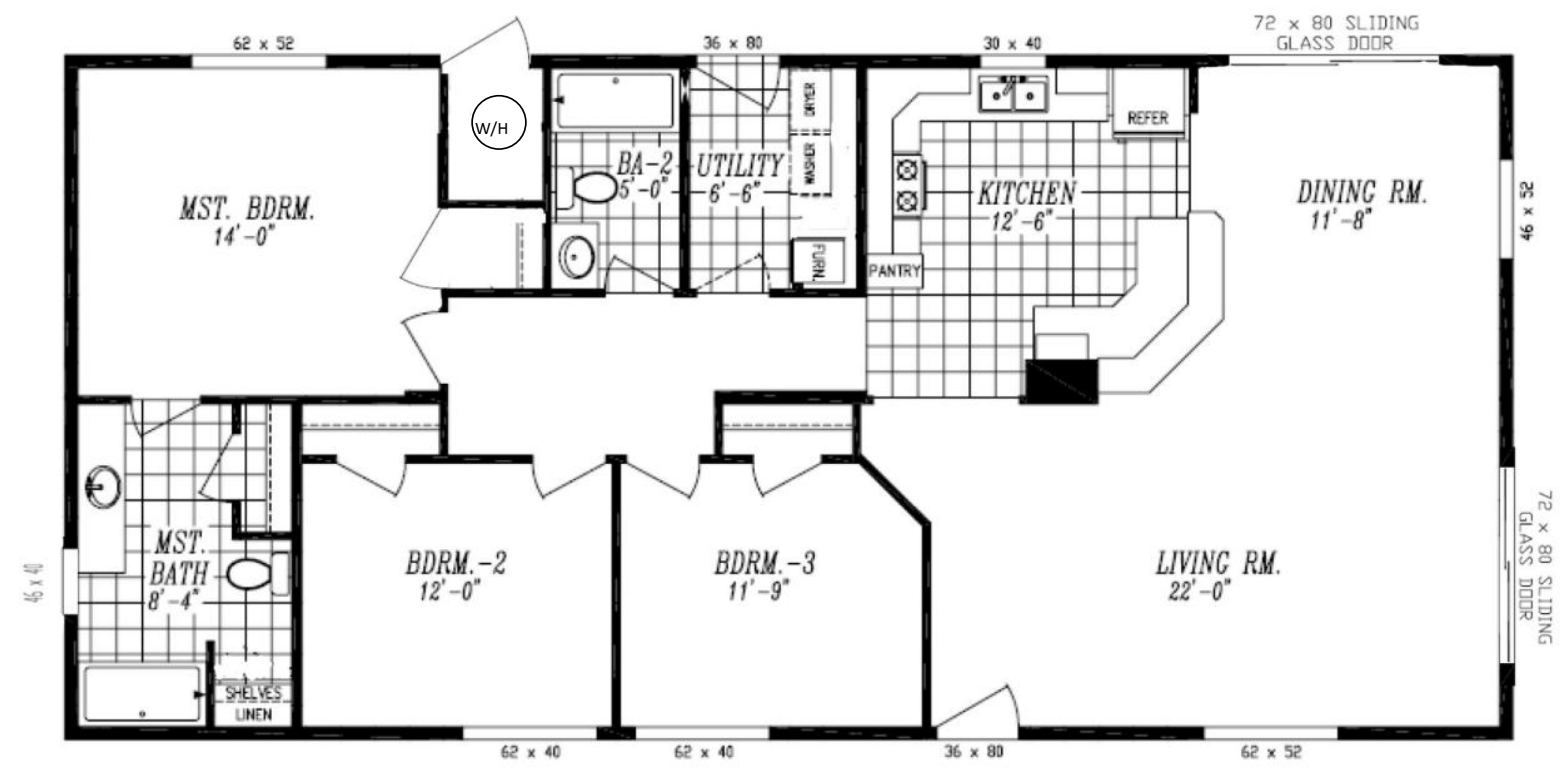

Figure 3.1. Floor Plan of the Lab Homes as Constructed

Features of the 1,493- $\mathrm{ft}^{2}$ double-wide 3-bedroom/2-bathroom homes that are relevant to the highly insulating windows evaluation include the following: 
- all-electric

- window area: $195.7 \mathrm{ft}^{2}$ or $\sim 13 \%$ of the floor area

- frame: 2 in. $\times 6$ in. walls; 2 in. $\times 10$ in. floor and ceiling

- insulation: R-22 floors (with belly wrap), R-11 walls; R-22 vaulted ceiling, R-4.2 exterior ducts

- heating/cooling: non-setback central thermostat-controlled ducted 2.5-ton heat pump; 13 Seasonal Energy Efficiency Ratio (SEER)/8.0 Heating Seasonal Performance Factor (HSPF) with single-speed air handler, three $5 \mathrm{~kW}$ electrical elements, plus alternative heating provided by Cadet Model \#RMC151W 120V fan wall heaters with individual thermostats ${ }^{1}$

- underfloor HVAC ducting

- lighting: $100 \%$ incandescent

- 6-in. (overhang) vented eaves all around

- bath fans, kitchen range hood, and whole-house exhaust fan

- $\operatorname{wood}\left(\right.$ SmartSide $\left.{ }^{2}\right)$ panel siding

- carpet + vinyl flooring

- vented crawlspace with Rapid Wall 2-in. thick expanded polystyrene foam-backed aluminum with R9 insulation value with access panels

- exterior access foam-core door to water heater.

The homes were placed $90 \mathrm{ft}$ apart on the PNNL campus in a flat, open area with no buildings or trees near them that would create shade on the homes during any time of the year. The homes were oriented in an east/west direction with the main entry doors to the living room facing north. This orientation resulted in one sliding glass patio door facing west and the other sliding glass patio door facing south. The homes were sited such that neither house shades the other or is affected by the other home's prevailing wind shadow.

The homes are surrounded by irrigated grass with gravel driveways on the east end and a gravel walkway all around each home. The homes are adjacent to an irrigated alfalfa field to the east.

Figure 3.2, Figure 3.3, Figure 3.4, and Figure 3.5 show the homes as they are currently sited. Appendix B contains additional photos of the exterior and interior of the homes.

\footnotetext{
${ }^{1}$ Note that the locations of the Cadet wall heaters are not shown in Figure 3.1. These heaters were not used/not activated during any part of the highly insulating windows winter evaluation.

${ }^{2}$ Registered trademark of Louisiana-Pacific Corporation, Binghamton, New York.
} 


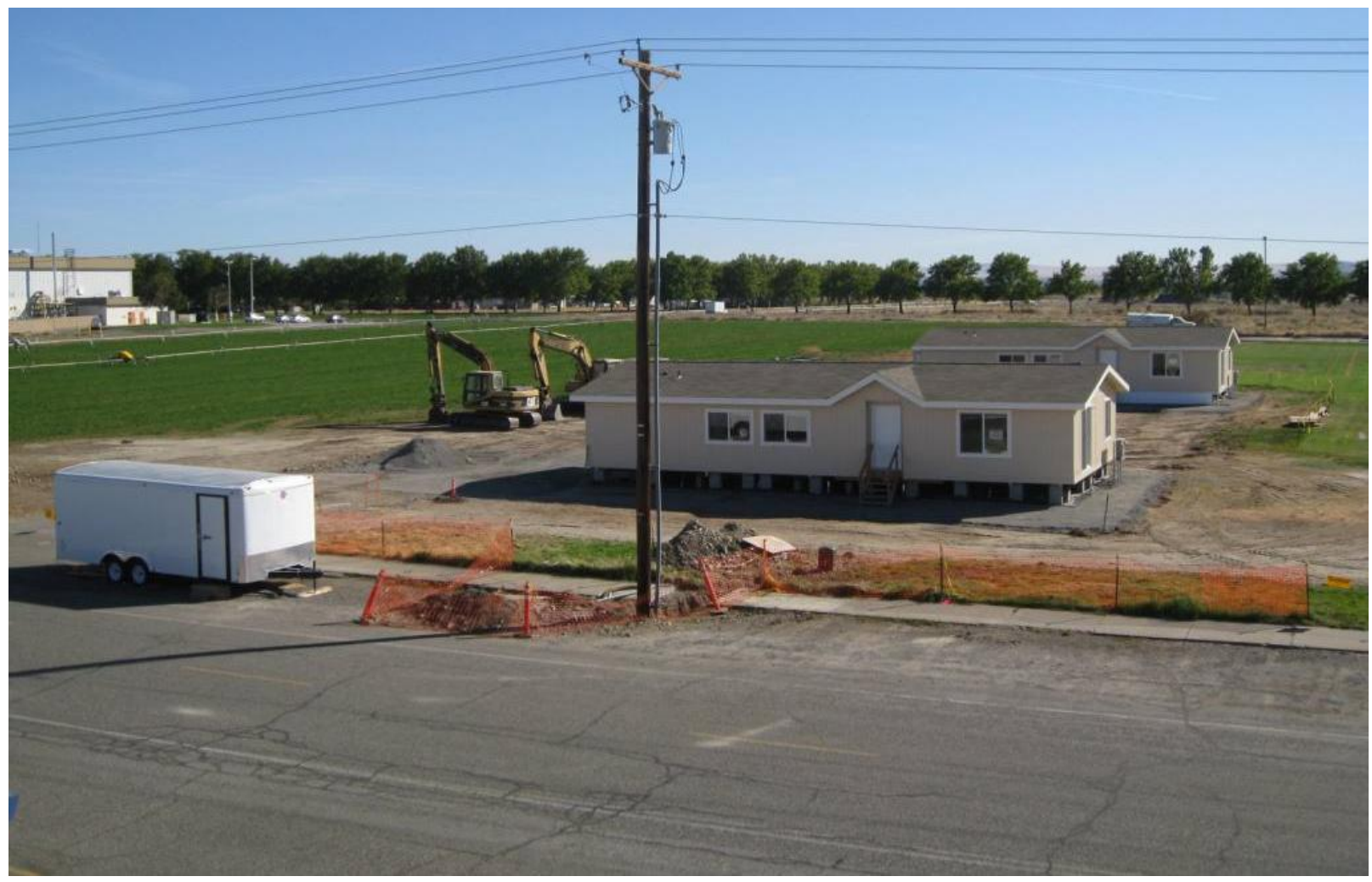

Figure 3.2. Lab Home B (foreground) and Lab Home A (background) after Setup During Final Site Preparation
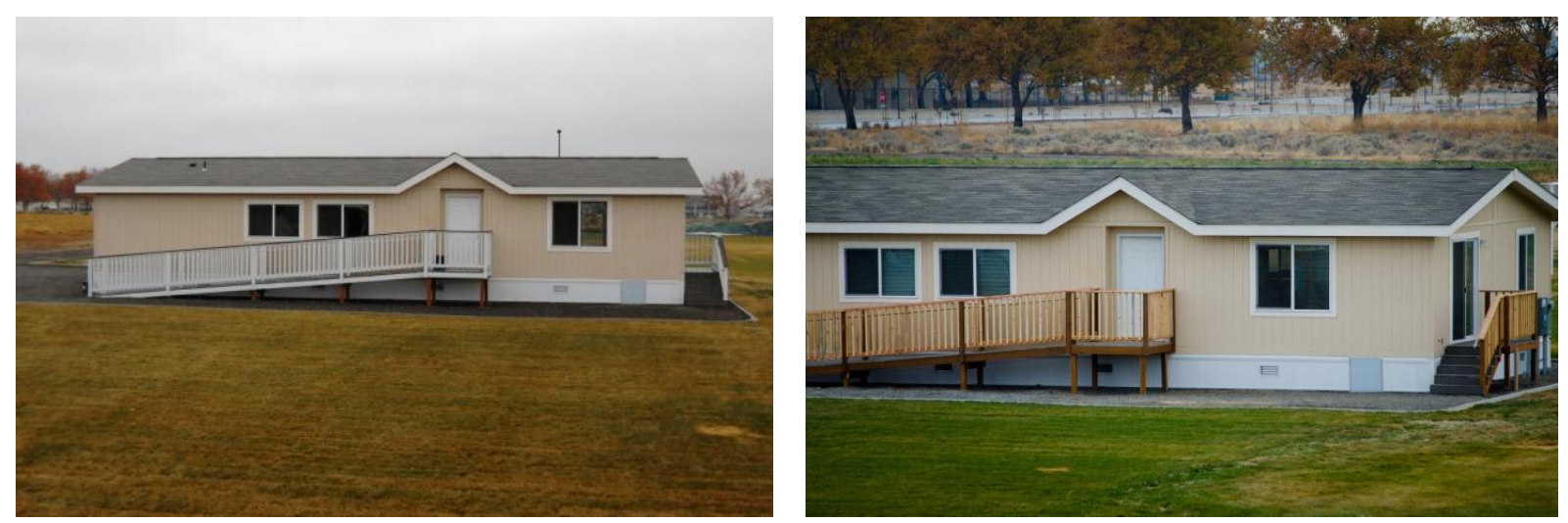

Figure 3.3. North Side and North and West Sides of Lab Home A (Baseline Home) 


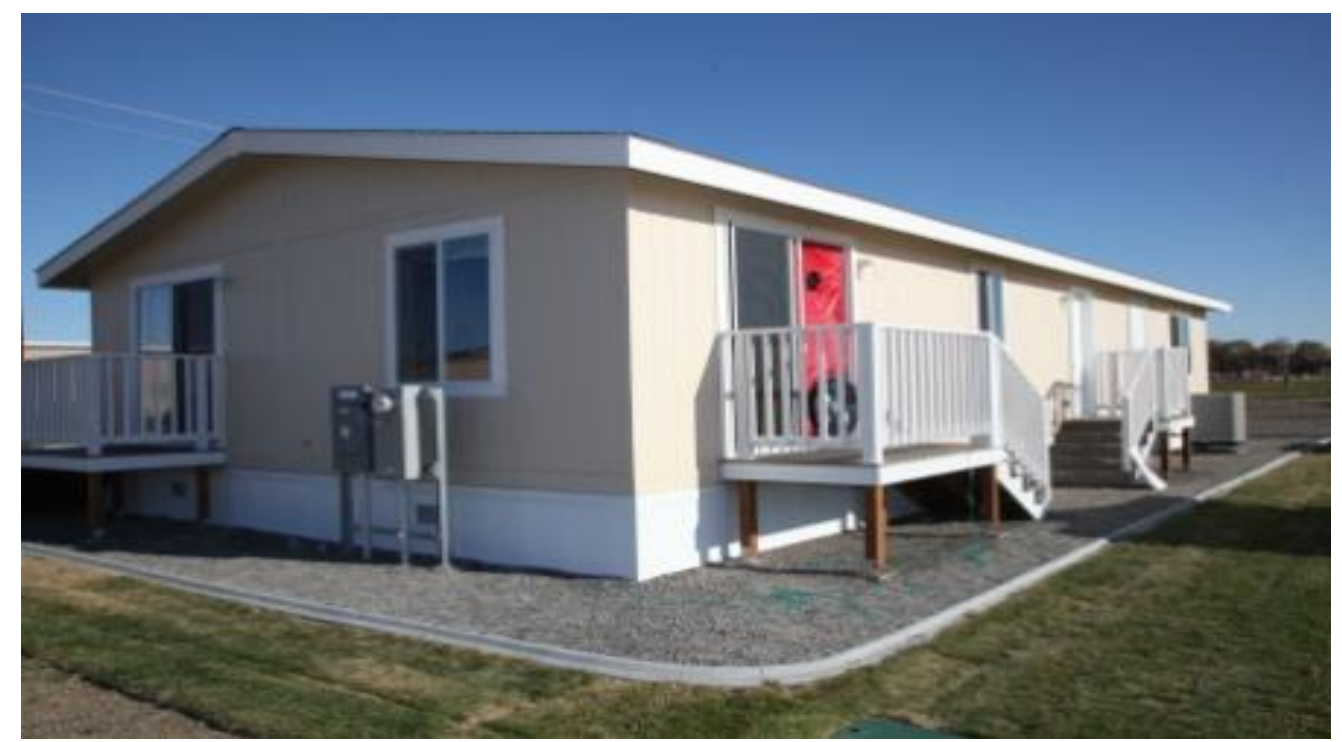

Figure 3.4. West and South Sides of Lab Home B (Experimental Home)

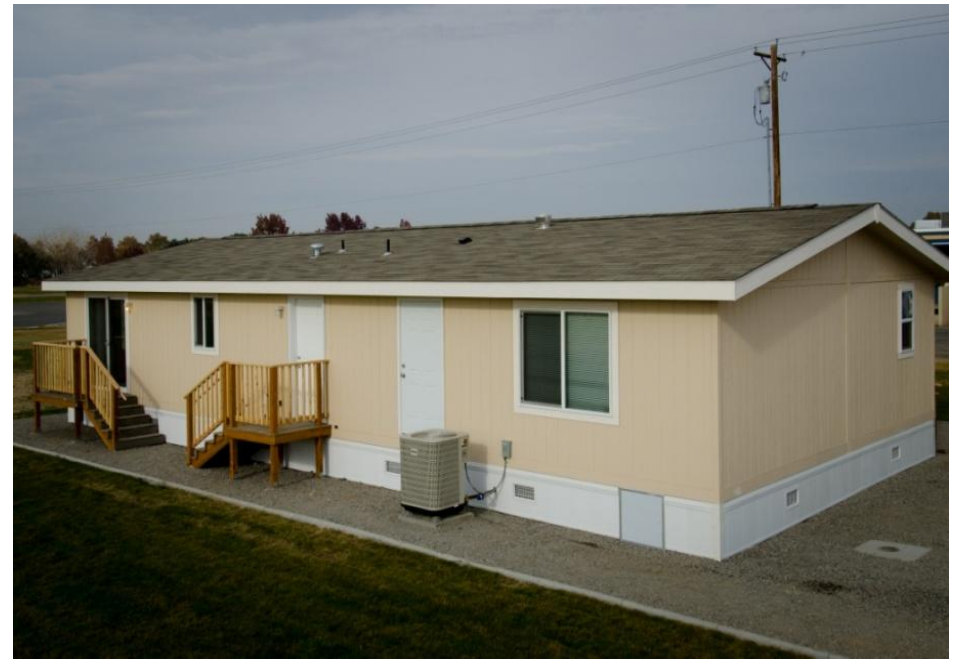

Figure 3.5. South Side of Lab Home B (Experimental Home)

\subsection{Metering, Monitoring, and Experimental Plan}

The windows performance evaluation relied on a tiered approach to performance and evaluation in the Lab Homes. The approach was designed to generate a multilevel performance evaluation whereby each level was used to aggregate to the next highest level (component, to building system, and then whole building) to arrive at the net impact. A major advantage of this approach is the ability to implement a "check-sum" methodology during the evaluation; i.e., the sum of the end-use parts compared to the expected/metered whole with a capability to drill down to the individual component level.

\subsubsection{Metering and Monitoring Approach}

The approach to the metering included metering and system-control activities taking place at both the electrical panel and at the end-use or point of use. Monitoring was broken into electrical (Table 3.1) and 
temperature/other (Table 3.2). Each table highlights the performance metric (the equipment/system being monitored), the monitoring method and/or point, the monitored variables, and the data application.

Table 3.1. Electrical Points Monitored

\begin{tabular}{|c|c|c|c|}
\hline $\begin{array}{l}\text { Performance } \\
\text { Metric }\end{array}$ & $\begin{array}{c}\text { Monitoring } \\
\text { Method/Points }\end{array}$ & $\begin{array}{l}\text { Monitored } \\
\text { Variables }\end{array}$ & Data Application \\
\hline $\begin{array}{l}\text { Whole Building } \\
\text { Energy Use }\end{array}$ & $\begin{array}{l}\text { Electrical panel } \\
\text { mains }\end{array}$ & $\mathrm{kW}$, amps, volts & $\begin{array}{l}\text { Comparison and difference calculations between } \\
\text { homes of } \\
\text { - power profiles } \\
\text { - time-series energy use } \\
\text { - differences and savings }\end{array}$ \\
\hline $\begin{array}{l}\text { HVAC Energy } \\
\text { Use (heat pump) }\end{array}$ & $\begin{array}{l}\text { Panel metering } \\
\text { compressor } \\
\text { Panel metering air } \\
\text { handling unit } \\
\text { End-use metering } \\
\text { condensing unit (CU) } \\
\text { fan/controls }\end{array}$ & $\begin{array}{l}\mathrm{kW} \text {, amps, volts } \\
\mathrm{kW} \text {, amps, volts } \\
\mathrm{kW} \text {, amps, volts }\end{array}$ & $\begin{array}{l}\text { Comparison and difference calculations between } \\
\text { systems of } \\
\text { - power profiles } \\
\text { - time-series energy use } \\
\text { - differences and savings }\end{array}$ \\
\hline $\begin{array}{l}\text { HVAC Energy } \\
\text { Use (ventilation) }\end{array}$ & $\begin{array}{l}\text { Panel metering of } 3 \\
\text { ventilation breakers } \\
\text { ( } 2 \text { bathroom and } \\
\text { whole-house fans) }\end{array}$ & $\mathrm{kW}$, amps, volts & $\begin{array}{l}\text { Comparison and difference calculations between } \\
\text { systems of } \\
\text { - power profiles } \\
\text { - time-series energy use } \\
\text { - differences and savings }\end{array}$ \\
\hline Water Heating & $\begin{array}{l}\text { Panel metering of } \\
\text { water heater breakers }\end{array}$ & $\mathrm{kW}$, amps, volts & $\begin{array}{l}\text { Comparison and difference calculations between } \\
\text { systems of } \\
\text { - power profiles } \\
\text { - time-series energy use } \\
\text { - differences and savings }\end{array}$ \\
\hline $\begin{array}{l}\text { Appliances and } \\
\text { Lighting }\end{array}$ & $\begin{array}{l}\text { Panel metering of all } \\
\text { appliance and } \\
\text { lighting breakers }\end{array}$ & $\mathrm{kW}$, amps, volts & Comparison and difference calculations. \\
\hline
\end{tabular}

Table 3.2. Temperature and Environmental Points Monitored

\begin{tabular}{|c|c|c|c|}
\hline $\begin{array}{l}\text { Performance } \\
\text { Metric }\end{array}$ & Monitoring Method/Points & Monitored Variables & Data Application \\
\hline \multirow[t]{2}{*}{$\begin{array}{l}\text { Space } \\
\text { Temperatures }\end{array}$} & $\begin{array}{l}13 \text { Ceiling-hung } \\
\text { thermocouples/1-2 sensors } \\
\text { per room/area, and } 1 \text { HVAC } \\
\text { duct supply temperature per } \\
\text { home }\end{array}$ & Temp. ${ }^{\circ} \mathrm{F}$ & $\begin{array}{l}\text { Comparison and difference calculations } \\
\text { between homes of: } \\
\text { - temperature profiles } \\
\text { - time-series temperature changes }\end{array}$ \\
\hline & $\begin{array}{l}2 \text { mean radiant sensors per } \\
\text { home (main living area, } \\
\text { master bedroom) }\end{array}$ & Temp. ${ }^{\circ} \mathrm{F}$ & \\
\hline $\begin{array}{l}\text { Space Relative } \\
\text { Humidity (RH) }\end{array}$ & $\begin{array}{l}2 \text { percent-relative-humidity } \\
\text { sensors per home (main } \\
\text { living area, hall outside of } \\
\text { bathroom) }\end{array}$ & $\% \mathrm{RH}$ & $\begin{array}{l}\text { Comparison and difference calculations } \\
\text { between homes of: } \\
\text { - RH profiles } \\
\text { - time-series RH changes }\end{array}$ \\
\hline
\end{tabular}


Table 3.2. (contd)

\begin{tabular}{|c|c|c|c|}
\hline $\begin{array}{l}\text { Performance } \\
\text { Metric }\end{array}$ & Monitoring Method/Points & Monitored Variables & Data Application \\
\hline $\begin{array}{l}\text { Glass Surface } \\
\text { Temperatures }\end{array}$ & $\begin{array}{l}22 \text { thermocouples ( } 2 \text { sensors } \\
\text { per window interior/exterior } \\
\text { center of glass); west } \\
\text { window with } 6 \text { sensors }\end{array}$ & Temp. ${ }^{\circ} \mathrm{F}$ & $\begin{array}{l}\text { Comparison and difference calculations } \\
\text { between homes of: } \\
\text { - temperature profiles } \\
\text { - time-series temperature changes }\end{array}$ \\
\hline $\begin{array}{l}\text { Through-Glass } \\
\text { Solar } \\
\text { Radiation }\end{array}$ & $\begin{array}{l}1 \text { pyranometer sensor per } \\
\text { home trained on west-facing } \\
\text { window }\end{array}$ & Watts $/ \mathrm{m}^{2}$ & $\begin{array}{l}\text { Comparison and difference calculations } \\
\text { between homes of: } \\
\text { - profiles by window and location }\end{array}$ \\
\hline $\begin{array}{l}\text { Meteorological } \\
\text { Station }\end{array}$ & $\begin{array}{l}\text { Package station mounted on } \\
\text { Lab Home B }\end{array}$ & $\begin{array}{l}\text { Temp. }{ }^{\circ} \mathrm{F} \\
\text { Humidity } \% \\
\text { Wind speed } \mathrm{m} / \mathrm{s} \\
\text { Wind direction } \\
\text { Barometric pressure } \\
\text { mm } \\
\text { Rainfall, inches }\end{array}$ & $\begin{array}{l}\text { Analytical application to quantify setting } \\
\text { and develop routines for application to } \\
\text { other climate zones }\end{array}$ \\
\hline
\end{tabular}

All metering was done using Campbell ${ }^{\circledR}$ Scientific data loggers and matching sensors. Two Campbell data loggers were installed in each home, one allocated to electrical measurements and one to temperature and other data collection. Data from all sensors were collected via cellular modems that were individually connected to each of the loggers. The polling computer located in the metering lab on the PNNL campus connected to each logger using Campbell Scientific software.

Initially, data were collected at tight intervals (starting at 1-minute integration) to make sure all systems and equipment were operating as expected - both within each home and in comparison home-tohome. These 1-minute data have been supplemented with 15-minute and 1-hour data to afford different analysis activities.

In a parallel effort, occupancy in the homes was simulated via programmed access to a customdesigned breaker panel (one per home) using motorized breakers. These breakers were programmed to activate connected loads on schedules to simulate human occupancy. The occupancy simulation schedule is included in Appendix C. Technical information about the controllable breaker panel, the Campbell data logger, and relevant sensors is included in Appendix D.

\subsubsection{Electrical Measurements}

In each home, all 42 panel electrical breakers were monitored for amperage and voltage. The resulting data were used to calculate apparent and real power $(\mathrm{kVA} / \mathrm{kW})$. All data were captured at 1minute intervals by the Campbell Scientific data logger.

\subsubsection{Temperature and Environmental Sensors}

Space Temperature. To provide for maximum flexibility for existing and future experiments, identical networks of temperature sensors were deployed in both homes. Each defined area of the home (individual rooms, hallway, and open living areas) had at least one thermocouple; a total of 13 space 
temperature thermocouples were installed per home. All temperature measurements were taken with type $\mathrm{T}$ thermocouples at 1-minute intervals by the Campbell data logger.

Glass Surface Temperature. All seven windows and two sliding glass doors in each home were instrumented with surface-mount type $\mathrm{T}$ thermocouples in a center-of-glass position on both the interior and exterior surfaces. The west-facing 46-in. $\times 52$-in. window in each home was instrumented with three thermocouples to capture variance in temperature from the center of glass to the window edge and frame. A total of 22 window/sliding glass door surface temperature thermocouples were installed per home.

Mean Radiant Temperature. To estimate thermal comfort, mean radiant temperature (MRT) sensors were installed in each home. One was located in the living room in the northwest corner (facing the west window and the north sliding glass door) and the other was located in the master bedroom facing the north window. These devices, also known as black-globe temperature sensors, use a thermistor inside a 6-in. hollow black copper sphere to measure incident radiant temperature. This measurement becomes a proxy for thermal comfort/discomfort resulting from the radiant heat exchange between an occupant and surrounding (e.g., window) surface temperatures.

Relative Humidity. Two humidity sensors were installed in each home, one in the living area and one in the hallway. The data from these sensors were collected and compared to verify that comparable humidity profiles were present in each home.

Transmitted Solar Radiation. Through-glass transmission of solar radiation was measured with a thermopile pyranometer. Each home was instrumented with one solar pyranometer facing the west window. The pyranometers were installed identically (height and distance from the window) in each home to provide a measure of comparative transmitted solar radiation.

Light Level Measurements. Measurements of light level were taken by PNNL staff in each home before and after the windows retrofit prior to the start of the winter experiment (see Appendix F). The instrument used was a Konica Minolta T-10 illuminance meter with detachable head, cable, and connector. 



\subsection{Testing Protocol}

The metering and data collection approach for the highly insulating windows demonstration was designed to make sure that the performance data collected in the windows experiment would reflect only the performance impact of the windows retrofitted in the two homes and that all other variables that would affect the performance would be identical in the two homes. The experimental testing protocol is summarized below in chronological order of implementation. The details of the testing and the schedule and duration of each test follow.

1. Post-Siting Testing of the Homes. After the homes were sited and modified, but before the instrumentation was installed, PNNL, NEW and WSU-Extension Energy staff conducted blower door tests, duct testing, and infrared (IR) scans. These tests were conducted to determine qualitatively the comparative construction and setup of the two homes.

2. Post Instrumentation Installation Testing. After post-setup testing of the Lab Homes, PNNL instrumented both of the manufactured homes with appropriate monitoring, sensors, and data collection/archiving equipment used to determine the comparative energy performance of the two homes. After equipment installation, the homes were blower door tested to determine building shell air leakage, and penetrations due to the instrumentation were sealed to bring the homes to a statistically identical level of air tightness. The HVAC (heat pump) operation and performance in each home were also ascertained.

3. Float Null Testing. Temperatures were monitored in both homes in a float null case (no heating, cooling, lighting, etc., loads enabled) to determine any differences in the homes as delivered and set up.

4. HVAC Null Testing. Temperatures, whole-house energy use, and HVAC energy use were monitored in both homes in an HVAC system-enabled null case with identical thermostat set points in both homes to determine any differences in whole-house or HVAC system performance.

5. Full-System Null Testing. Both homes were monitored in a full-system activation null case that included operating the HVAC systems (heat pumps) at identical thermostat set points and identical occupancy simulation in both homes to determine any differences in systems performance.

6. Windows Retrofit and Initiate Experiments. Once the homes were full-system null tested, the windows winter and summer experiments were initiated. The original (factory-supplied) windows in Lab Home A were retrofitted with double-pane, clear, aluminum-frame windows and the windows in Lab Home B were retrofitted with the Jeld-Wen ${ }^{\circledR}$ Inc triple-pane, argon gas-filled,1 low-e coated windows. Performance testing included monitoring of the following:

- whole-building energy use

- HVAC-specific energy use

- multiple interior zone/space temperature measurement

- interior relative humidity measurement (two locations)

\footnotetext{
${ }^{1}$ Window manufacturers fill the sealed gap in multi-pane windows with an inert gas such as argon to reduce the conduction of heat between panes and thus increase the overall U-factor of the window assembly.
} 
- window surface temperatures - interior/exterior center-of-glass measurements

- window solar irradiation (solar radiation transmittance)

- MRT (black body) measurement (two locations).

The testing undertaken, the retrofit windows specifications, and post-windows retrofit testing protocol for the Lab Homes are described in detail below. The data derived from the testing are presented in Section 5.0.

\subsection{Post-Siting Testing of the Homes}

After siting the Lab Homes, extensive baseline testing was conducted to verify similar construction, envelope leakage, duct leakage, ventilation fan flow rates, and heat pump operation between the homes. These physical parameters were evaluated by PNNL, with assistance from the WSU-Extension Energy Program and NEW, using industry standard methods and protocols, as described in the following sections.

\subsubsection{IR Testing}

Similar construction and thermal performance was evaluated from the interior and exterior using a Fluke Ti32 IR camera. Scans were recorded in the Fluke proprietary .is2 file format with descriptive vocal annotations to locate the image in the proper home and location within the home.

\subsubsection{Building Shell Air Leakage}

Air leakage through the building shell was quantified in both homes using a Minneapolis Blower Door Model 3 and DG-700 digital pressure gauge in accordance with ASTM E779, Standard Test Method for Determining Air Leakage Rate by Fan Pressurization (ASTM 2010) and manufacturer recommendations. The accuracy of the blower door test is $3 \%$ of the reading, as stated in manufacturer's literature (The Energy Conservatory 2012). All reported blower door values have been adjusted based on the density of air using the correction factors supplied in the Blower Door Operation Manual (The Energy Conservatory 2012). The air leakage was measured before the start of the winter experiment and again before the start of the summer experiment.

\subsubsection{Duct Leakage and Pressure Mapping}

Duct leakage was measured using a Minneapolis Duct Blaster Series B fan and DG-700 digital pressure gauge supplied by The Energy Conservatory. The test was conducted according to the protocol defined in the duct blaster operating manual (The Energy Conservatory 2011). The accuracy of the duct blaster fan is 3\% of the measurement, as stated in the manufacturer's literature (The Energy Conservatory 2011). Distribution of the duct system was also characterized in each home by measuring the flow through each supply register using an Exhaust Fan Flow Meter from The Energy Conservatory (The Energy Conservatory 2010). 


\subsubsection{Ventilation Fan Flow Rate}

Flow rates of the whole-house ventilation fan and two bathroom exhaust fans were measured using an Exhaust Fan Flow Meter and DG-700 digital pressure gauge from The Energy Conservatory. The stated accuracy of the Exhaust Fan Flow Meter is $\pm 10 \%$ of the reading (The Energy Conservatory 2010).

\subsubsection{Heat Pump Performance}

The performance of both homes' heat pumps was verified by measuring the temperature differential across the coil in both homes when heating was called for. This was done during the baseline testing prior to the start of the winter windows experiment using a small digital readout thermometer. Temperature sensor accuracy was not verified and measurement error is not known for this device. The heat pump was allowed to run for at least 20 minutes prior to taking readings and the supply air temperature was taken immediately downstream from the indoor coil.

Flow through the air handler was also measured using an Energy Conservatory TrueFlow air handler flow meter and DG-700 digital pressure gauge. The accuracy of the combined system is $\pm 7 \%$ of the reading, as stated in manufacturer literature (The Energy Conservatory 2006). For this measurement, the duct system pressure tap was placed in the duct at the north entryway register to obtain system operating pressure readings and Plate 20 was used in the air handler. The automated procedure in the DG-700 gauge was used to obtain corrected airflow readings directly.

\subsection{Post-Siting Instrumentation Installation and Data Collection Protocols}

All metering equipment, data loggers, and indoor and outdoor sensors were installed and commissioned prior to initiating null testing. Data from all sensors were collected via four data acquisition systems, one for environmental sensors and one for energy sensors in each home. Data were downloaded using Internet Protocol cellular modems. A polling computer, located in the metering lab on the PNNL campus, was connected to each logger using Campbell Scientific software. Data were recorded at 1-minute, 15-minute, and hourly intervals. One-minute data were used for all analysis to capture any short-duration changes in energy use within the home-for example from a heating element cycling on - and to limit error introduced from averaging over longer time periods. Data were averaged over 15-minute intervals.

The metering equipment is described in Section 5.0; equipment specifications are given in Appendix D.

\subsection{Float, HVAC, and Full-System Null Testing}

Baseline null testing was performed prior to the windows retrofits by comparing the whole-house energy use given identical operating conditions. Null testing was performed for 8 days from January 16 through 23,2012 , with the thermostat set point increased by $5^{\circ} \mathrm{F}$ increments in each home (identically) from $60^{\circ} \mathrm{F}$ on the first day to $85^{\circ} \mathrm{F}$ on the last day of testing. This was done to verify the identical performance of the homes over a range of interior temperatures and indoor/outdoor temperature 
differentials. During the null tests, the homes were operated identically in heat pump and electric resistance modes. Null testing was not undertaken prior to the summer experiment.

\subsection{Windows Retrofit}

The homes as received from the factory came with Kinro Series 1500 windows and two Kinro Series 1600 sliding glass doors (patio doors). The windows were horizontal sliders with double glaze, argonfilled, low-e 036 coating, and vinyl frames. ${ }^{1}$ The sliding glass patio doors were also vinyl-framed, double-glazed, and argon-filled with low-e 036 coating. The factory windows provided were selected to meet the HUD overall building shell thermal performance criteria for manufactured homes in the climate zone of Richland, Washington. ${ }^{2}$

In Lab Home B, the factory-supplied slider windows and two patio doors were replaced by JeldWen® Premium Energy Saver-MAX-K slider vinyl windows and patio doors. ${ }^{3}$ These vinyl-frame windows are triple-pane, argon/krypton-filled with low-e coatings on both inside glass surfaces. In addition, these windows have a Jeld-Wen®'s low-e3-366 coating, which comprises three layers of silver particles instead of two for increased insulation performance and decreased solar heat gain. A photo of the National Fenestration Rating Council (NFRC) label from one of the windows installed in the experimental home is included in Figure 4.1.

\footnotetext{
${ }^{1}$ The window in the master bathroom was retrofitted with a single-hung window because that was the window type supplied by the factory. The Jeld-Wen ${ }^{\circledR}$ retrofit window, however, was not frosted as is the case for the retrofitted window in Lab Home A (see footnote on next page).

${ }^{2}$ See http://www.gpo.gov/fdsys/pkg/CFR-2001-title24-vol1/content-detail.html.

${ }^{3}$ Note that the retrofitted window in the master bathroom was a single-hung (non-frosted) window because a singlepane window was the factory-supplied window in the home (see Figure 4.1).
} 


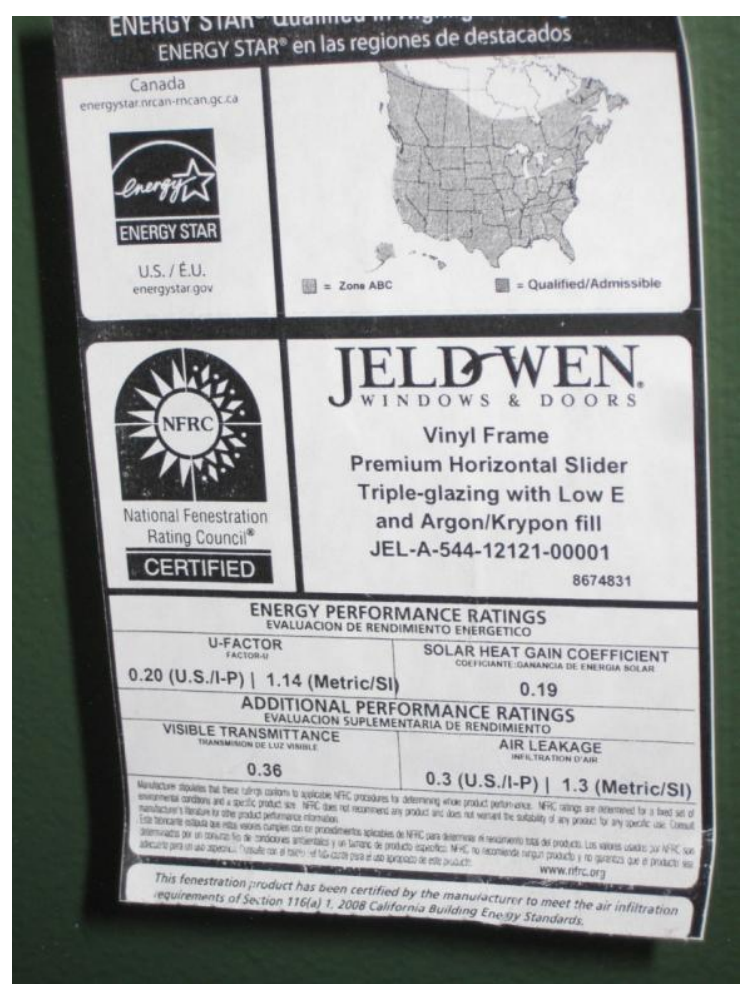

Figure 4.1. NFRC Certification Label for Jeld-Wen® Highly Insulating Windows Installed in Lab Home B

The Jeld-Wen ${ }^{\circledR}$ highly insulating windows were installed by the primary general contractor (GC) for the Lab Homes procurement with guidance provided onsite by Jeld-Wen®-trained installers and according to the documented instructions provided by Jeld-Wen ${ }^{\circledR}$ on each window for retrofitting its windows. Installation included removal of the existing window, installation of a drain mat with selfsticking felt and foam moisture barrier on the sill plate, installation of the new highly insulating windows squarely in the opening, and sealing around the window with preformed rolled foam and caulk. See Appendix E for more details and photos of the Lab Home B windows retrofit.

In Lab Home A, windows were installed that are representative of a large percentage of existing home construction in the PNW region and across much of the country. The windows are double-pane, clear glass aluminum-frame sliders. ${ }^{1}$ The windows were installed by the GC with no special training or assistance, to represent a "typical" installation. ${ }^{2}$ Installation included removal of the existing windows, insertion of the new double-pane clear windows, and caulking of the opening. ${ }^{3}$

Table 4.1 provides the specifications for the factory-supplied windows, the baseline retrofit windows in Lab Home A and the highly insulating retrofit windows in Lab Home B. As can be seen in Table 4.1,

\footnotetext{
${ }^{1}$ The retrofit master bathroom window in Lab Home A (see Figure 4.1) is a single-hung frosted (privacy) glass window with the same specifications and from the same manufacturer as the other retrofit windows in Lab Home A given that the single-hung window was the window type installed at the factory.

${ }^{2}$ The windows retrofitted in Lab Home A could only approximate a representation of windows in typical existing homes given that the windows were new, the caulking was fresh, and the windows were installed in a new home without the effects of aging.

${ }^{3}$ The Lab Homes were constructed without an air barrier because an air barrier was not a requirement in the specifications, nor was one required to meet the HUD code thermal performance.
} 
the U-factor of the windows and patio doors in Lab Home B is $\sim 70 \%$ less than that of the standard windows in Lab Home B. Also the low-e coatings of the windows in Lab Home B significantly decrease the solar heat gain coefficient (SHGC) by $~ 77 \%$ compared to the standard double-pane clear windows and patio doors. The visible transmittance (VT) of the highly insulating windows is approximately half that of the double-pane clear windows in Lab Home A.

Table 4.1. Window Performance Characteristics of the Factory-Installed, Baseline Retrofit, and Highly Insulating Retrofit Windows and Patio Doors Installed in the Lab Homes

\begin{tabular}{llccccc}
\hline & \multicolumn{2}{c}{ Lab Homes A \& B } & \multicolumn{2}{c}{ Baseline Lab Home A } & \multicolumn{2}{c}{$\begin{array}{c}\text { Experimental Lab Home B } \\
\text { Standard Retrofit Windows }\end{array}$} \\
\cline { 2 - 6 } Value & Factory Installed Windows & \multicolumn{2}{c}{ Stowsulating Retrofit Windows } \\
\cline { 2 - 7 } & Windows & Patio Doors & Windows & Patio Doors & Windows & Patio Doors \\
\hline U-factor & 0.31 & 0.29 & 0.68 & 0.66 & 0.20 & 0.20 \\
SHGC & 0.3 & 0.31 & 0.7 & 0.66 & 0.19 & 0.19 \\
VT & 0.56 & 0.59 & 0.73 & 0.71 & 0.36 & 0.37 \\
\hline
\end{tabular}

The possible impact of reduced interior light levels in Lab Home B from the reduced VT of the highly insulating windows was measured. Light levels were measured in both homes prior to and after the windows retrofit. The measurements and the results are described in Appendix F.

\subsection{Initiation of Windows Field Evaluation}

After the highly insulating and standard windows were installed in Lab Home B and Lab Home A, respectively, the air leakage of the two homes was again measured with a blower door test to determine air leakage changes and differences due to the windows retrofit. The homes were then set up identically for data collection of the energy use and thermal performance and to characterize savings and comfort impacts of the highly insulating windows compared to the standard windows during the heating and the cooling season.

As part of the experimental plan, the homes were operated identically in a variety of scenarios to understand the importance of different variables. Specifically, the impact of occupancy loads, heating system type (heat pump and electric resistance heat with central distribution system), and use of interior blinds (summer experiment only) were each evaluated. A timeline of the operating parameters and scenarios exercised during the data collection period are listed in Table 4.2. 
Table 4.2. Timeline and Summary of Operating Parameters During the Data Collection Period

\begin{tabular}{lll}
\hline Activity & Start Date & End Date \\
WINTER EXPERIMENT & $11 / 15 / 2012$ & $11 / 15 / 2012$ \\
Air leakage testing & $1 / 11 / 2012$ & $1 / 16 / 2012$ \\
Post-metering air leakage testing & $1 / 17 / 2012$ & $1 / 23 / 2012$ \\
Null testing & $1 / 24 / 2012$ & $1 / 25 / 2012$ \\
Windows installation & $1 / 27 / 2012$ & $1 / 27 / 2012$ \\
Post-windows leakage testing & $2 / 4 / 2012$ & $2 / 10 / 2012$ \\
Post-windows heating system only (HP) & $2 / 11 / 2012$ & $3 / 1 / 2012$ \\
Windows with lighting and occupancy (ER) & $3 / 1 / 2012$ & $3 / 7 / 2012$ \\
MRT and solar implemented & $3 / 7 / 2012$ & $3 / 7 / 2012$ \\
Windows with lighting and occupancy (HP) & $3 / 8 / 2012$ & $3 / 8 / 2012$ \\
Switch to 80 ${ }^{\circ}$ F set point (HP) & $4 / 13 / 2012$ & $4 / 13 / 2012$ \\
End winter data collection & & \\
SUMMER EXPERIMENT & $7 / 3 / 2012$ & $7 / 3 / 2012$ \\
Air leakage testing, setup & $7 / 4 / 2012$ & $7 / 18 / 2012$ \\
Summer data collection with lighting and occupancy & $7 / 19 / 2012$ & $8 / 5 / 2012$ \\
Implement appliance schedule for additional sensible load & $8 / 6 / 2012$ & $8 / 13 / 2012$ \\
Implement blinds closed 24 hrs/day & $8 / 14 / 2012$ & $8 / 15 / 2012$ \\
Implement blinds closed at night (9pm - 9am) & $8 / 16 / 2012$ & $8 / 17 / 2012$ \\
Implement blinds closed during the day (9am - 9pm) & $8 / 18 / 2012$ & $8 / 18 / 2012$ \\
\hline End summer season data collection & & \\
\hline
\end{tabular}

As shown in Table 4.2 , the thermostat set points were set at $75^{\circ} \mathrm{F}$ early in the study period and at $80^{\circ} \mathrm{F}$ later in the study period to maximize the indoor/outdoor temperature difference as outdoor average temperatures began to increase toward the end of winter. The set point during the cooling season experiment was maintained at $70^{\circ} \mathrm{F}$.

The field evaluation was run with and without simulated occupancy. The field evaluation was also performed with all appliances disabled to minimize any possible differences in appliance performance that might influence the heating of the homes. When run under simulated occupancy, the homes were run identically using the protocols described in Appendix C. For the heating season experiment and the majority of the cooling season experiment the homes were operated with no equipment or latent loads, but with people-related occupancy, simulated by $60-\mathrm{W}$ light bulbs in each of the bedrooms, and with simulated lighting loads. After sufficient summer data were collected for comparison to heating season data, equipment loads (e.g. appliances and other equipment) were simulated using the wall-mounted space heaters and controlled via the electrical panel. These additional sensible loads were used to determine the impact of the equipment loads on whole-house and HVAC energy use.

All interior window coverings (vinyl blinds) in both Lab Homes were removed to ensure that the homes were identically configured and operated for the heating season experiment and the majority of the cooling season experiment. During the final 3 weeks of the cooling season experiment, sensitivity experiments were conducted to investigate the impact of blinds on the energy-savings results. Blinds were closed for 24 hours per day to determine the maximum impact on the measured savings from the highly insulating windows. Also, anecdotal observation by the research team has noted that homeowners 
frequently keep blinds closed 24 hours per day in the summer for shading and privacy reasons. Thus, it is believed that this configuration is representative of a scenario that could be experienced in occupied homes.

\subsection{Energy Modeling}

The energy analysis for the Lab Homes was carried out using the EnergyPlus energy simulation engine. EnergyPlus is a whole-building detailed energy simulation engine capable of carrying out calculations at the hourly and sub-hourly level. It is the successor of powerful building energy modeling programs DOE-2 and BLAST. It combines the strong points of both prior programs and adds some more of its own. It is one of the most powerful whole-building energy modeling programs available today and is publicly available. ${ }^{1}$ The model requires a text input file (.idf) with information about the building and a weather file (.epw) to generate an annual energy simulation.

EnergyPlus lacks a graphical user interface and the building information is input to the program through a text input file. Because EnergyPlus lacks a graphical user interface, OpenStudio, ${ }^{2}$ developed by the National Renewable Energy Laboratory (NREL), is used to specify building geometry. OpenStudio allows the user to visualize and modify building geometry and creates an EnergyPlus input file (.idf) for the whole building. It was desirable to use OpenStudio's graphical abilities while still maintaining the freedom of using all of EnergyPlus' mechanical systems capability. In order to accomplish this, the building geometry was created in OpenStudio and exported in the form of an idf. The idf was then modified directly in EnergyPlus to model all of the mechanical systems.

Building geometry, envelope leakage parameters, internal gains, and HVAC equipment characteristics were specified to be consistent with the experimental parameters. Detailed input for the EnergyPlus input parameters are included in Appendix G.

To do an annual simulation, EnergyPlus needs weather data in form of an .epw file. NREL developed and maintains weather files for over 1200 locations in the United States. ${ }^{3}$ The closest typical meteorological year (TMY) site available is Pasco, Washington (airport), and it was used for energy simulation.

Energy use for the high-performance windows test was recorded from February 3, 2012 to April 13, 2012 and from July 6 to August 18, 2012. The 'runperiod' field in EnergyPlus was set to this exact period for comparison. Additional runs were conducted to get the annual energy savings from using the high-performance windows.

\subsection{Cost Effectiveness}

While windows may have a significant impact on whole-house energy use, the cost of windows compared to the value of the achieved savings is also important to consider when evaluating the

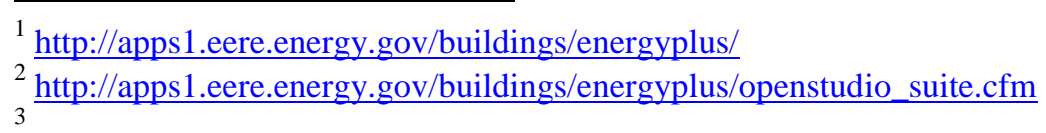

http://apps1.eere.energy.gov/buildings/energyplus/cfm/weather_data3.cfm/region=4 north and central_america w mo_region $4 /$ country $=1$ usa/cname $=$ USA\#WA 
effectiveness of windows as an energy efficiency measure. Windows have traditionally been perceived as a high-cost measure, such that the savings on a homeowner's utility bill will take years or even decades to recoup upfront costs. There are many ways to calculate cost effectiveness. In this report, the cost effectiveness of highly insulating windows is determined using the simple payback period (PBP), which describes the number of years it will take to payback the capital investment in the measure using nondiscounted energy savings, as shown in the following equation:

$$
\text { Simple PBP }(y r s)=\frac{\text { Capital Cost of Measure }(\$)}{(\text { Annual Energy Savings }[k W h] \times \text { Electricity Price }[\$ / k W h])}
$$

The capital cost of highly insulating windows, including installation costs, was used to determine the cost effectiveness of windows in a retrofit scenario. An incremental cost was also considered for new construction or if windows are being replaced for another reason (e.g., safety, functionality, aesthetics). In the incremental cost scenario, installation cost is not included and only the cost difference between code minimum and highly insulating (triple-pane) windows is used. The code minimum window is determined based on the 2009 Washington State Energy Code requirements for climate zone 1, shown below in Table 4.3 (Washington State Building Code Council 2009). Also, the incremental case considers the incremental savings of highly insulating windows over code minimum windows, as modeled in EnergyPlus.

Table 4.3. 2009 Washington State Energy Requirements for Climate Zone 1

\begin{tabular}{ll}
\hline Metric & Value \\
\hline U-factor & 0.32 \\
SHGC & 0.40 \\
\hline
\end{tabular}





\subsection{Results}

Evaluation results relative to data analysis, the thermal performance of the Lab Homes, heat pumps and air handlers, pre-windows-retrofit null testing, post-windows-retrofit building shell air leakage, postwindows retrofit HVAC and whole-house energy performance, peak load, energy modeling, and highly insulating windows retrofit cost effectiveness are described in the following sections.

\subsection{Data Analysis}

Data were averaged over 15-minute intervals and hourly and daily time-steps for data visualization and trends analysis. Data analysis was performed using Microsoft Excel and R statistical software. The error around each variable was calculated as the instrument error specific to each measurement instrument, if available, plus the $95 \%$ confidence interval around the geometric mean (average) value, assuming a normal distribution about the mean and based on a two-tailed student's t-statistic. Data were checked for completeness and accuracy prior to use in the analysis. Error analysis was only conducted on relevant data. Statistical significance of measured differences is determined using a t-test, based on the calculated $95 \%$ confidence intervals.

\subsection{Lab Homes Thermal Characteristics}

After the Lab Homes were set up on the PNNL campus and prior to the installation of the metering equipment and sensors, a home energy assessment was conducted on both homes to verify similar construction as built and sited. The results of these tests are given below.

\subsubsection{Infrared Testing}

Thermal imaging with an IR camera showed very similar thermal characteristics of the floor, ceiling, and exterior walls in both homes. However, the images can only be compared qualitatively due to differences in the interior temperature of each home. The baseline home average interior temperature was between 74.1 and $74.8^{\circ} \mathrm{F}$, while the experimental home's average interior temperature ranged between 71.6 and $71.8^{\circ} \mathrm{F}$. The exterior scans on the experimental home were taken from 7:09 pm to 7:18 pm, while those on the baseline home were taken between 7:50 pm and 7:58 pm. The night sky was clear, and the outside temperature was $22^{\circ} \mathrm{F}$ during the scans. The time difference allowed the baseline home's outer surfaces to cool longer than the outside of the experimental home. Figure 5.1 shows two images of the baseline and experimental homes from the outside. Each image has a box drawn on it with the maximum, average, and minimum temperature in the box; however, conclusions should not be drawn from the temperature differentials presented in the images, as explained above. In Figure 5.1, the increased thermal conductivity of the studs is evident, shown as brighter vertical lines on the wall. Heat also appears to be escaping from the top of the wall at the joint where the wall meets the ceiling. 

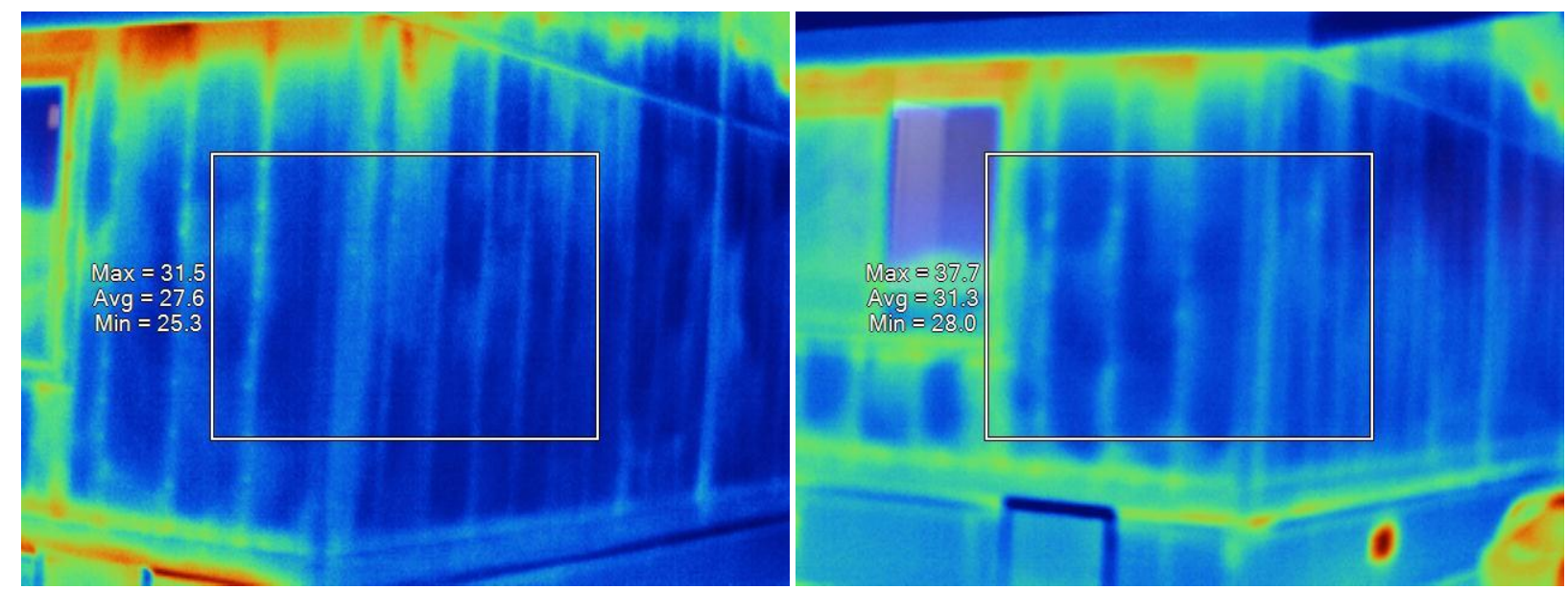

Figure 5.1. Baseline (left) and Experimental (right) Homes Exterior Side/Endwall Corner Thermal Images

Other thermal images indicate infiltration at electrical outlets and building joints, and inconsistency in wall insulation. The exterior scans indicate increased heat transfer at the joints between the ceiling and floor as well as above the windows where a solid structural heater exists (see Figure 5.1). Also, the temperature of the wall surface on each home varies as if there are inconsistencies in the insulation. This insulation inconsistency is particularly evident in the east- and west-facing end walls, as shown in Figure 5.2. In this image, insulation appears to not be in contact with this interior wall in the master bedroom near the foot of the wall, as indicated by the greater than $10^{\circ} \mathrm{F}$ temperature differential. This insulation inconsistency is probably caused by movement and slumping of the R-11 batt insulation, which does not completely fill the 2 x 6 stud cavity and may not be well-attached. Much of this movement may have occurred during transportation of the homes from the factory to the site.

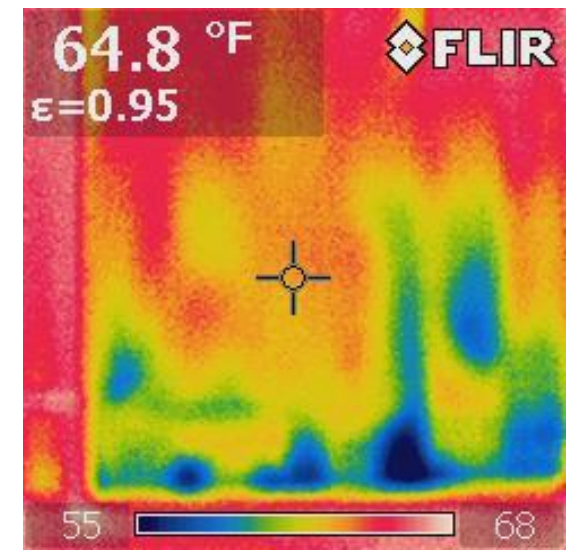

Figure 5.2. Thermal Image of Experimental Home East End Wall from the Master Bedroom. This image was taken with a FLIR b60 IR camera; image resolution is that of the instrument.

The scans focused mainly on the walls and joints. Where the ceiling and floors were included in scans they appear to be much more consistent in temperature across the assembly than the walls. 


\subsubsection{Pre-Windows-Retrofit Building Shell Air Leakage}

Blower door tests were conducted after siting of the homes to document air leakage of the homes as procured from the manufacturer and after installation of the metering equipment, but prior to the retrofit of the windows, to verify all penetrations were adequately sealed in both homes and that they had nearidentical air leakage. It is important that both homes have similar air leakage, because the amount of air leakage will affect HVAC energy use in each home. Differences in air leakage will thus confound determination of energy savings due to the highly insulating windows in Lab Home B.

As received, the two homes exhibited very similar building envelope leakage, within 30 cubic feet per minute at 50 Pascals depressurization (cfm50) of each other. Lab Home A had a measured $\mathrm{ACH}_{\mathrm{n}}$ of 0.14 and Lab Home B had a measured $\mathrm{ACH}_{\mathrm{n}}$ of 0.14 , as shown in Table 5.1.

Table 5.1. Building Envelope Air Leakage of Baseline and Experimental Home As-Received and Sited (prior to metering installation)

\begin{tabular}{lcc}
\hline & $\begin{array}{c}\text { Lab Home A } \\
\text { Baseline Home }\end{array}$ & $\begin{array}{c}\text { Lab Home B } \\
\text { Experimental Home }\end{array}$ \\
\cline { 2 - 3 } Parameter & Average Value & Average Value \\
\hline cfm25 $^{(a)}$ & 410.8 & 417.6 \\
$\operatorname{cfm} 50$ & 625.3 & 653.9 \\
$\mathrm{ACH50}{ }^{(\mathrm{b})}$ & 3.01 & 3.15 \\
$\mathrm{ACHn}$ & 0.14 & 0.15 \\
\hline
\end{tabular}

(a) Cubic feet per minute at 25 Pascals depressurization

(b) Air changes per hour at 50 Pascals depressurization

After installation of metering equipment, the homes were retested for similar air leakage, because the installation of metering equipment required minor penetrations of the building envelope, which could increase leakage. After slight additional air sealing was performed, the blower door test results showed the air leakage of the two homes is statistically the same, with $95 \%$ confidence. The homes are both fairly tight, which is typical of the manufactured housing industry in the PNW. The baseline home has leakage of $0.14 \pm 0.01 \mathrm{ACH}_{\mathrm{n}}$ and the experimental home has leakage of $0.15 \pm 0.01 \mathrm{ACH}_{\mathrm{n}}$. Detailed air leakage test results are given in Table 5.2.

Table 5.2. Building Envelope Leakage as Measured by Blower Door Tests in the Baseline and Experimental Home with Metering Equipment Installed

\begin{tabular}{|c|c|c|c|c|}
\hline \multirow[b]{2}{*}{ Parameter } & \multicolumn{2}{|c|}{$\begin{array}{c}\text { Lab Home A } \\
\text { Baseline Home }\end{array}$} & \multicolumn{2}{|c|}{$\begin{array}{c}\text { Lab Home B } \\
\text { Experimental Home }\end{array}$} \\
\hline & Average Value & \pm Error & Average Value & \pm Error \\
\hline $\operatorname{cfm} 25$ & 477.4 & 30.4 & 478.5 & 30.5 \\
\hline $\operatorname{cfm} 50$ & 638.5 & 27.8 & 681.1 & 26.7 \\
\hline ACH50 & 3.07 & 0.13 & 3.28 & 0.13 \\
\hline $\mathrm{ACH}_{\mathrm{n}}{ }^{(\mathrm{a})}$ & 0.14 & 0.01 & 0.15 & 0.01 \\
\hline
\end{tabular}




\subsubsection{Duct Leakage and Pressure Mapping}

Duct leakage and distribution performance was characterized in each home prior to the start of the winter experiment to verify similar performance. As shown in Table 5.3, Lab Home A has duct leakage of $203 \pm 6 \mathrm{cfm}$ at 25 Pascals ( $\mathrm{cfm} 25$ ) depressurization with respect to the house and duct leakage to outside $^{1}$ of $70 \pm 2 \mathrm{cfm} 25$ depressurization with respect to outside (cfm 25 to out), while Lab Home B has duct leakage of $197 \pm 6 \mathrm{cfm} 25$ and duct leakage to outside of $57 \pm \mathrm{cfm} 25$ to out. Overall duct leakage was shown to be reasonably similar between the two homes, with Lab Home A slightly leakier than Lab Home B but within measurement error. For duct leakage to the outside, Lab Home A is leakier than Lab Home B by approximately $10 \mathrm{cfm} 25$ to out, which is statistically significant. This may indicate greater leakage from the belly into the crawlspace in Lab Home A. However, much care was taken to maintain the integrity of the belly pan in the manufactured homes in their original condition because extensive duct sealing and penetration of the belly could introduce additional leakage. This additional leakage could increase the difference between the homes, rather than make the homes air and duct leakage more similar it. Also, $10 \mathrm{cfm} 25$ to out is still a small difference and is not expected to significantly affect the measured energy performance. Thus, the team did not take measures to reduce the duct leakage in Lab Home A to make it statistically the same as Lab Home B. The duct systems were tested in the homes as sited at PNNL and the ducting has not been modified since then.

Table 5.3. Duct Leakage Measurements in Lab Home A and Lab Home B

\begin{tabular}{lcccc}
\hline & \multicolumn{2}{c}{ Baseline Lab Home A } & \multicolumn{2}{c}{ Experimental Lab Home B } \\
\cline { 2 - 5 } \multicolumn{1}{c}{ Measured Parameter } & Value & \pm Error & Value & \pm Error \\
\hline Total Duct Leakage, near 25 Pa (cfm) & 203 & 6.09 & 197 & 5.91 \\
Total Duct Leakage, near 50 Pa (cfm) & 311 & 9.33 & 304 & 9.12 \\
Duct Leakage to Outside, near 25 Pa (cfm) & 70 & 2.1 & 57 & 1.71 \\
Duct Leakage to Outside, near 50 Pa (cfm) & 104 & 3.12 & 83 & 2.49 \\
\hline
\end{tabular}

The distribution system in each home also showed reasonably similar performance, with higher flow rates for supply registers near the air handler and lower flow rates farther away, as shown in Table 5.4. These results indicated that all ducts are connected and there are no large problems with the duct work. Error is not calculated for these static pressure and fan flows and their relative magnitude of concern and precise values are not necessary.

\footnotetext{
${ }^{1}$ Duct leakage to outside quantifies the amount of air leakage from the duct work that exfiltrates to outside the building's air barrier (usually the same as the thermal boundary). Because some of the duct work is located in conditioned space, air that leaks out of the ducts is not "lost," because it is still (unintentionally) heating, cooling, or ventilating a conditioned space. Duct leakage that is outside the conditioned space causes heated or cooled air to be wasted and is more important than duct leakage inside the conditioned space. That is why it is calculated separately.
} 
Table 5.4. Duct Distribution System Performance, Static Pressure and Flows in Baseline Lab Home A and Experimental Lab Home B

\begin{tabular}{lcccc}
\hline & \multicolumn{2}{c}{ Baseline Lab Home A } & \multicolumn{2}{c}{ Experimental Lab Home B } \\
\cline { 2 - 5 } \multicolumn{1}{c}{ Location } & $\begin{array}{c}\text { Static Pressure } \\
\text { (Pa) }\end{array}$ & Flow (cfm) & $\begin{array}{c}\text { Static Pressure } \\
(\text { Pa) }\end{array}$ & Flow (cfm) \\
\hline Living Room (northwest corner) & 5.2 & 60 & 2.7 & 54 \\
North Entryway & 25.2 & 124 & 25.7 & 120 \\
Bedroom 1 & 25.9 & 124 & 28.0 & 138 \\
Bedroom 2 & 25.7 & 124 & 28.8 & 129 \\
Master Bath (northeast corner) & 26.1 & 103 & 28.2 & 116 \\
Master Bedroom (southeast corner) & 4.0 & 73 & 3.7 & 100 \\
Hall Bath & 50.9 & 176 & 61.0 & 172 \\
Utility Room & 2.2 & 62 & 5.1 & 65 \\
Kitchen & 14.8 & 92 & 10.7 & 85 \\
Dining Room (southwest corner) & 3.0 & 90 & 1.8 & 69 \\
Total Flow, sum of register flows & - & 1028 & - & 1048 \\
Average Static Pressure and Register Flow & 18.3 & 103 & 19.6 & 105 \\
\hline
\end{tabular}

\subsubsection{Ventilation Fan Flow Rate}

Flow rates of the whole-house ventilation fan and two bathroom exhaust fans were measured prior to the start of the winter experiment. Measurements showed very similar flow rates, which were lower than their rated value as shown in Table 5.5. The bathroom fans were rated as $50 \mathrm{cfm}$ and the whole-house fan was rated as $90 \mathrm{cfm}$. These values were taken from the manufactured home manufacturer literature. .

Table 5.5. Flow Rate of Bath and Whole-House Ventilation Exhaust Fans Measured in the Baseline and Experimental Homes

\begin{tabular}{lcc}
\hline \multicolumn{1}{c}{ Ventilation Fan } & $\begin{array}{c}\text { Baseline Lab Home A } \\
(\mathrm{cfm})\end{array}$ & $\begin{array}{c}\text { Experimental Lab Home B } \\
(\mathrm{cfm})\end{array}$ \\
\hline Hall Bath Fan, Broan 655 & 38 & 41 \\
Whole-House Fan, Active Ventilation EC-25 & 49 & 50 \\
Master Bath Fan, Broan 655 & 35 & 39 \\
\hline
\end{tabular}

\subsection{Heat Pump and Air Handler Performance}

The performance of both homes' heat pumps was verified during null testing, which occurred prior to the start of the winter experiment, by measuring the temperature differential across the coil in both homes when heating was called for. The measured temperature differential using a hand-held thermometer was

\footnotetext{
${ }^{1}$ Telephone call to Larry Burdette and Mike Boylan, Marlette Industries, by Greg Sullivan, Efficiency Solutions, December 20, 2011, confirming rated fan flows.
} 
very similar for both homes, which suggests similar performance of the units. Error is not provided on these readings because the accuracy of the thermometer is not known.

Table 5.6. Heat Pump Temperature Differential Across the Coil

\begin{tabular}{lcccc}
\hline & \multicolumn{2}{c}{ Baseline Lab Home A } & \multicolumn{2}{c}{ Experimental Lab Home B } \\
\cline { 2 - 6 } \multicolumn{1}{c}{ Measurement } & $\begin{array}{c}\text { Return Air Temp. } \\
\left({ }^{\circ} \mathrm{F}\right)\end{array}$ & $\begin{array}{c}\text { Supply Air Temp } \\
\left({ }^{\circ} \mathrm{F}\right)\end{array}$ & $\begin{array}{c}\text { Return Air Temp. } \\
\left({ }^{\circ} \mathrm{F}\right)\end{array}$ & $\begin{array}{c}\text { Supply Air Temp. } \\
\left({ }^{\circ} \mathrm{F}\right)\end{array}$ \\
\hline $\begin{array}{l}\text { Air Temperature in Home and } \\
\text { Downstream from Coil }\end{array}$ & 74.45 & 96.35 & 71.7 & 94.3 \\
$\begin{array}{l}\text { Temperature Rise across Indoor Coil } \\
\text { in Heating Mode }\left({ }^{\circ} \mathrm{F}\right)\end{array}$ & & 21.9 & & \multicolumn{2}{c}{22.6} \\
\hline
\end{tabular}

Air flow across the coil was also measured to assess adequate and similar fan performance. As shown in Table 5.7, the measured flow rate through the air handler is statistically similar for Lab Home A and Lab Home B.

Table 5.7. Air Handler Flow and Static Operating Pressure

\begin{tabular}{lcc}
\hline \multicolumn{1}{c}{ Measurement } & $\begin{array}{c}\text { Baseline Home } \\
\text { Lab Home A }\end{array}$ & $\begin{array}{c}\text { Experimental } \\
\text { Lab Home B }\end{array}$ \\
\hline Air Handler Flow Measurement, TrueFlow Plate (cfm) & $927 \pm 65$ & $875 \pm 61$ \\
Normal System Operating Pressure (Pa) & 27.2 & 27.0 \\
\hline
\end{tabular}

\subsection{Pre-Windows-Retrofit Null Testing}

After instrumentation and the baseline assessments were completed in both Lab Homes, null testing was performed to compare energy-use information over several days. Null testing with no occupancy or moisture generation showed exceptionally similar energy use between the two homes, within $0.5 \% \pm$ $0.5 \%$ over the 6 -day period. Figure 5.3 shows a comparison of energy use between the experimental home (Lab Home A) and the baseline home (Lab Home B), for 1 day of the null test. The black 45degree line indicates perfect agreement. This chart is indicative of the agreement observed on the other days of null testing. 


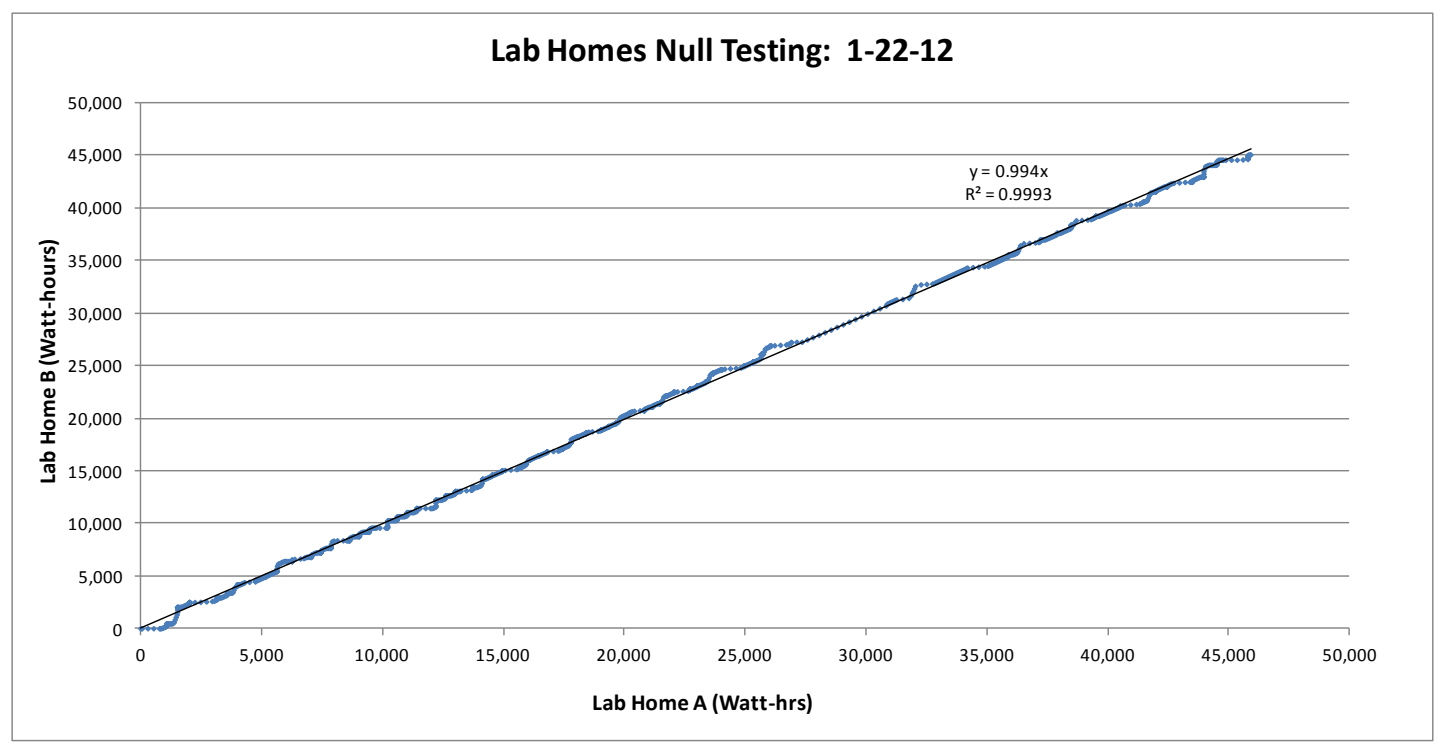

Figure 5.3. Comparison of Cumulative HVAC Energy Use of Lab Home A (Baseline Home; $x$-axis) Versus Lab Home B (Experimental Home; y-axis)

\subsection{Post-Windows-Retrofit Building Shell Air Leakage}

Building shell air leakage was measured after the windows retrofit in the two homes to characterize the impact of the two installation techniques. Table 5.8 shows the null-test building leakage values, the building leakage after windows installation, and the difference achieved by the different installation practices. In the experimental home, air leakage, as characterized by the cfm50 depressurization with respect to the outside value, decreased by $46.4 \pm 34.9 \mathrm{cfm} 50$. Conversely, air leakage in the baseline home increased $50.3 \pm 34.1 \mathrm{cfm} 50$. While the error is large in comparison to the magnitude of the change, the overall impact of these changes was statistically significant. The improved installation technique of the highly insulating windows in Lab Home B in comparison to the typical installation of the baseline windows in Lab Home A caused the experimental home to be measurably tighter, if only slightly so, than the baseline home.

Table 5.8. Building Shell Leakage in the Baseline and Experimental Homes After Window Retrofits

\begin{tabular}{lrrrr}
\hline & Baseline Home & \pm Error & Experimental Home & \multicolumn{1}{c}{ \pm Error } \\
\hline Null Data & & & & \\
cfm25 & 477.4 & 30.4 & 478.5 & 30.5 \\
cfm50 & 638.5 & 27.8 & 681.1 & 26.7 \\
ACH50 & 3.07 & 0.13 & 3.28 & 0.13 \\
ACHn & 0.14 & 0.01 & 0.15 & 0.01 \\
Post-Windows Install & & & & \\
cfm25 & 446.9 & 19.0 & 372.8 & 15.7 \\
cfm50 & 690.8 & 24.6 & 639.3 & 22.5 \\
ACH50 & 3.32 & 0.12 & 3.08 & 0.11 \\
ACHn & 0.15 & 0.01 & 0.14 & 0.01 \\
\hline
\end{tabular}


Table 5.8. (contd)

\begin{tabular}{lrrrr}
\hline & Baseline Home & \multicolumn{1}{c}{ \pm Error } & Experimental Home & \pm Error \\
\hline Difference & & & & \\
cfm25 & -30.4 & -11.4 & -105.7 & -14.8 \\
cfm50 & 52.3 & -3.2 & -41.8 & -4.3 \\
ACH50 & 0.25 & -0.02 & -0.20 & -0.02 \\
ACHn & 0.01 & 0.00 & -0.01 & 0.00 \\
\hline
\end{tabular}

Prior to initiation of the summer, cooling season experiments, the air leakage of each home was retested, to ensure that any activity that occurred in the homes between the winter and summer experiments had not altered the building envelopes significantly. The measured blower door results showed the air leakage of the two homes was not significantly altered from the winter to the summer experiments. The difference between Lab Home A and Lab Home B was maintained and the measured blower door reading for each home in the winter and the summer is statistically the same, with $95 \%$ confidence. The baseline home has leakage of $0.15 \pm 0.01 \mathrm{ACH}_{\mathrm{n}}$ and the experimental home has leakage of $0.14 \pm 0.01 \mathrm{ACH}_{\mathrm{n}}$, as shown in Table 5.9. Note that these blower door values (and all reported blower door values) have been adjusted based on air density to allow for an accurate comparison.

Table 5.9. Building Envelope Leakage as Measured by Blower Door Tests in the Baseline and Experimental Home Prior to Initiation of Summer Cooling Season Experiments

\begin{tabular}{lrrrr}
\hline & \multicolumn{2}{c}{ Baseline Lab Home A } & \multicolumn{2}{c}{ Experimental Lab Home B } \\
\cline { 2 - 5 } Parameter & Average Value & \multicolumn{1}{c}{ \pm Error } & Average Value & \multicolumn{1}{c}{ \pm Error } \\
\hline cfm25 & 432.8 & 17.7 & 401.8 & 26.3 \\
cfm50 & 660.1 & 21.1 & 622.9 & 21.9 \\
$\mathrm{ACH} 50$ & 3.18 & 0.10 & 3.00 & 0.11 \\
$\mathrm{ACH}_{\mathrm{n}}{ }^{(a)}$ & 0.15 & 0.005 & 0.14 & 0.005 \\
\hline
\end{tabular}

(a) $n=21.5$, based on single-story home in climate zone 3 , minimal shielding

\subsection{Post-Windows Retrofit HVAC and Whole-House Energy Performance}

After retrofitting the highly insulating and baseline windows, the experiment began in earnest. Data were collected from February 3 to April 13, 2012, to describe the energy and thermal performance of the windows in the heating season and July 6 to August 18, 2012, to characterize performance during the cooling season.

During both the winter heating and summer cooling season experiments, data were collected over a range of temperature and operational scenarios. To assess the performance of the highly insulating windows compared to the baseline windows, energy use and interior and glass surface temperatures were compared daily. Comparison shows significant whole-house energy savings and comfort improvement in the Lab Home with the highly insulating windows (Lab Home B). The overall whole-house savings are $11.6 \% \pm 1.53 \%$ in the heating season and $18.4 \% \pm 2.06 \%$ in the cooling season. 


\subsubsection{Thermostat Set Points}

The thermostat set point was changed to maintain a sufficient temperature differential between indoors and outdoors to drive heating system use. Changing the thermostat set point was also successful at maintaining a fairly uniform average temperature differential between indoors and outdoors on a daily basis. The average difference between the indoor and outdoor temperatures was $69.9^{\circ} \mathrm{F}$; the maximum and minimum temperature differentials were $75.7^{\circ} \mathrm{F}$ and $63.3^{\circ} \mathrm{F}$, respectively. During the cooling season, the thermostat set point was maintained at $70^{\circ} \mathrm{F}$, which resulted in an average daily difference between the indoor and outdoor temperatures of $8.6^{\circ} \mathrm{F}$. The maximum average daily temperature differential in the cooling season was $16.2^{\circ} \mathrm{F}$ and the minimum was $2.1^{\circ} \mathrm{F}$. While not observed in the average daily temperature differentials, significant temperature differentials were observed in the heat of the day, when temperatures regularly reached over $100^{\circ} \mathrm{F}$.

\subsubsection{Winter Heating Season Results}

During the heating season study period, the Lab Homes were operated in a number of configurations including with and without occupancy simulation, in heat pump (HP) and electric resistance (ER) heating modes, and at two different interior thermostat set points. Comparing the periods without occupancy simulation to comparable periods after occupancy simulation was introduced, the savings decrease approximately $2.5 \%$ when occupancy is introduced, as shown in Table 5.10. This decrease is logical, because you would expect increased energy use of equivalent magnitudes from the identical occupancy simulations in both homes and the resulting decrease in energy savings. However, this difference is not statistically significant due to the variation in savings based on other factors, such as outdoor air temperature and solar insolation.

Table 5.10. Average Heating Season Energy Savings and 95\% Confidence Interval from Highly Insulating Windows in Different Operating Scenarios: With and Without Occupancy Simulation and in HP Versus ER Heating Modes

\begin{tabular}{lcccc}
\hline & Average & $\begin{array}{c}\text { 95\% Confidence } \\
\text { Interval } \\
\text { Operating Scenario }\end{array}$ & $\begin{array}{c}\text { Average Confidence } \\
\text { Savings (Wh) }\end{array}$ & $\begin{array}{c}\text { Interval } \\
\text { (\%) }\end{array}$ \\
\hline Without Occupancy Simulation & 9,392 & 4,611 & 14.3 & 5.23 \\
With Occupancy Simulation & 4,420 & 1,025 & 11.7 & 2.08 \\
HP Mode (with occupancy simulation) & 7,137 & 2,348 & 10.4 & 2.96 \\
ER Mode (with occupancy simulation) & 4,420 & 1,023 & 11.7 & 2.08 \\
\hline
\end{tabular}

When comparing savings from periods when the HP mode was providing heating versus ER mode, no statistically significant difference was observed. In HP mode, the ER elements were still enabled and cycled to provide heating during extremely cold periods.

\subsubsection{Summer Cooling Season Results}

During the cooling season, the homes were first operated with simulated lighting and occupancy (sensible heat from occupants), but with no simulated appliance loads. This is consistent with the 
operating regime for the majority of the heating season. Simulated equipment loads were added and interior blinds were drawn in both homes. As observed in the heating season data, additional load in both homes decreased the percentage savings by $2.9 \%$, comparing the percentage savings with and without simulated equipment loads, however the reduction in the magnitude of energy savings was not statistical different.

Table 5.11. Average Energy Savings and 95\% Confidence Interval from Highly Insulating Windows in Different Operating Scenarios: With and Without Simulated Equipment Loads and With Blinds

\begin{tabular}{lcccc}
\hline & $\begin{array}{c}\text { Average } \\
\text { Savings } \\
\text { Operating Scenario }\end{array}$ & $\begin{array}{c}95 \% \text { Confidence } \\
\text { Interval } \\
(\mathrm{Wh})\end{array}$ & $\begin{array}{c}\text { Average } \\
\text { Savings } \\
(\%)\end{array}$ & $\begin{array}{c}95 \% \text { Confidence } \\
\text { Interval } \\
(\%)\end{array}$ \\
\hline With Occupancy Simulation & 6,518 & 842 & 18.4 & 2.06 \\
With Occupancy\& Equipment Simulation & 5,443 & 244 & 15.5 & 0.67 \\
With Blinds Closed 24 Hours/Day & 2,831 & 1,161 & 7.1 & 2.58 \\
\hline
\end{tabular}

The drawinf of blinds in the cooling season decreased the percentage of savings by $46 \%$. Blinds were implemented in addition to lighting, occupancy, and equipment related loads, so the savings from the simulated equipment period are compared to the period with blinds closed for 24 hours per day to determine the impact. The overall whole house energy use scaled based on cooling degree day (CDD) ${ }^{1}$ with and without blinds drawn was compared to determine the impact of blinds on the whole-house energy use. In this case the period without blinds in Lab Home A was compared to the period with blinds drawn in Lab Home A and similarly in Lab Home B. While the blinds reduce energy use in the homes, as shown in Figure 5.4, the difference in each home is not statistically significant.

\footnotetext{
${ }^{1}$ Cooling degree days are calculated as the average daily temperature, in ${ }^{\circ} \mathrm{F}$, minus $65^{\circ} \mathrm{F}$.
} 


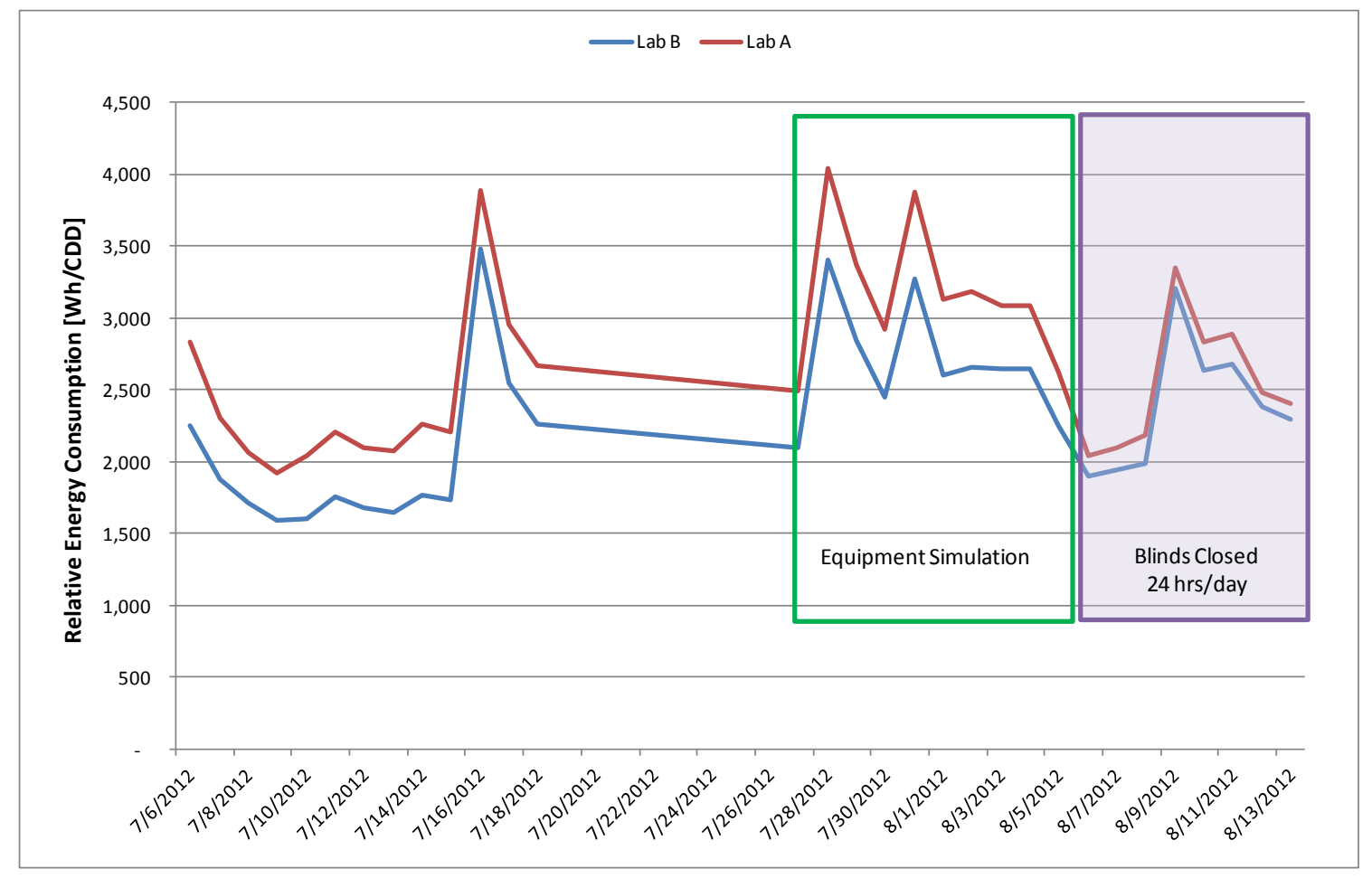

Figure 5.4. Relative Daily Whole House Energy Consumption of Lab Home A and Lab Home B Scaled Based on CDD (Wh/CDD) for Each Day During the Summer Experiment. The period with equipment simulation is identified by the green rectangle and the period with blinds closed 24 hours per day is indicated by the shaded purple rectangle.

\subsubsection{Dependence on Outdoor Air Temperature and Solar Insolation}

Savings were also analyzed with respect to daily weather variation, including outdoor air temperature and degree of cloud cover. In the heating season, the magnitude of whole-house energy savings showed significant dependence on weather patterns.

Energy use of the baseline and experimental homes both show a linear dependence on outdoor air temperature, as shown in Figure 5.5. In the figure, Lab Home A (blue diamonds) exhibits slightly greater average energy use (higher points) than Lab Home B (red squares). Figure 5.5 also depicts greater temperature dependence of heating season energy use versus cooling season. This is expected due to lower efficiency of the heating system, which employed electric resistance strip heat as well as the heat pump during the heating season. 


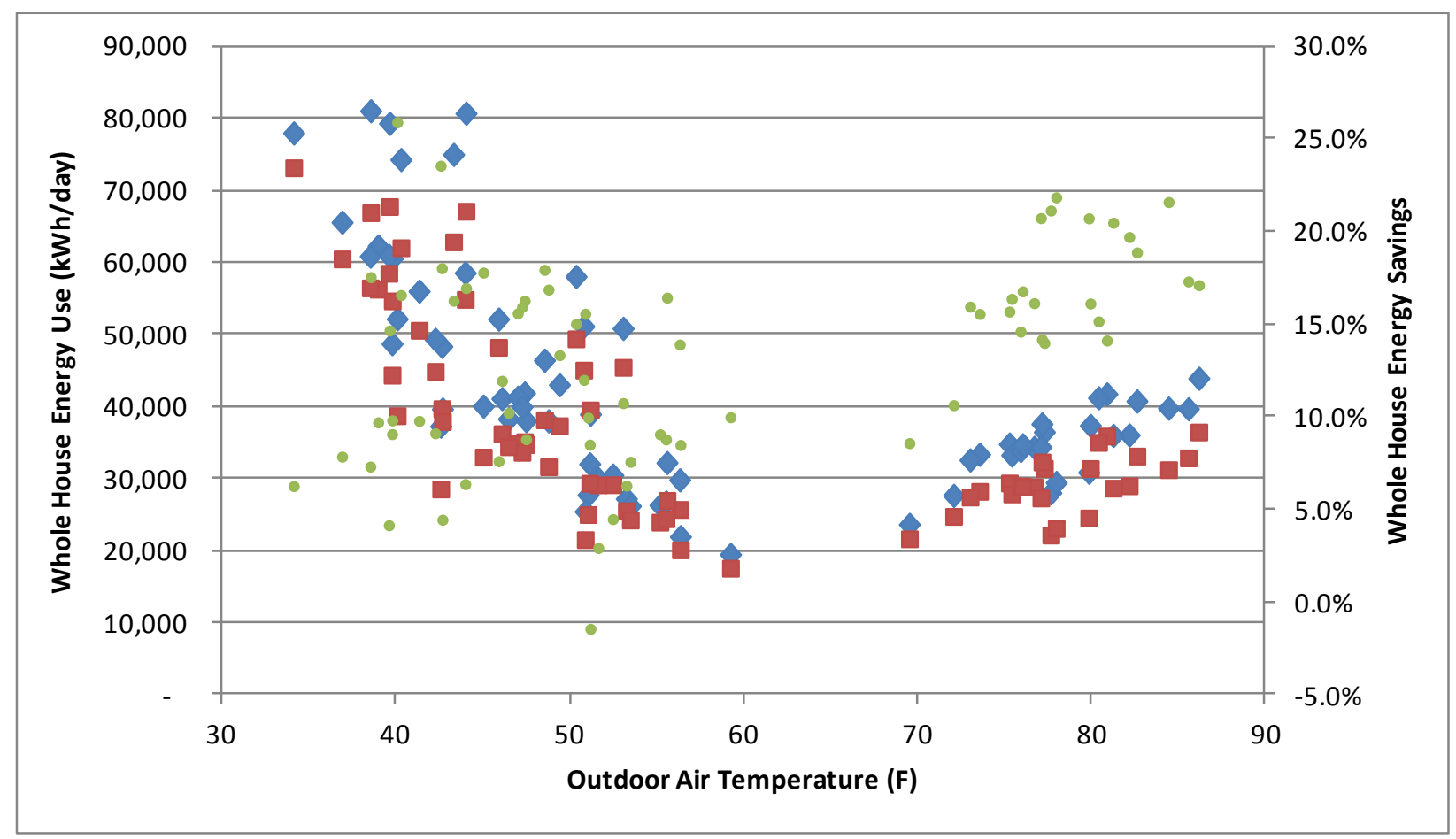

Figure 5.5. Whole-House Energy Use (Wh/day; left axis) and Whole-House Energy Savings (\%; right axis) Versus Outdoor Air Temperature $\left({ }^{\circ} \mathrm{F}\right)$

However, the whole-house energy savings do not show the temperature dependence that the wholehouse energy use does. This suggests that actual measured savings are dependent on other variables in addition to outdoor temperature, principally solar insolation, which complicates the relationship between savings and outdoor air temperature. During the heating season, the impact of solar insolation is illustrated by the dependence of the variability and extent of savings on the degree of cloud cover. Over the study period, most days were either overcast or clear. These classifications are based on data recorded visually and verified by weatherunderground.com historical information. Figure 5.6 shows the savings achieved on each day grouped with respect to these two weather extremes. Days that were difficult to place into one of these categories (i.e., widespread dust) were omitted from the analysis, but are included in Figure 5.6 as separate data series. There is no relevance to the horizontal ordering of data. When depicted this way, one can see that, during the heating season, the majority of high-savings days are overcast days (green triangles), while the majority of low-savings days are clear (blue diamonds). The average savings achieved on overcast days is $14.6 \% \pm 1.86 \%$, while the average savings on clear days is $8.9 \% \pm 1.42 \%$ during the heating season experiment. The average savings and error are indicated in the figure by solid and dashed lines, respectively.

The decreased savings observed on clear days is due to solar heat gain, which offsets some heating system energy use in the winter months. Because the baseline windows are not low-e coated and have a much higher SHGC, the baseline home is able to take advantage of the incident solar heat and offset more of the heating system energy use on sunny days. 


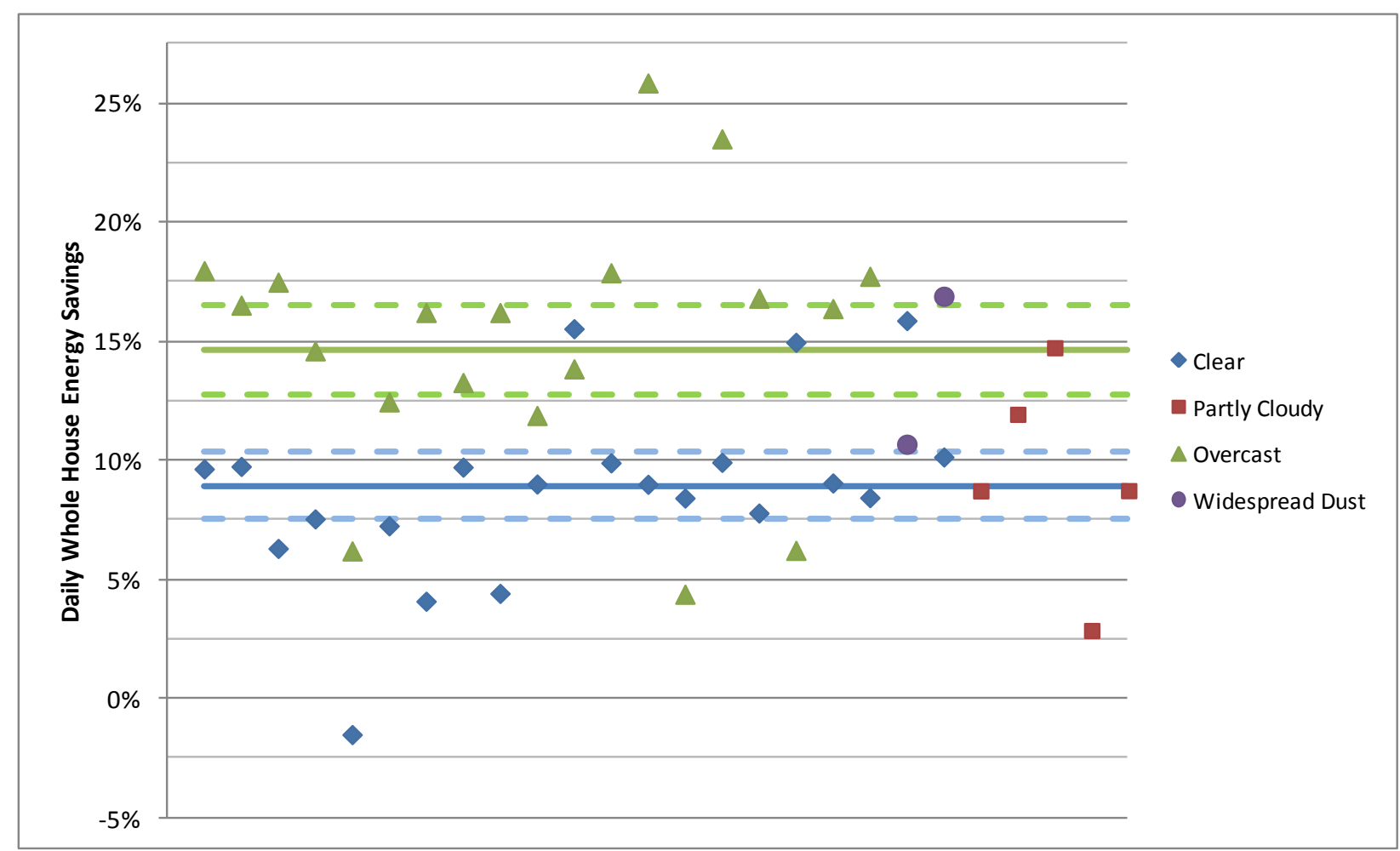

Figure 5.6. Daily Whole-House Energy Savings Due to Highly Insulating Windows for Overcast (green triangles), Clear (blue diamonds), Partly Cloudy (red squares), and Dusty (purple circles) Conditions. Blue and green solid lines indicate average savings, with $95 \%$ confidence interval indicated by the dashed lines.

The effect of solar heat gain on heating system operation is clearly seen in Figure 5.7, which shows a representative time series of whole-house energy use for the experimental home and the baseline home on a clear, sunny day in the winter. Data from February 12, 2012, are shown with the Lab Homes in HP mode with a $75^{\circ} \mathrm{F}$ set point and no occupancy. The outside average temperature on this day was $39^{\circ} \mathrm{F}$. This graph is illustrative and conclusions shown in this graph are applicable to other similar sunny days.

The significant decrease in energy use in the middle of the day is due to solar heating and is experienced in both homes. However, the thermal properties and high SHGC (0.7) of the windows in the baseline home (blue line) take full advantage of this effect and the heat pump does not have to cycle on from 9:00 am until 8:00 pm. The heat pump in the experimental home (red line) is engaged until approximately 10:00 am and is only off until 6:00 pm. Although the heat pump in the experimental home cycles less frequently throughout the night, which achieves a significant level of savings, some of this decreased energy use is negated by increased heat pump operation during the day. 


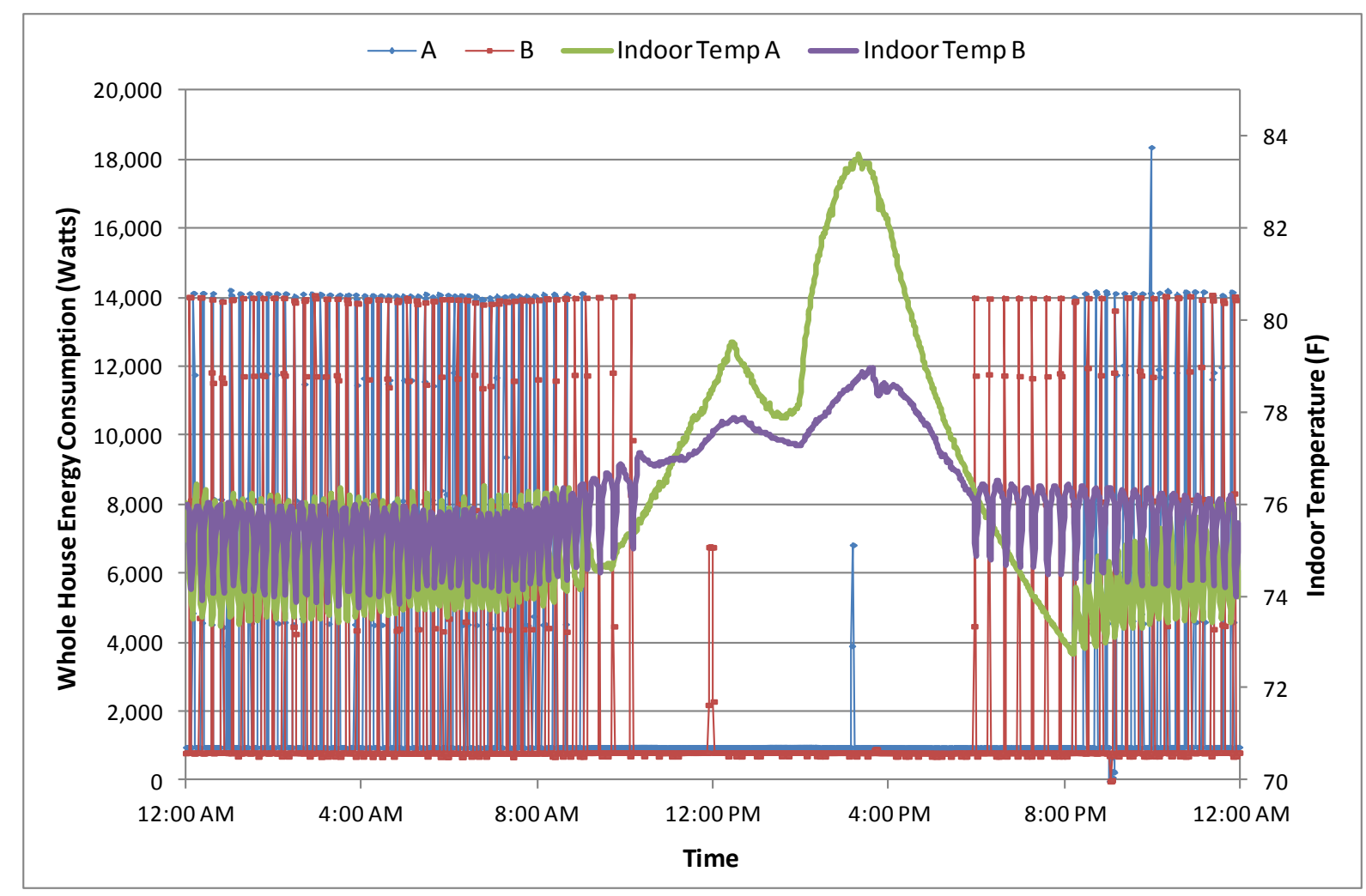

Figure 5.7. Whole-House Energy Use and Indoor Temperature for the Experimental Home (blue and green lines) and the Baseline Home (red and purple lines) on a Sunny Day

Not obvious from Figure 5.7 is the magnitude of energy use. Figure 5.8 compares the cumulative energy use of Lab Home A to that of Lab Home B on the same day. A whole-house savings of $9.6 \%$ is achieved on this cold, sunny day (the $45^{\circ}$ red line represents equal energy use by the two homes). The impact of solar heat gain is evident in Figure 5.8 as well. The first change in slope just before Lab Home A consumes 40,000 Wh corresponds to 8:00 am when the heat pump turns off in Lab Home A, but remains on until 9:00 am in Lab Home B. Thus, the line trends back towards the red line of equal energy use (losing savings). At 9:00 am, the slope of the blue line runs parallel the red line for a period, which corresponds to the middle of the day when the heating system is off in both homes. Just before $50,000 \mathrm{Wh}$ on the $\mathrm{x}$-axis, the slope of the blue line changes again when the heat pump in Lab Home B turns on again and remains off in Lab Home A. Additional savings are "lost" until the heat pump in Lab Home A turns on again and the superior thermal properties of the highly insulating windows in Lab Home B provide additional savings in the evening via decreased heat pump energy use.

This hypothesis is confirmed by observing the energy use and thermal performance of the two homes on cloudy days in the winter. On cloudy days, whole-house energy savings for Lab Home B compared to Lab Home A of $14.6 \% \pm 1.86 \%$ are observed, due to the reduced impact of solar heating. Similar graphics to those presented above for a sunny day are presented in Figure 5.9 and Figure 5.10 for cloudy days. Data from February 13, 2012, are shown with the Lab Homes in HP mode with a $75^{\circ} \mathrm{F}$ set point and no occupancy. The outside average temperature on this day was $40^{\circ} \mathrm{F}$. Figure 5.9 is illustrative and conclusions shown in this graph are applicable to other similar cloudy days. Without the impact of solar heat gain, the heat pump operates fairly consistently throughout the day in both homes, as shown in Figure 5.9. 


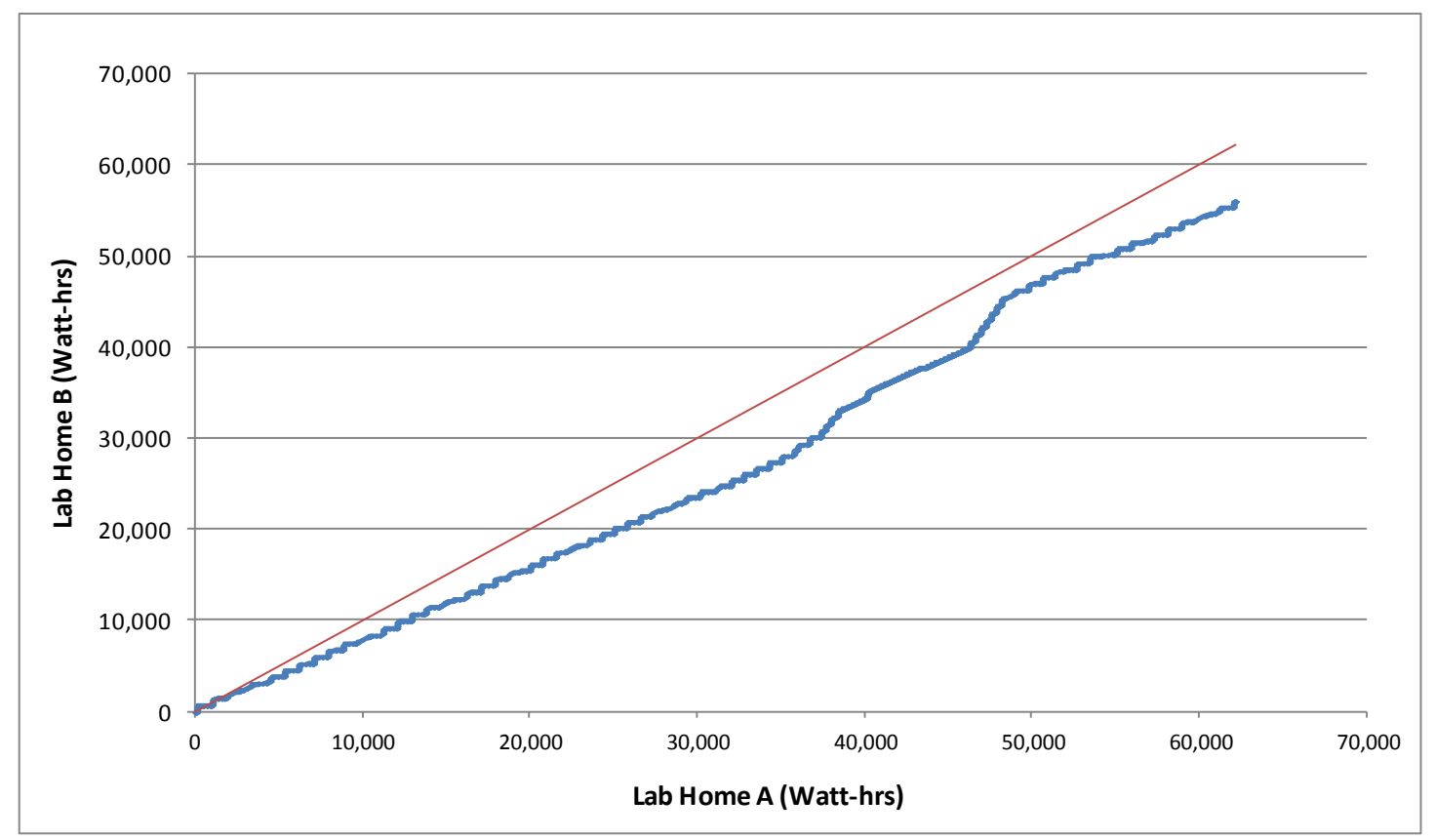

Figure 5.8. Cumulative Energy Use of Lab Home B (Experimental Home) Versus Lab Home A (Baseline Home) on a Sunny Day. The $45^{\circ}$ red line represents equal energy use of the two homes.

Figure 5.10 shows a much more uniform slope and greater overall level of savings. Also note the overall increased energy use apparent when comparing Figure 5.10 to the previous Figure 5.8 (the other Lab Home A vs. Lab Home B chart). On this cloudy day, Lab Home A consumes approximately 74,200 Wh and Lab Home B consumes 61,900 Wh. On the previous sunny day, Lab Home A consumed 62,100 Wh and Lab Home B consumed 56,200 Wh. 


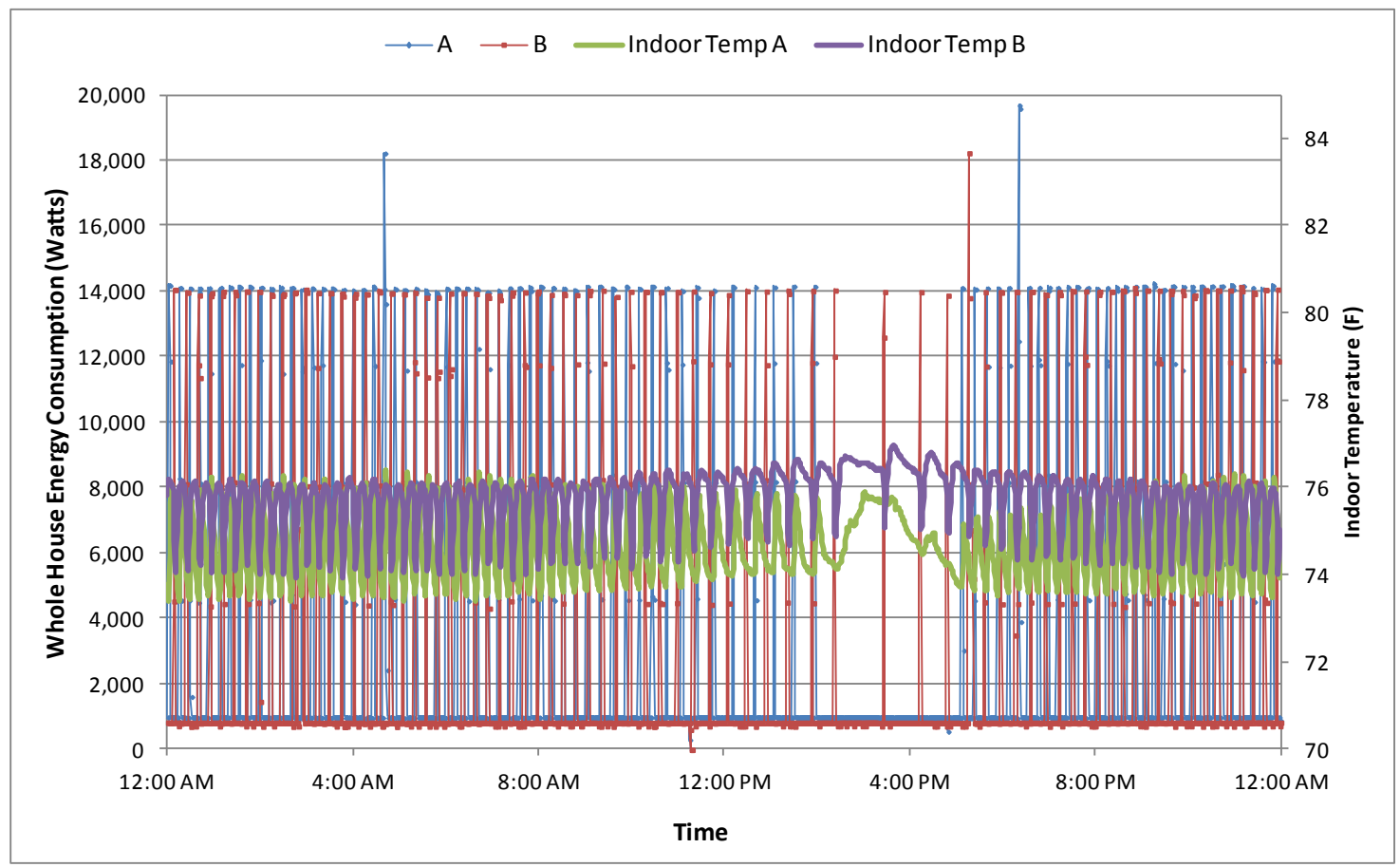

Figure 5.9. Whole-House Energy Use and Indoor Temperature for the Experimental Home (blue and green lines) and the Baseline Home (red and purple lines) on a Cloudy Day

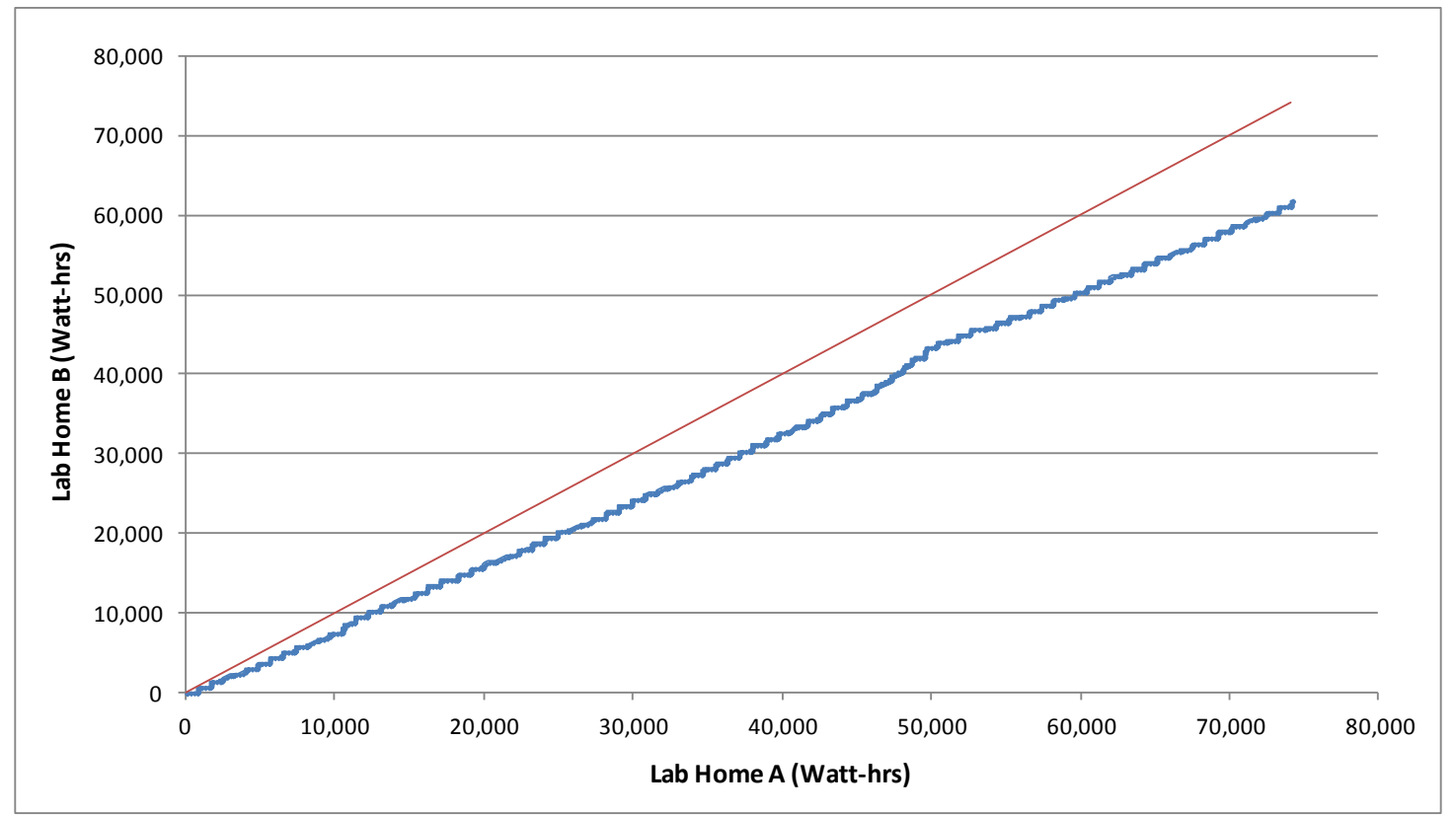

Figure 5.10. Cumulative Energy Use of Lab Home B (Experimental Home) Versus Lab Home A (Baseline Home) on a Cloudy Day. The $45^{\circ}$ red line represents equal energy use of the two homes.

This relationship between energy use and solar insolation in the winter is further illustrated by Figure 5.11 and Figure 5.12, which depict daily whole-house energy use in watt-hours versus solar insolation in watts per square meter $\left(\mathrm{W} / \mathrm{m}^{2}\right)$ for Lab Home A and Lab Home B, respectively. In both 
homes, increased solar insolation decreased whole-house energy use. However, the difference in solar heat gain can clearly be seen by comparing the x-axes of the two charts. The measured solar insolation through the window is $83.2 \% \pm 1.2 \%$ less through the low-e coated windows in Lab Home B than through the clear glass windows in Lab Home A. ${ }^{1}$

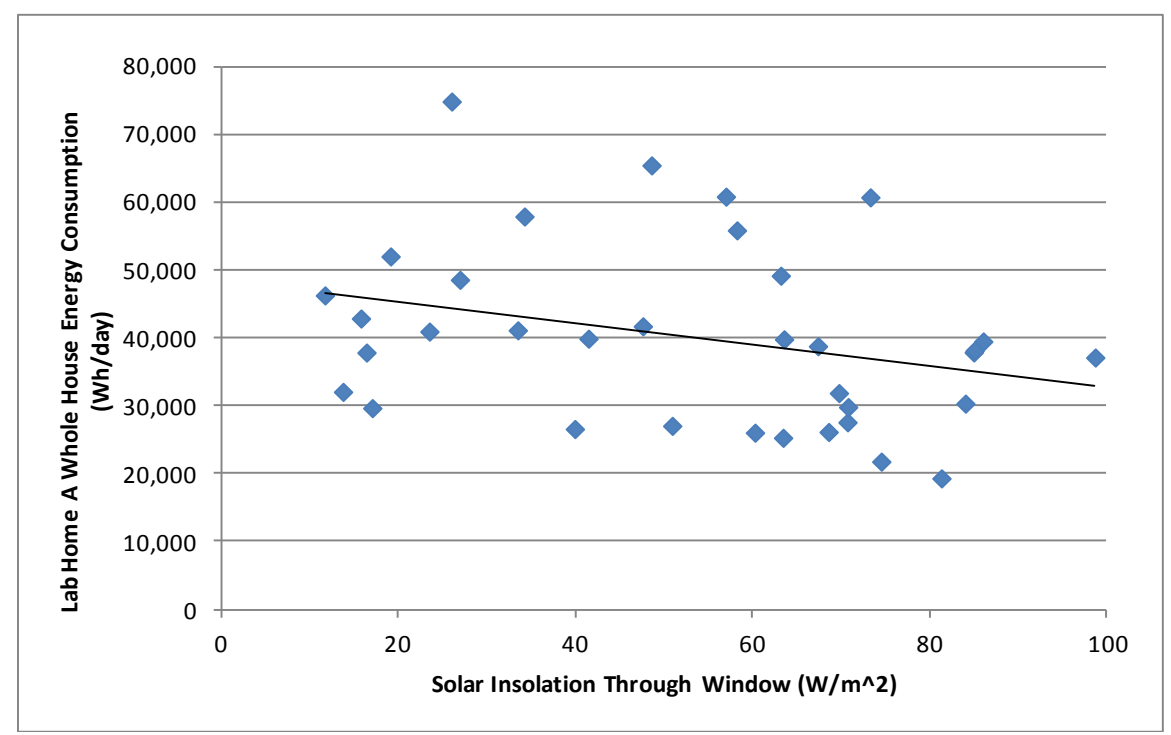

Figure 5.11. Whole-House Energy Use in Lab Home A Versus Solar Insolation for the Heating Season

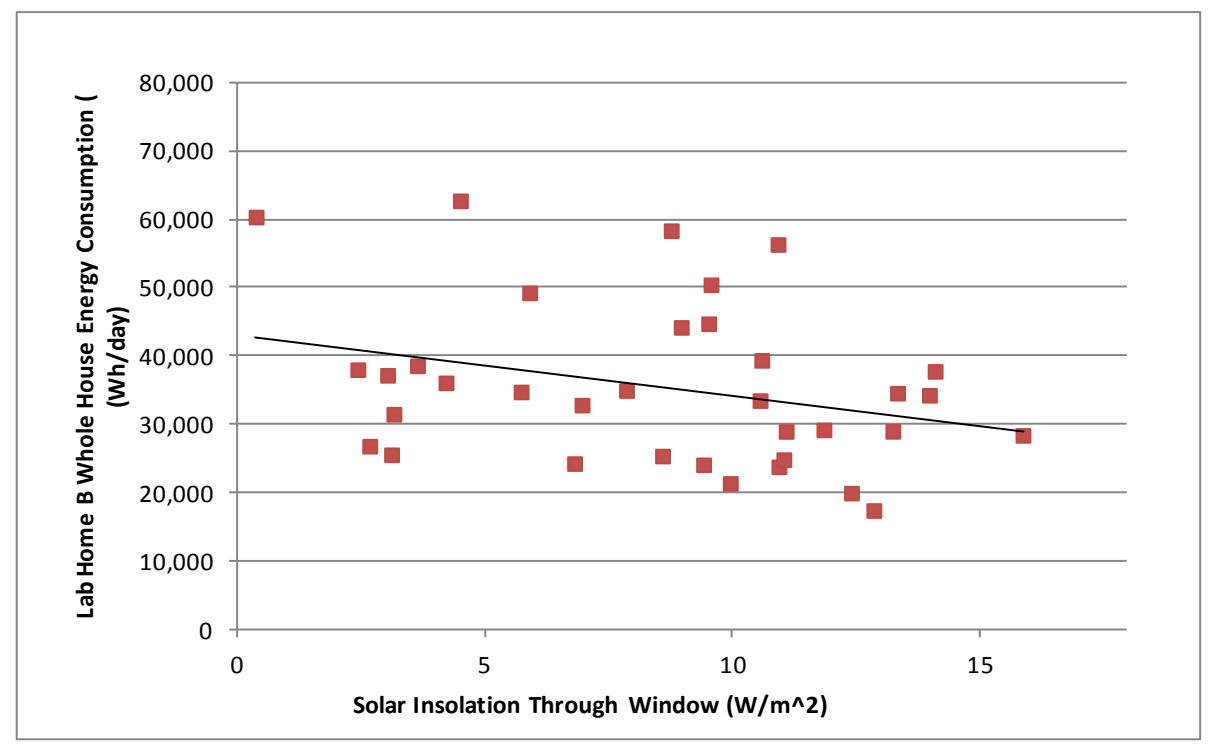

Figure 5.12. Whole-House Energy Use in Lab Home B Versus Solar Insolation for the Heating Season

\footnotetext{
${ }^{1}$ Note that the solar heat gain measurement reported here is in situ and does not represent or replicate the measurement of the SHGC measurement that takes place in a highly controlled laboratory environment to certify a window. However, the magnitude of the solar insolation reduction is consistent with the magnitude of the difference in SHGC of the windows in Lab Homes A (SHGC=0.7) compared to the windows in Lab Home B (SHGC=0.19).
} 
However, during the cooling season, sunny days were much more common, which made regression based on solar insolation difficult, as can be seen by the concentration of high solar heat gain observations in Figure 5.13., which plots whole-house energy use versus solar insolation for both Lab Home A and Lab Home B, respectively.
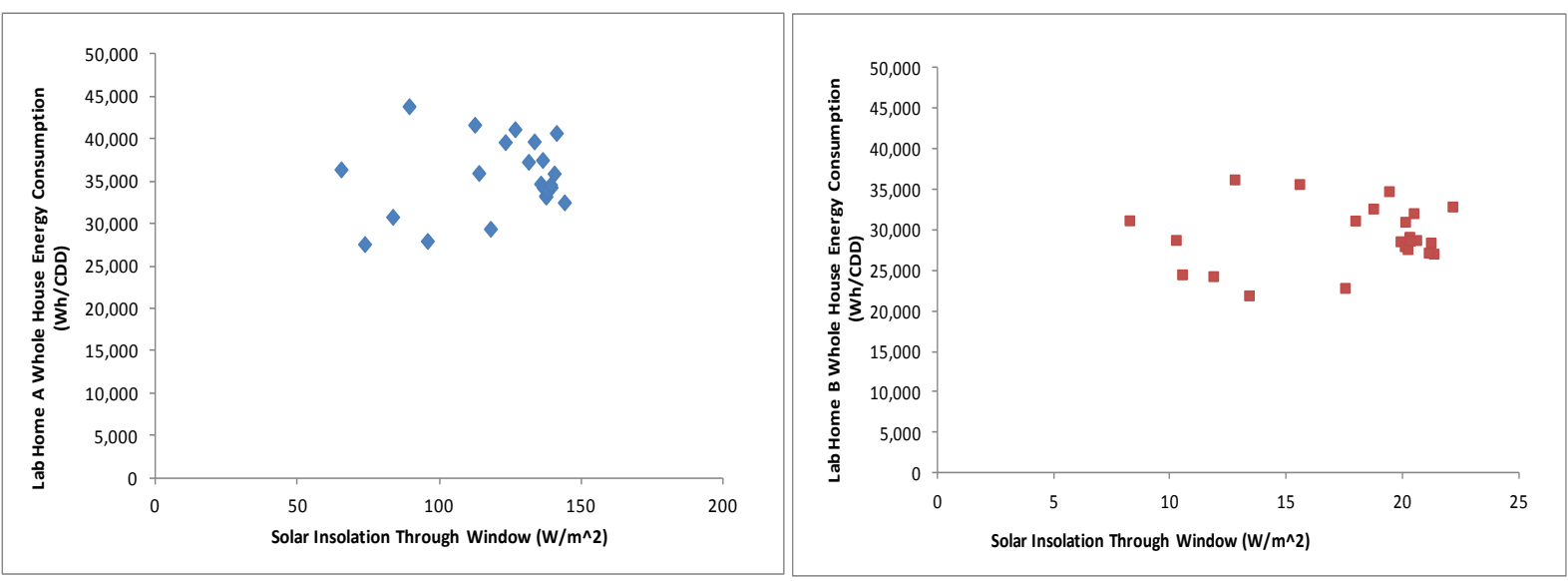

Figure 5.13. Whole-House Energy Use in Lab Home A (left) and Lab Home B (right) Versus Solar Insolation for the Cooling Season

Energy use and energy savings in the cooling season, appear to be much more related to outdoor air temperature, due to the relatively consistent solar insolation, as shown in Figure 5.14 and Figure 5.15, which plot energy savings with respect to solar insolation as measured in Lab Home A and whole-house energy savings for Lab Home B with respect to Lab Home A.

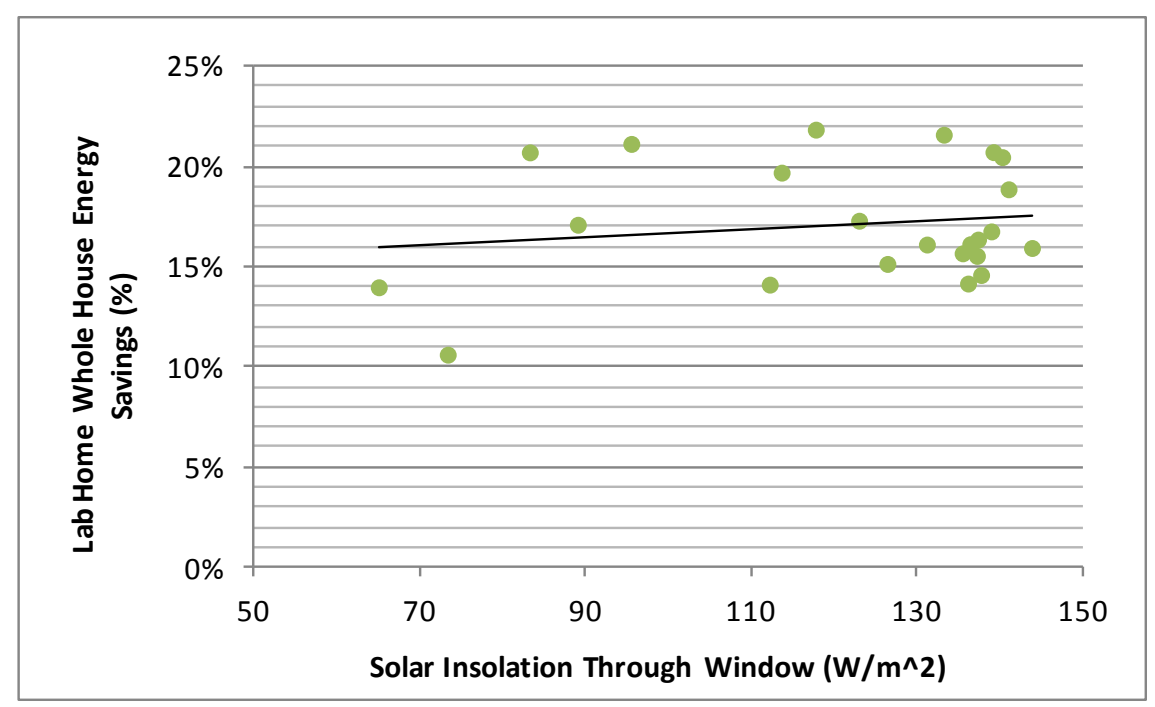

Figure 5.14. Whole-House Energy Savings in Lab Home B as Compared to Lab Home A in the Cooling Season Versus Solar Insolation Through the Window in Lab Home A 


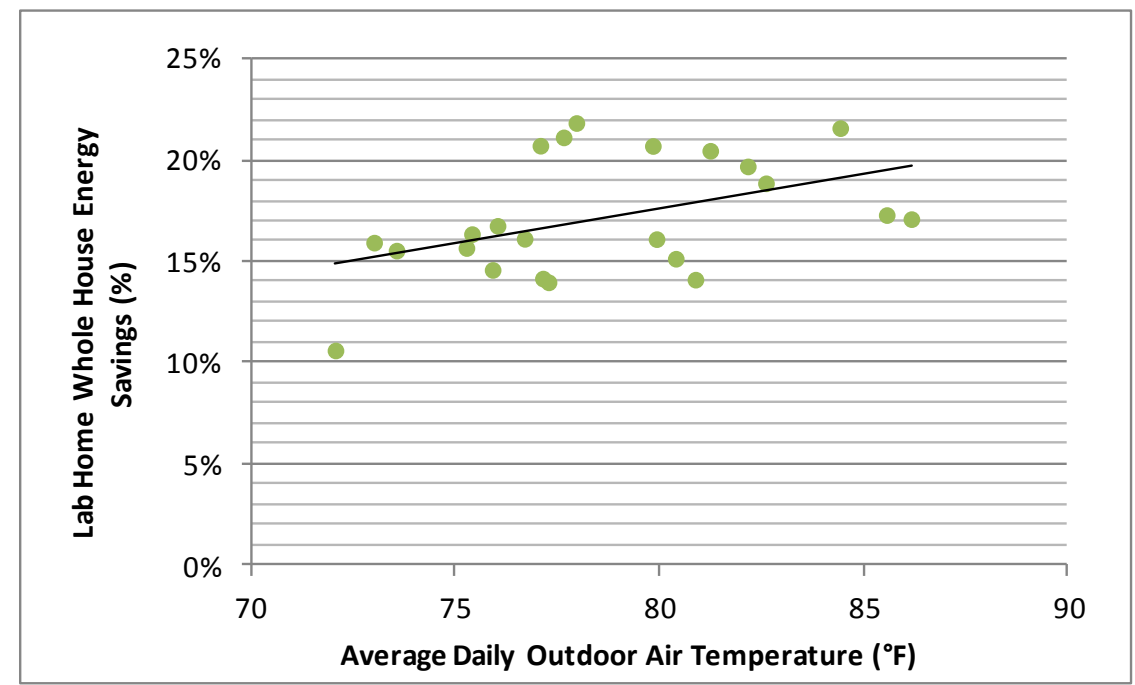

Figure 5.15. Whole House Energy Savings in Lab Home B as Compared to Lab Home A in the Cooling Season Versus Outdoor Air Temperature

The dependence of energy use and energy savings on outdoor air temperature is illustrated by comparing two representative days, July 10, 2012 and July 16, 2012, both periods when the homes were operated with occupancy and lighting loads, but no equipment loads. July 10 was much hotter than July 16; the average daily outdoor air temperature was $84.4^{\circ} \mathrm{F}$ and the maximum temperature in the afternoon was $95^{\circ} \mathrm{F}$. Figure 5.16 shows the whole-house energy use in Lab Home A (blue) and Lab Home B (red), as well as interior temperatures in both homes (purple and green lines) and outdoor air temperature (turquoise line). Whole-house energy use tracks well with outdoor air temperature, as expected, but is reduced in Lab Home B compared to Lab Home A. Unlike, the winter season, energy savings occur at a similar rate throughout the day, as can be seen from the consistent slope of cumulative energy use in Lab Home B versus Lab Home A, the blue line in Figure 5.17. On this hot, sunny day, Lab Home A used 39,631 Wh of energy and Lab Home B used 31,093 Wh, a savings of 21.5\% in Lab Home B. 


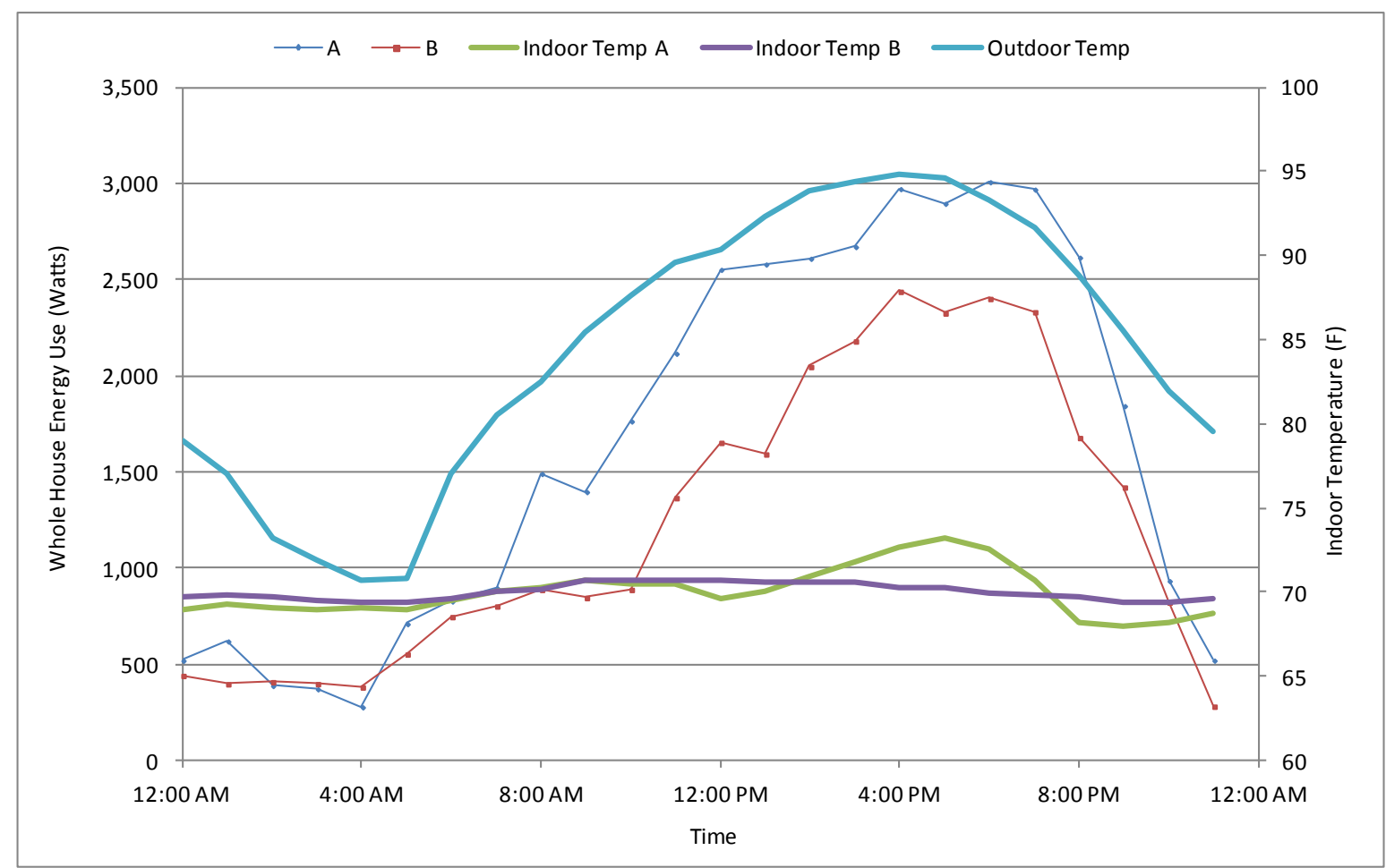

Figure 5.16. Hourly Average Whole-House Energy Use and Indoor Temperature for Lab Home B (Experimental Home; blue and green lines) and Lab Home A (Baseline Home; red and purple lines) and Outdoor Air Temperature on a Hot Day

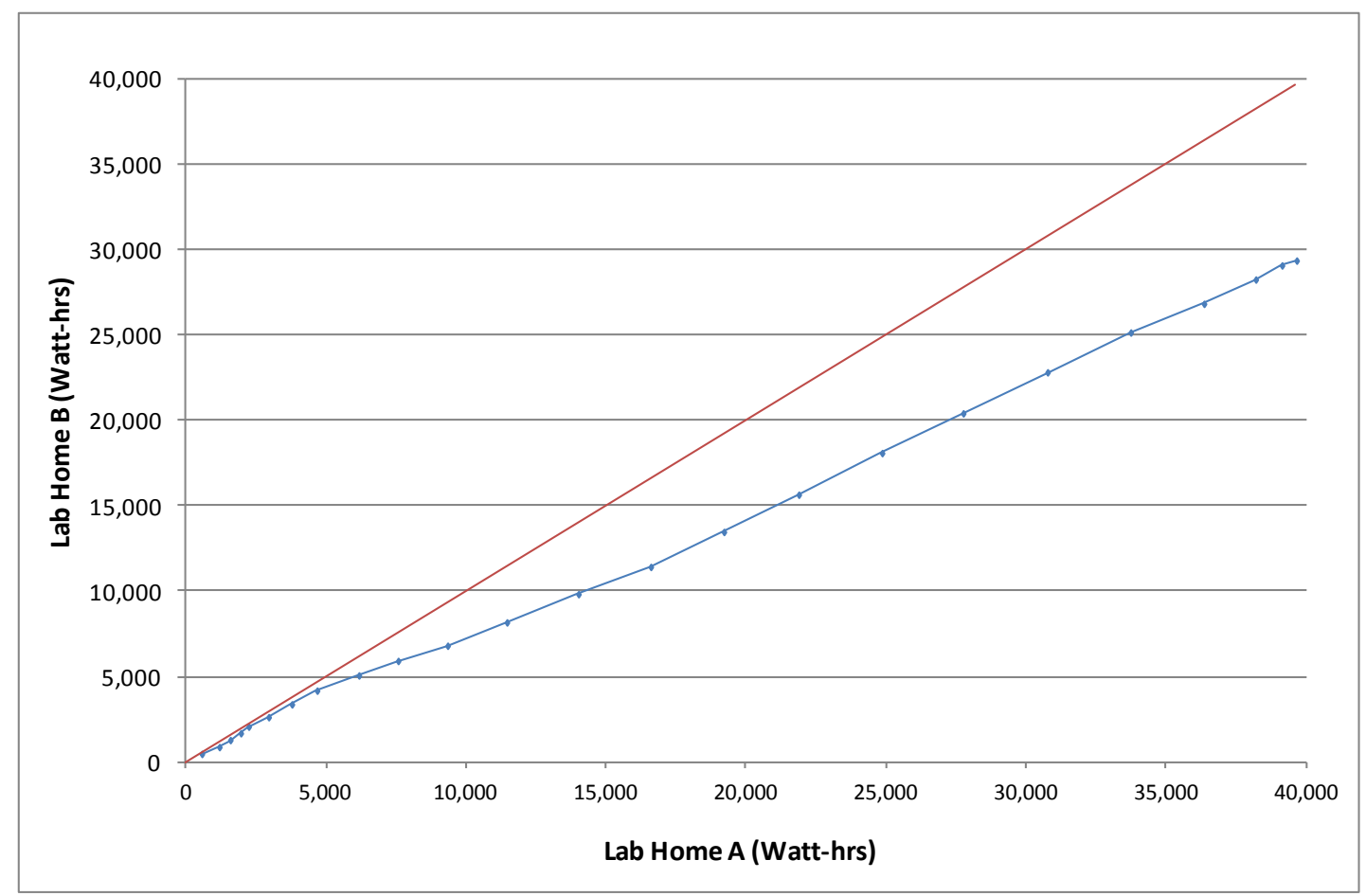

Figure 5.17. Cumulative Energy Use of Lab Home B (Experimental Home) Versus Lab Home A (Baseline Home) on a Hot Day. The $45^{\circ}$ red line represents equal energy use of the two homes. 
The savings and energy use on July 10 can be compared to a day with milder daily average outdoor air temperature of $72.1^{\circ} \mathrm{F}$ and an afternoon peak of $83^{\circ} \mathrm{F}$ observed on July 16. As heat transmission, and thus energy use, is dependent on the temperature difference between indoors and out, significantly greater savings are observed on hotter days. A cumulative energy use plot of whole house energy use in Lab Home B versus Lab Home A (Figure 5.18) still shows consistent savings throughout the day, but the slope of the line is much closer to 1 (the red $45^{\circ}$ line, representative equal energy use in both homes). On July 16, Lab Home A used 27,512 Wh of energy and Lab Home B used 24,603 Wh, resulting in total daily energy savings of $10.6 \%$ in Lab Home B.

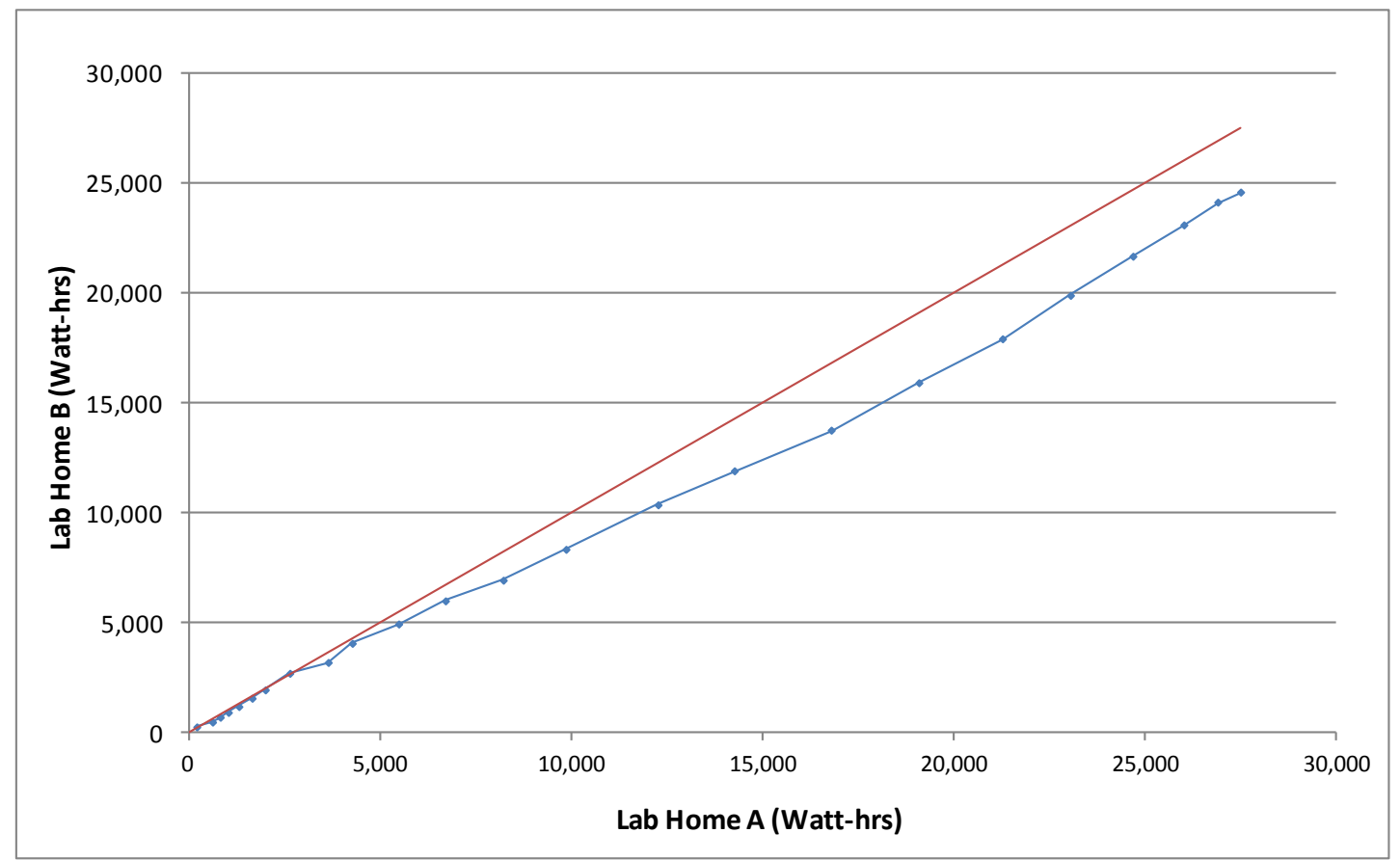

Figure 5.18. Cumulative Energy Use of Lab Home B (Experimental Home) Versus Lab Home A (Baseline Home) on a Milder Day (daily average outdoor air temperature of $72.1^{\circ} \mathrm{F}$ ). The $45^{\circ}$ red line represents equal energy use of the two homes.

Due to the small difference in average temperature between indoors and out $\left(2.1^{\circ} \mathrm{F}\right)$, the whole-house energy use in both Lab Home A and Lab Home B is much less tied to outdoor air temperature because the HVAC energy use is significantly reduced. As shown in Figure 5.19, more variability in occupancy and lighting loads are more visible in the whole-house energy use due to the HVAC load being less dominant. 


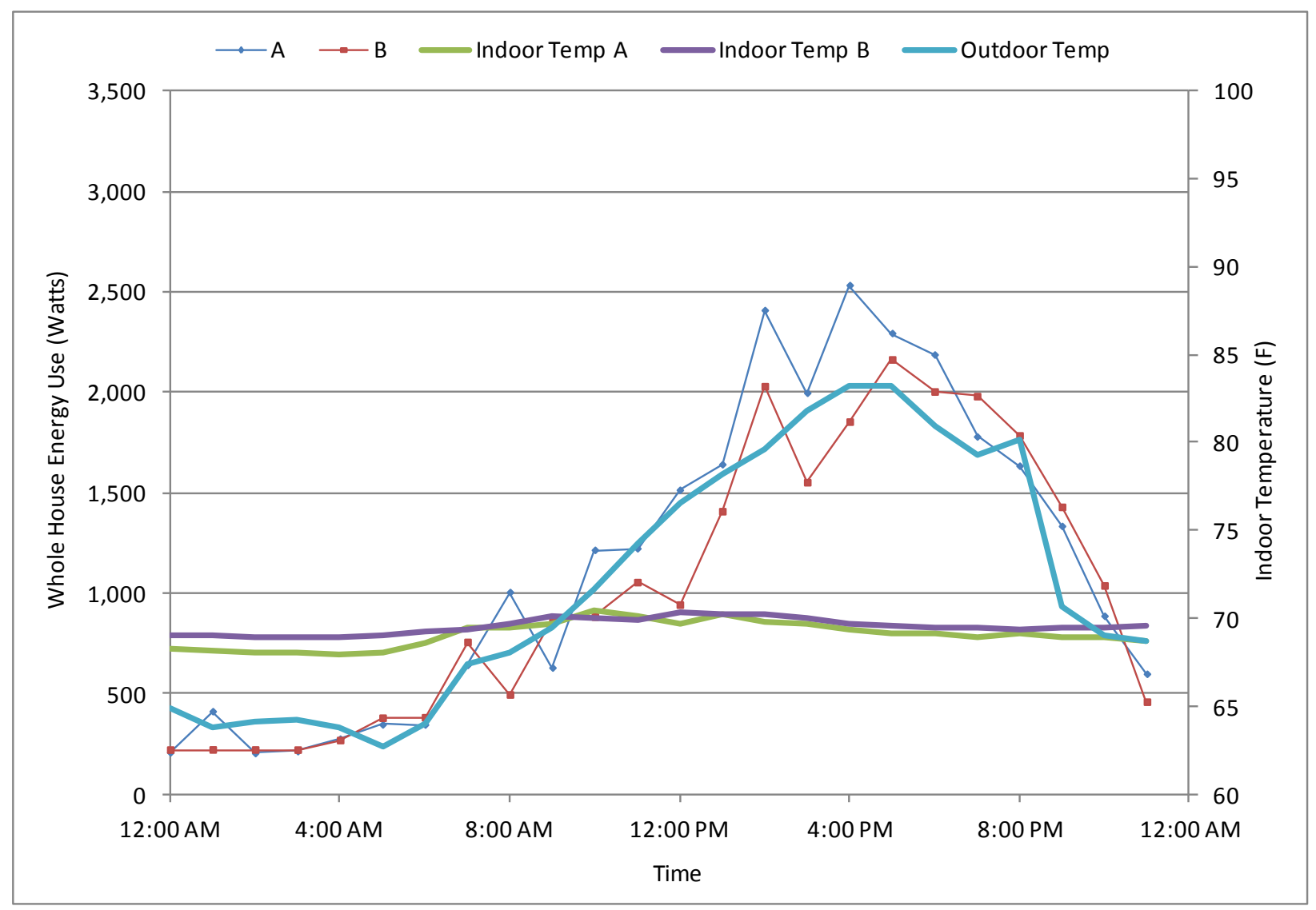

Figure 5.19. Hourly Average Whole-House Energy Use and Indoor Temperature for the Experimental Home (blue and green lines) and the Baseline Home (red and purple lines) and Outdoor Air Temperature on a Mild Day

\subsubsection{Average Annual Savings}

Measured data were extrapolated to estimate annual energy savings based on the heating degree days (HDD - base $65^{\circ} \mathrm{F}$ ) and cooling degree days (CDD - base $65 \mathrm{~F}^{\circ}$ ). Energy savings, in kilowatt-hours, were scaled based on HDD and then extrapolated to total annual heating season savings based on the number of HDD in a typical year (TMY3 file) in Pasco, Washington. A similar analysis was done for cooling savings measured during the summer experimental period and typical CDD in the TMY3 file. This calculation is shown in the following equations:

$$
\begin{aligned}
& \text { Annual Heating Savings }(k W h)=\frac{\text { Measured Savings } \text { Heating Test Period }(k W h)}{H D D_{\text {Heating Test Period }}\left({ }^{\circ} \mathrm{F}\right)} \times H D D_{T M Y 3}\left({ }^{\circ} \mathrm{F}\right) \\
& \text { Annual Cooling Savings }(k W h)=\frac{\text { Measured Savings } \text { Cooling Test Period }(k W h)}{C D D_{\text {Cooling Test Period }}\left({ }^{\circ} \mathrm{F}\right)} \times \operatorname{CDD}_{T M Y 3}\left({ }^{\circ} \mathrm{F}\right) \\
& \text { Annaul Savings }(k W h)=\text { Annual Heating Savings }(k W h)=\text { Annual Cooling Savings }(k W h)
\end{aligned}
$$


Summing the estimated annual average heating and cooling savings, $12.2 \%$ annual savings are expected based on the measured data, or 1,784 kWh. However, because the HDD/CDD data do not explicitly account for the incident solar radiation these savings are considered to be conservative.

\subsection{Interior Temperature Distributions}

In addition, the impact of performance of the highly insulating windows on indoor temperature distribution within the homes cannot be discounted. Indoor temperature in the kitchen of each home is shown in Figure 5.7 and Figure 5.9 for the heating season for sunny and cloudy days, respectively. As can be seen by the purple line in Figure 5.7, Lab Home B maintains a much more consistent indoor temperature throughout the day due to both the low U-factor and low SHGC (0.19) of the windows. In heating-only mode, interior temperatures in the baseline home climb to almost $84^{\circ} \mathrm{F}$, as illustrated by the green line in Figure 5.7. This would clearly cause a comfort problem for any occupants home during this time, even during days with cold outdoor temperatures. This elevated temperature is seen in all areas of the baseline home, while the experimental home maintains a much more consistent temperature profile, as shown in Figure 5.20. The interior temperature distribution in both homes on cloudy days are much more uniform, as illustrated in Figure 5.9 by the purple and green lines for Lab Home A and Lab Home B, respectively. Lab Home B maintains a slightly higher indoor temperature due to the improved thermal performance and lower SHGC of the highly insulating windows.

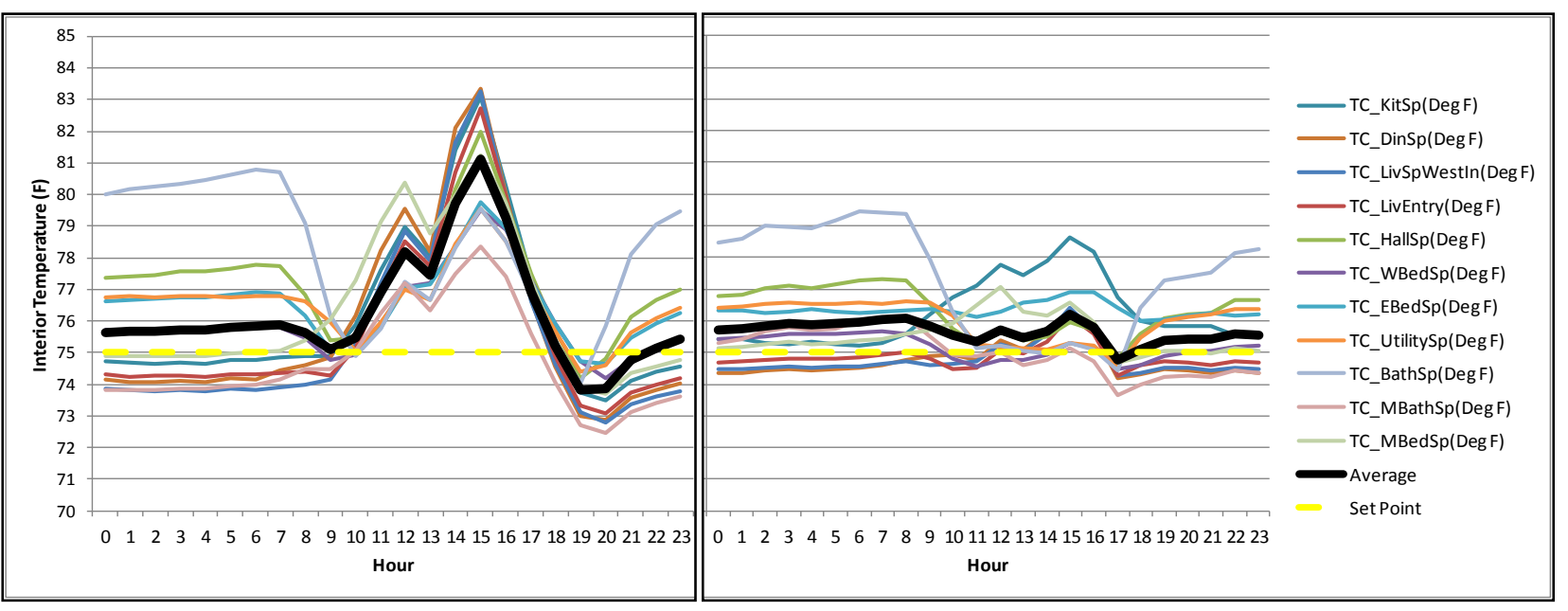

Figure 5.20. Interior Temperature Distribution for Lab Home A (left) and Lab Home B (right) on a Sunny Day

Comparing Figure 5.19 and Figure 5.16 in the previous section, the impact of increased outdoor air temperature on interior temperature distributions and comfort is also apparent during the cooling season. Indoor temperature in the kitchen of each home is shown in Figure 5.16 and Figure 5.19 for the heating season for hot and mild summer days, respectively. On hot days, Lab Home A is not able to maintain the thermostat set point during the hottest part of the day, as illustrated by the green line in Figure 5.16. Note that equipment loads are not exercised on this day, which would further exacerbate the problem. The heat pump is already operating at $100 \%$ capacity for several hours a day even in this reduced occupancy scenario (no equipment), as shown in Figure 5.21 between the hours of 2:00 pm and 7:00 pm. As can be seen by the purple line in Figure 5.16, Lab Home B maintains the thermostat set point and, thus, a much more consistent indoor temperature throughout the day due to both the low U-factor and low SHGC 
(0.19) of the windows. Also, in Lab Home B, the heat pump continues to cycle throughout the day and appears to have additional capacity to accommodate warmer days or increased internal loads.

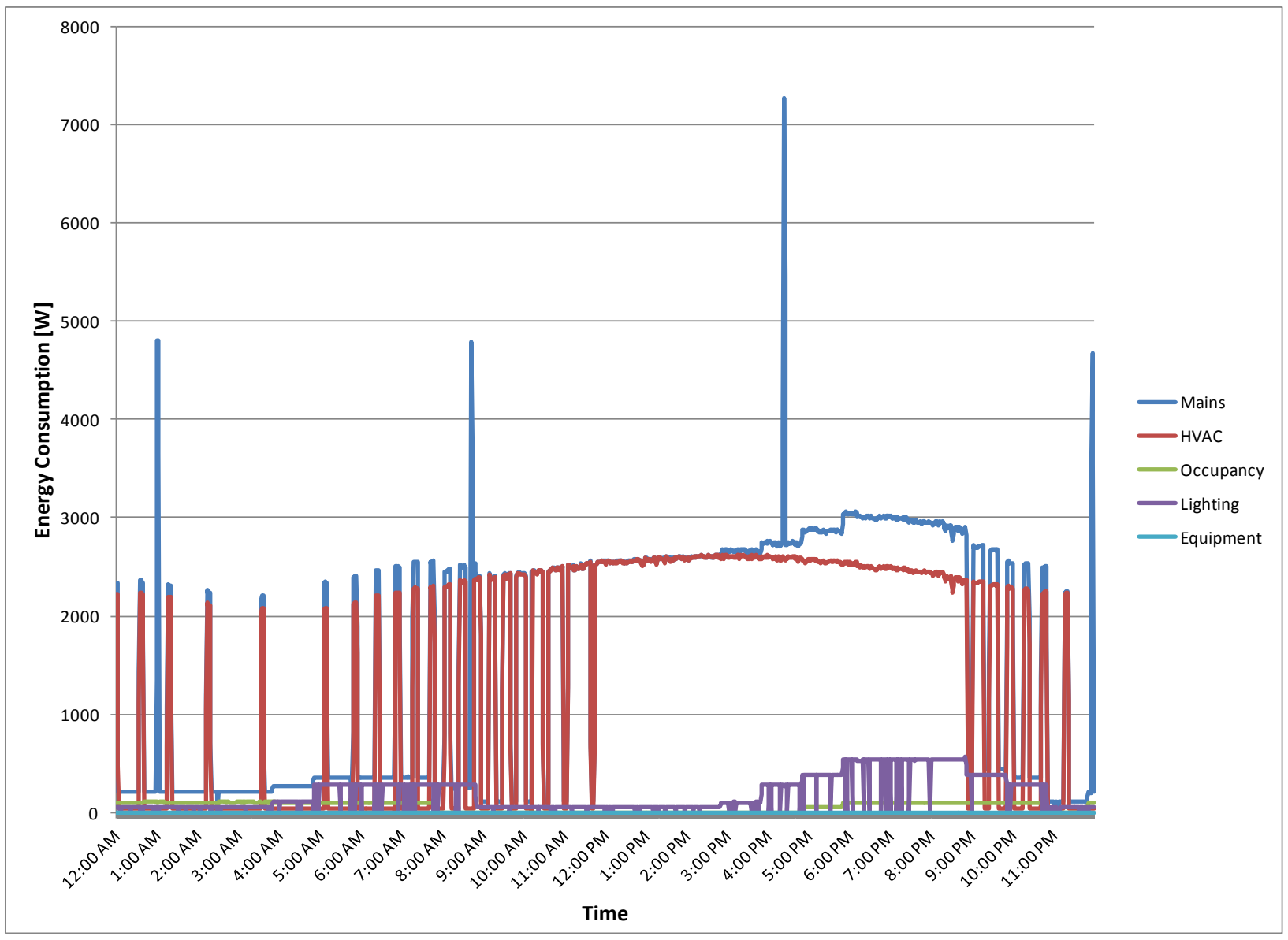

Figure 5.21. Whole House Energy Use in Lab Home A on a Hot Day (July 10) with HVAC, Occupancy, and Lighting Loads Disaggregated

This increased temperature is seen in all areas of the home in the baseline home, while the experimental home maintains a much more consistent temperature profile, as shown in Figure 5.22. Also, Figure 5.22 shows overcooling occurring in some rooms in both homes, probably due to the thermostat location (in the hallway adjacent to the kitchen in both homes). Temperatures as low as $64^{\circ} \mathrm{F}$ are observed in both Lab Home A and B in the rooms closest to the air handler and, thus, receiving the most air (the bathroom, west bedroom, and east bedroom) due to shorter duct runs. However, more extreme local temperature variations (lower lows and higher highs) are evident in Lab Home A due to the increased localized heat gain through the windows and the subsequent increased need for cooling. 

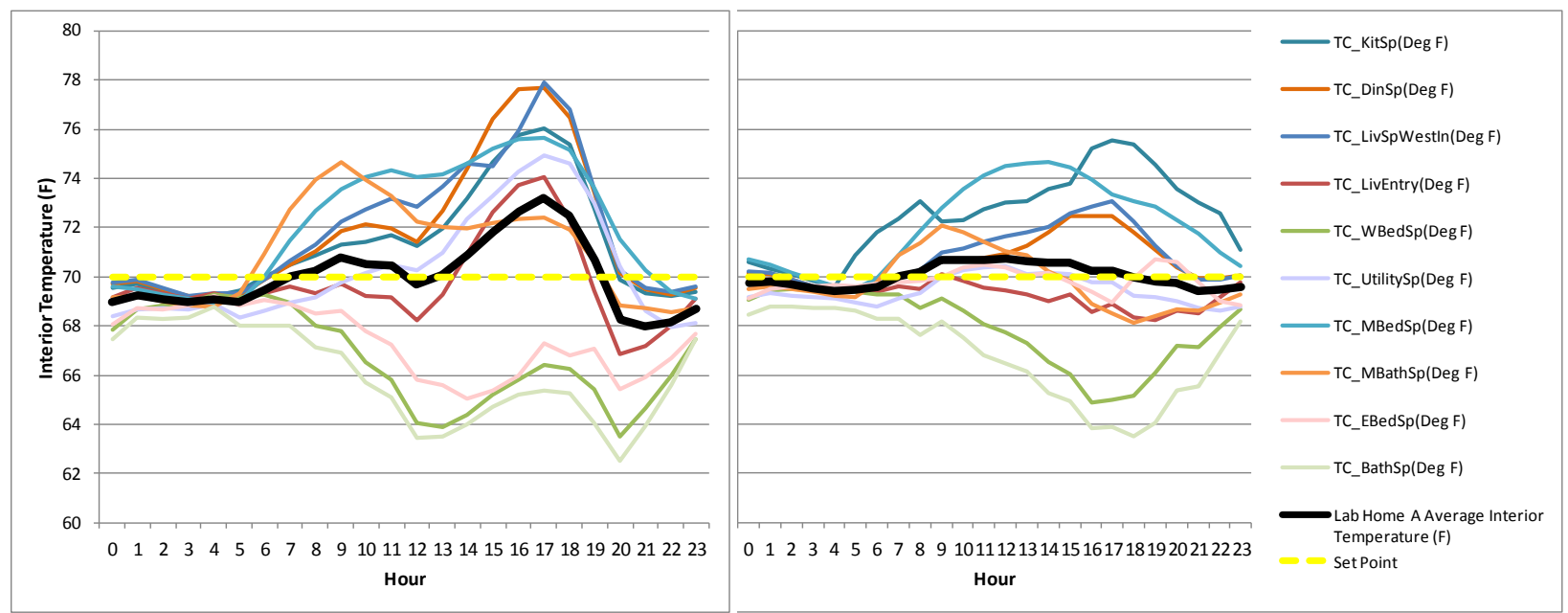

Figure 5.22. Interior Temperature Distribution for Lab Home A (left) and Lab Home B (right) on a Hot Day

On milder days, both Lab Home A and Lab Home B are able to maintain the $70^{\circ} \mathrm{F}$ thermostat set point, as illustrated in Figure 5.19 by the purple and green lines for Lab Home A and Lab Home B, respectively.

\subsection{Thermal Comfort and Condensation}

The increased thermal performance of highly insulating windows can also affect the health of a home. Poorly insulating windows, such as the double-pane clear glass windows installed in the baseline home (Lab Home A), can cause condensation to form on the window, which over time can contribute to mold growth on the window sill. While condensation was not observed with the low relative humidity in the homes, the thermal performance of the double-pane clear windows clearly indicated a potential for condensation during the heating season.

Figure 5.23 shows the interior temperature of all window surfaces in the baseline home (Lab Home A) and Figure 5.24 shows the interior temperature of all window surfaces in the experimental home (Lab Home B) during the period from March 11 through 17, 2012. The average outdoor air temperature during this period was $49^{\circ} \mathrm{F}$, with a high of $65^{\circ} \mathrm{F}$ and a low of $35^{\circ} \mathrm{F}$. As the figures show, the interior window temperature of the coolest window reaches $50^{\circ} \mathrm{F}$ on the west-facing dining room window in the baseline home, while the same window in the experimental home does not dip below $60^{\circ} \mathrm{F}$. With these temperatures and an interior room temperature of $75^{\circ} \mathrm{F}$ in both homes, the relative humidity of the air in the experimental home would have to exceed $70 \%$ to cause condensation on the highly insulating windows, while a minimum of $40 \%$ relative humidity in the baseline would cause condensation and potential mold problems with the windows. ${ }^{1}$ For reference, the average relative humidity in the baseline home (Lab Home A) was $20.7 \%$, with a maximum of $31.7 \%$, and the average relative humidity observed in the experimental home (Lab Home B) was $21.7 \%$, with a maximum of $28.1 \%$.

\footnotetext{
${ }^{1}$ Based on data from a psychrometric chart.
} 


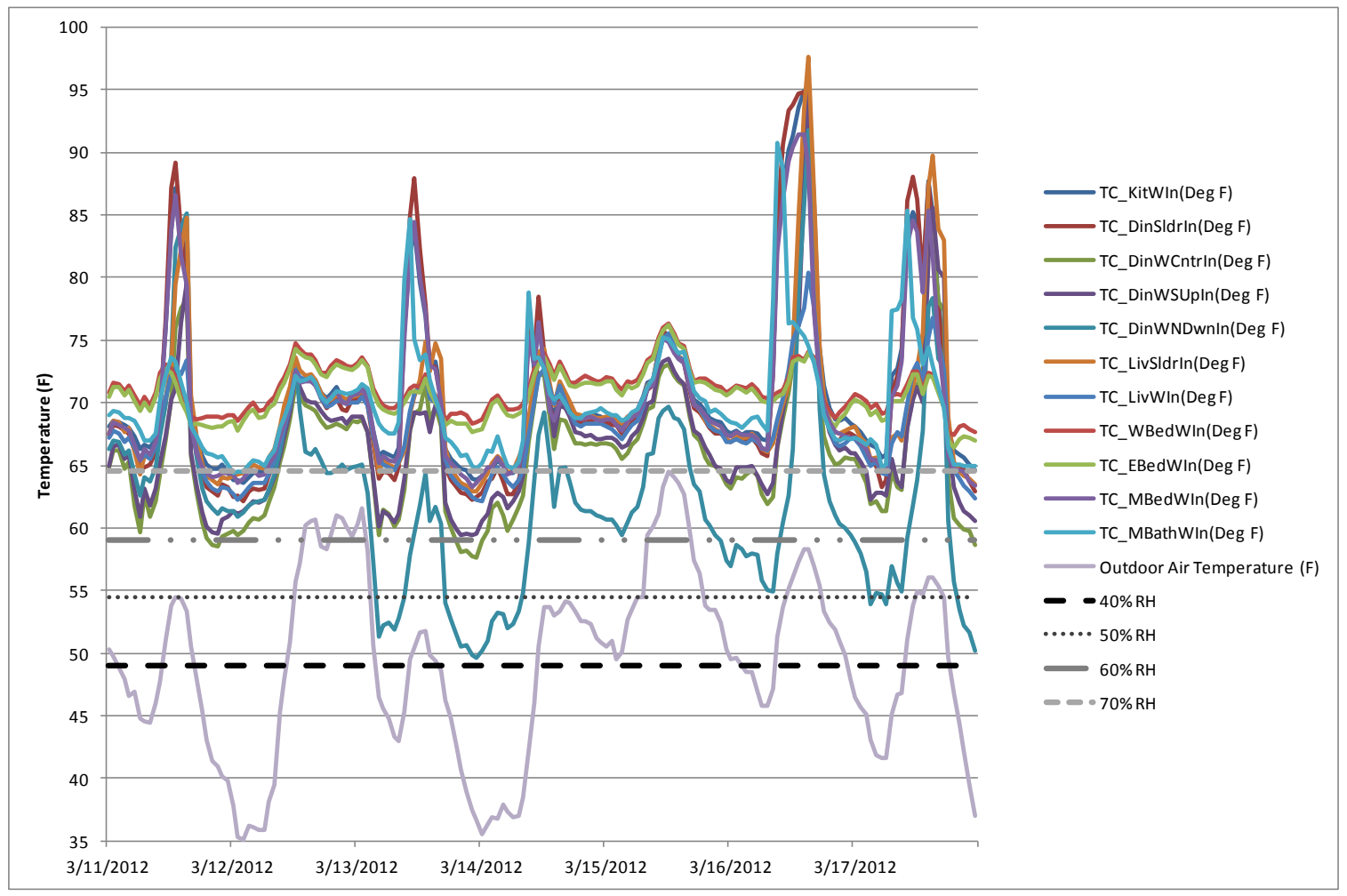

Figure 5.23. Interior Window Temperatures and Dew Point Temperatures Based on a $75^{\circ} \mathrm{F}$ Interior Air Temperature in the Baseline Home from March 11 Through 17, 2012

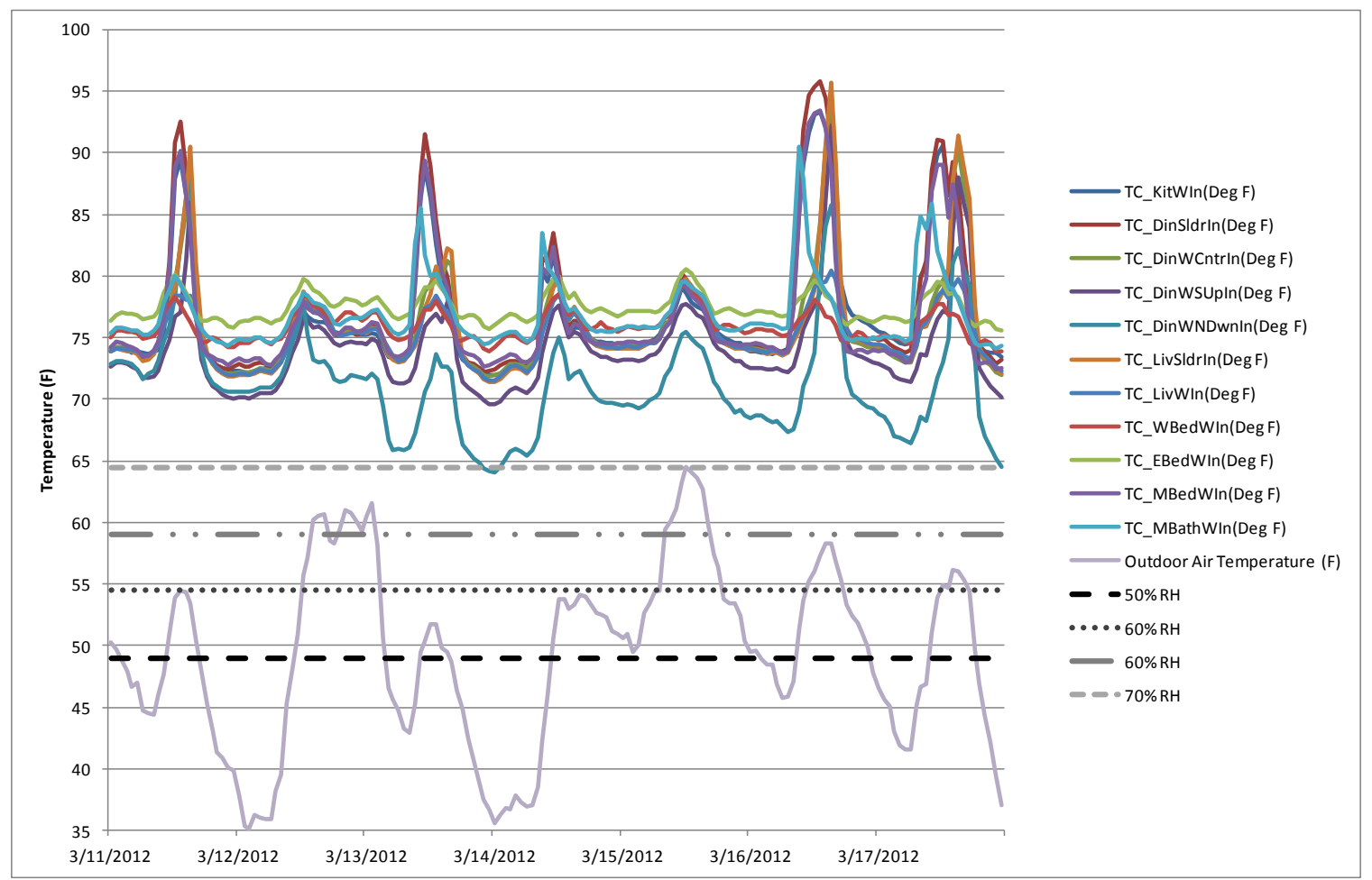

Figure 5.24. Interior Window Temperatures and Dew Point Temperatures Based on a $75^{\circ} \mathrm{F}$ Interior Air Temperature in the Experimental Home from March 11 Through 17, 2012 
Figure 5.23 and Figure 5.24 also depict the difference in average interior glass surface temperature in the two homes. The average interior glass surface temperature measurement of all the windows over this period was $68.7 \pm 0.05^{\circ} \mathrm{F}$ in Lab Home A compared to $75.7 \pm 0.04^{\circ} \mathrm{F}$ in Lab Home B, nearly $7^{\circ} \mathrm{F}$ cooler. The colder window surface temperatures also affect comfort felt by occupants in the home. A window with a colder surface temperature will cause rooms to feel colder than the measured dry bulb temperature would suggest.

The MRT also was monitored in two locations in each Lab Home during the period from March 11 through 17, 2012. In Figure 5.25, the average indoor air temperature and MRT are plotted for both the homes.

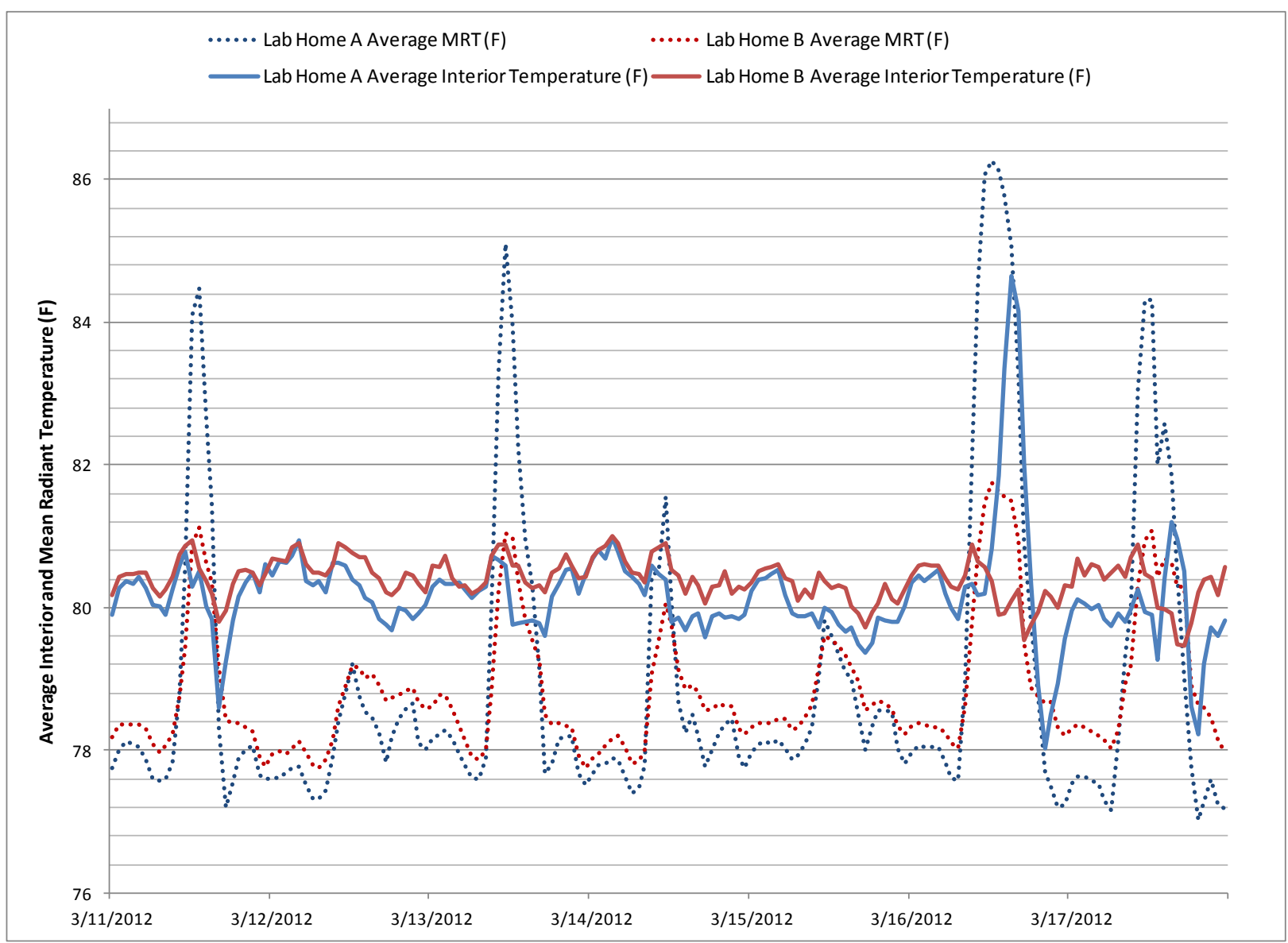

Figure 5.25. Average Indoor Air Temperature (solid line) and Mean Radiant Temperature (dotted line) in Lab Home A (blue) and Lab Home B (red)

During the same week, the average MRT in Lab Home A during the nighttime period when radiant heat loss was most extreme was $79.0 \pm 0.02^{\circ} \mathrm{F}$ in both the master bedroom and the living room compared to an average room temperature of $80.2 \pm 0.11^{\circ} \mathrm{F}$. The average MRT of both the living area and master bedroom was $1.63 \pm 0.01^{\circ} \mathrm{F}$ lower than the average interior room temperature in Lab Home A. The maximum MRT recorded in Lab Home A during the winter experiment was $86.3^{\circ} \mathrm{F}$ and the minimum MRT was $77.0^{\circ} \mathrm{F}$. 
In contrast, in Lab Home B, the average MRT in the living area and master bedroom was $1.64 \pm$ $0.01^{\circ} \mathrm{F}$ lower than the average room temperature of $80.4 \pm 0.01^{\circ} \mathrm{F}$ in the living area and master bedroom. The maximum MRT recorded in Lab Home B was $81.7^{\circ} \mathrm{F}$ and the minimum MRT was $77.7^{\circ} \mathrm{F}$. Overall, the average nighttime MRT in Lab Home B was slightly warmer than the average MRT in Lab Home A during the nighttime periods when radiant heat loss is most extreme. The very small temperature differences between the room temperature and MRT in Lab Home B compared to the larger difference in Lab Home A, as well as the higher average MRT in Lab Home B, suggest the highly insulating windows can provide a greater comfort level for occupants. Also, the MRT in Lab Home B was much more consistent, varying only $4.9^{\circ} \mathrm{F}$, while Lab Home A varied $9.2^{\circ} \mathrm{F}$. MRT and surface glass temperatures were not assessed in the summer cooling season experiment, since thermal comfort is an issue primarily in the winter heating season.

\subsection{Peak Load}

Another impact of reduced energy use that is important to mention from a utility and resource planning perspective is the ability to reduce peak load $(\mathrm{kW})$. Figure 5.26 depicts peak load impacts due to installation of the highly insulating windows in the experimental home over a representative 1-week time period in the summer. The impact on peak load is significantly more than the average daily energy savings, reducing the peak power consumed on an hourly basis in the home with highly insulating windows (Lab Home B) by $24.7 \% \pm 0.1 \%$ over the entire cooling experiment study period. This is because the peak load reduction represents a maximum real-time savings, rather than an average savings. Peak power savings occur, typically, between 10:00 am and 6:00 pm when the system demand is highest. 


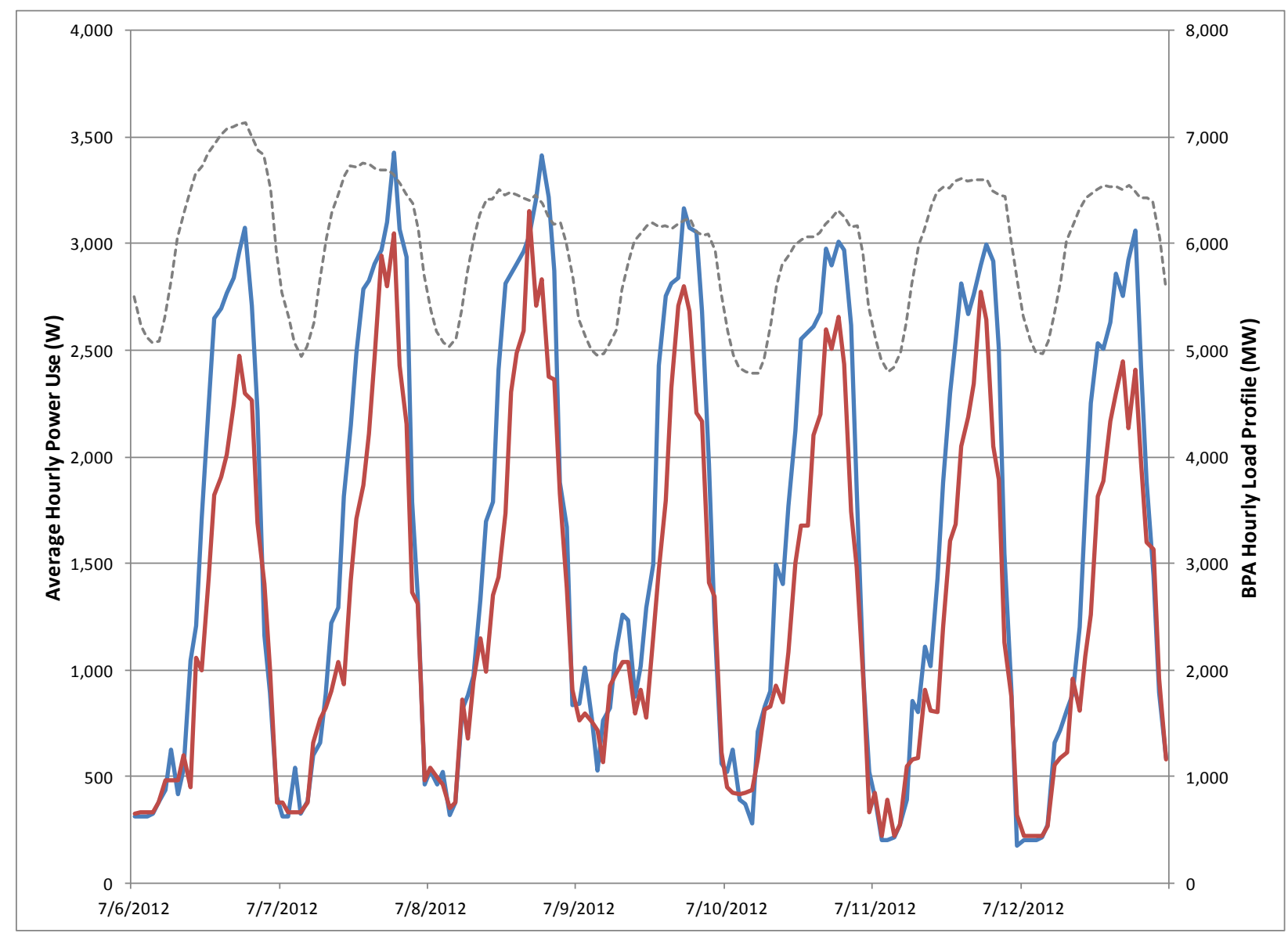

Figure 5.26. Average Hourly Power Use for Lab Home A (blue) and Lab Home B (red) and the Bonneville Power Administration Load Curve During a 1-Week Period from July 6 to July 13, 2012 (Note: the Bonneville Power Administration data is for the same days in 2011 since 2012 data was not available).

Peak load savings were also measured in the heating season. Average hourly peak savings for the heating season were $33.9 \pm 0.6 \%$. However, these savings occurred in the nighttime hours when outdoor air temperatures were coldest, which does not typically correspond with utility peak demand periods, as shown by the grey dashed line in Figure 5.26. The grey line shows the load curve, in megawatts (MW), for the Bonneville Power Administration service territory, for July 6 through July 13, 2011, since 2012 data was not available. ${ }^{1}$ While the load shape changes in the winter months, peaks still occur during the day, which juxtaposes the winter heating season peaks observed in the Lab Homes.

\subsection{Energy Modeling}

An EnergyPlus model was created for the Lab Homes to compare modeled savings from the highly insulating windows to measured results. The EnergyPlus analysis shows average whole-building energy savings in Lab Home B from the highly insulating windows to be $13.9 \%$ during the simulation period (February to April 2012 and from July to August 2012). Part of the savings is due to the slightly tighter

\footnotetext{
${ }^{1}$ Bonneville Power Administration peak load data was obtained from the Federal Energy Regulatory Commission Form 714 for respondent 122, available at http://www.ferc.gov/docs-filing/forms/form-714/data.asp.
} 
envelope of Lab Home B achieved as part of the windows retrofit (see Section 5.2.2). The general trends in energy use and savings are comparable to the measured data, which indicated observed savings of 11.6 $\pm 1.53 \%$ in Lab Home B compared to Lab Home A in the heating season and $18.4 \% \pm 2.06 \%$ in the cooling season, with an average of $15 \%$.

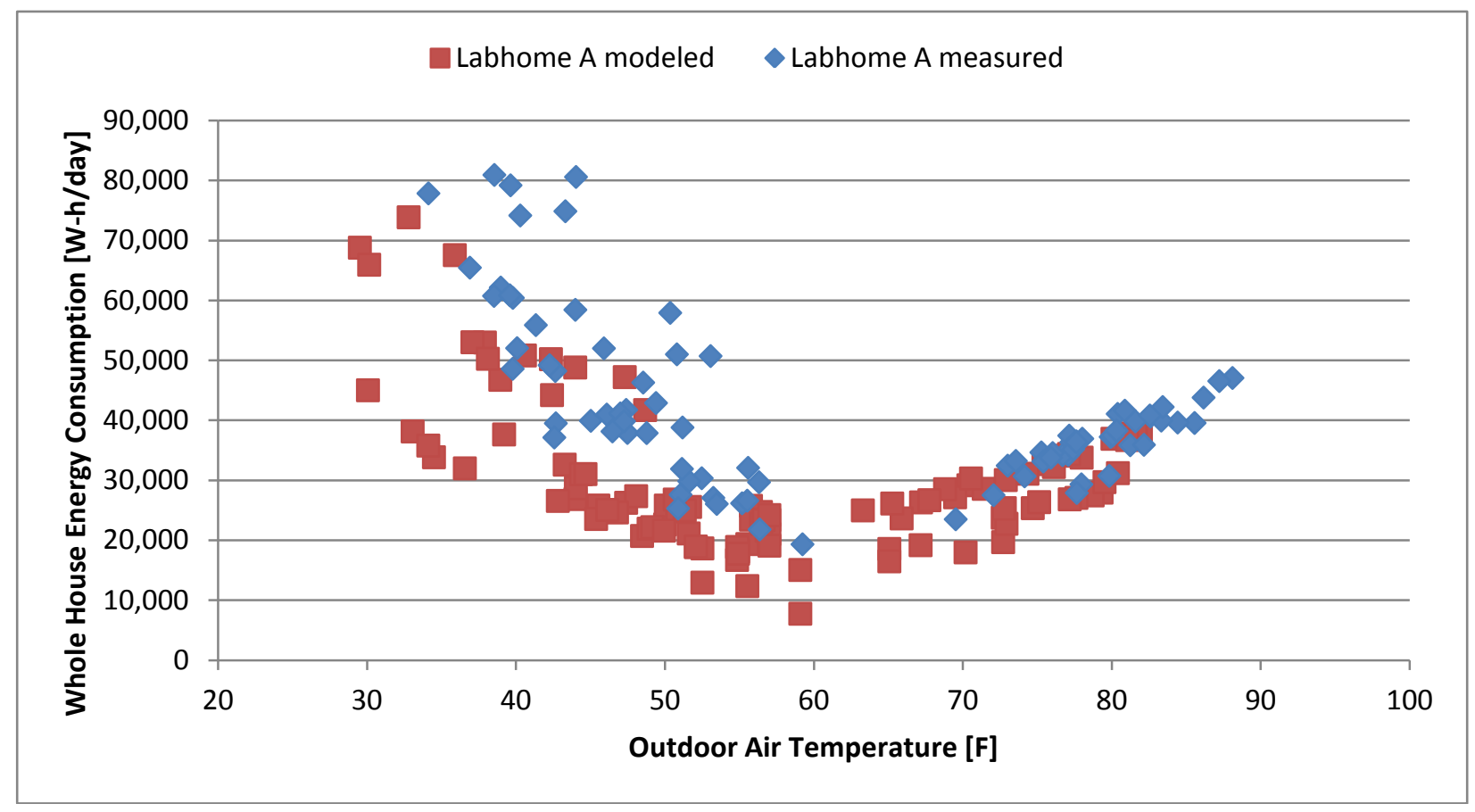

Figure 5.27. Modeled and Measured HVAC Energy Use for Lab Home A (Baseline Home)

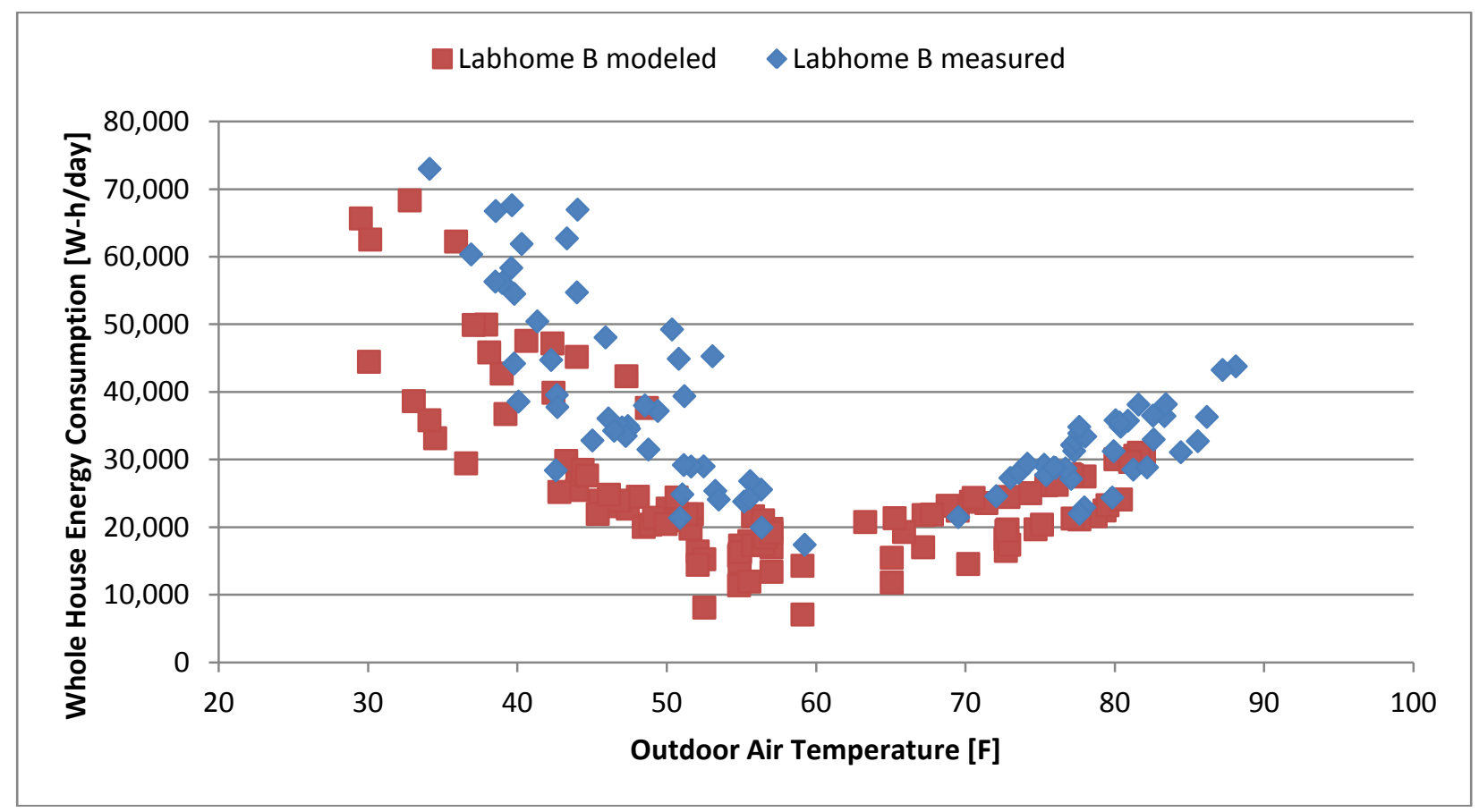

Figure 5.28. Modeled and Measured HVAC Energy Use for Lab Home B (Experimental Home) 


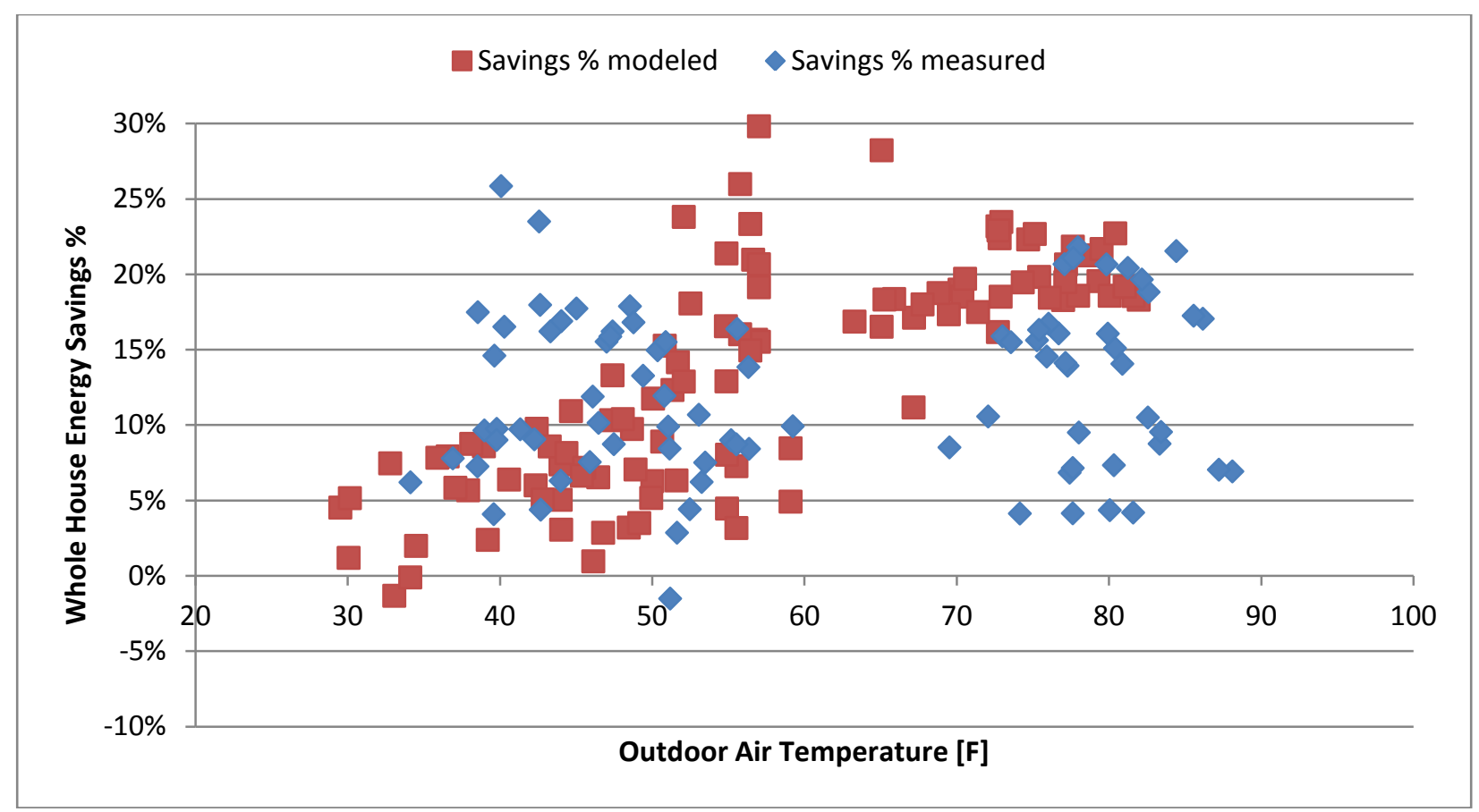

Figure 5.29. Modeled and Measured Energy Savings

Figure 5.27 and Figure 5.28 show the modeled and measured whole-house energy use compared to outdoor air temperature for Lab Home A and Lab Home B, respectively. Figure 5.29 shows the modeled and measured energy savings compared to outdoor air temperature of Lab Home B with respect to Lab Home A.

The modeled results correspond well with the measured data. However, the EnergyPlus models underpredict the energy use as compared to the measured data in both homes. The modeled average annual energy use for Lab Home A is 28,537 Wh and 24,784 Wh for Lab Home B, which results in $13.2 \%$, or 1,370 $\mathrm{kWh}$, annual energy savings from the highly insulating windows for Lab Home B with a cooling season set point of $75^{\circ} \mathrm{F}$ and a heating set point of $72^{\circ} \mathrm{F}$ and typical internal gains schedules, as described in Appendix G. This annual energy savings model typifies the savings that highly insulating windows would achieve in an average home, including an impact on envelope leakage. While this number is similar to the calculated annual savings based on measured data reported in Section 5.6, the model needs to undergo a more robust calibration before it can be used to accurately predict annual energy performance and savings or extrapolate findings to other climates. Future work will involve using onsite weather data in the energy simulation and matching daily load profiles exactly for the heating and cooling seasons.

\subsection{Cost Effectiveness of Highly Insulating Windows}

The energy savings achieved by highly insulating windows in the PNNL Lab Homes have demonstrated the potential of this technology to significantly improve the energy efficiency of homes. However, the viability of highly insulating windows as an energy efficiency measure depends not only on their energy saving potential, but also their costs. 
For the calculation of simple PBP, annual energy savings as determined by the EnergyPlus model as well as the extrapolated annual energy savings reported in Section 5.6 are used. In the EnergyPlus model, set points and occupancy parameters that typify existing homes in the United States are used to represent the energy savings, and thus cost effectiveness results, a typical homeowner could expect to see. In many cases, these assumed parameters were the same or similar to those exercised in the Lab Homes during the experimental periods (lighting and occupancy schedules, interior set points). See Section 5.10 and Appendix $\mathrm{G}$ for more information on this representative annual model. The annual savings determined by the annual savings model are 1,370 kWh per year or $13.2 \%$ in Lab Home B compared to Lab Home A. The estimated annual savings extrapolated based on the measured data and typical HDD and CDD are $1,784 \mathrm{kWh} / \mathrm{yr}$ or $12.2 \%$.

The annual utility bill cost savings are determined by multiplying the annual energy savings in $\mathrm{kWh}$ by the national average cost of electricity of $11.8 \notin / \mathrm{kWh}$ (EIA 2012). This results in an annual savings of $\$ 162 / y r$ for the modeled annual savings and \$211/yr for the measured annual savings estimate.

The costs of purchasing the highly insulating windows was obtained from the window distributor as $\$ 6,243$ or $\$ 32 / \mathrm{ft}^{21}$. However, window costs are highly variable and, thus, these costs were compared with other manufacturers and other windows types, to ensure the costs were representative of the range of window costs observed in the retrofit market. A delivered (to the PNW) cost range for highly insulating slider windows and patio glass doors in small quantities for retrofit was obtained from the vendors in the DOE Windows Volume Purchase Program who sell a product line of sliders and patio doors. ${ }^{2}$ However, costs were considered for casements and double-hung windows as well, for comparison. These costs are highly variable and range from $\$ 10 / \mathrm{ft}^{2}$ to $\$ 100 / \mathrm{ft}^{2}$. Although manufacturers were asked for data representing delivered costs (not including installation), it is assumed that higher costs represent window costs which include installation costs. Plotting the data, to identify any trends, yielded no clear differentiation or relationship, as shown in Figure 5.30. In all cases, several high outliers are observed. Because we do not know the degree of customization or complexity of each product in this data set, it is assumed that these three outliers (indicated by red circles) are specialty windows that are not representative of average $\mathrm{R}-5$ window costs.

\footnotetext{
${ }^{1}$ This price was obtained from the invoice from the local window supplier for the specified windows and sliding glass doors

${ }^{2}$ The window vendors selected for estimating costs from the qualified vendors in the Windows Volume Purchase Program were vendors who offered horizontal sliders and patio doors and who sold or delivered products in the Pacific Northwest. An average cost per square foot across the multiple sizes of windows in Lab Home B was determined.
} 


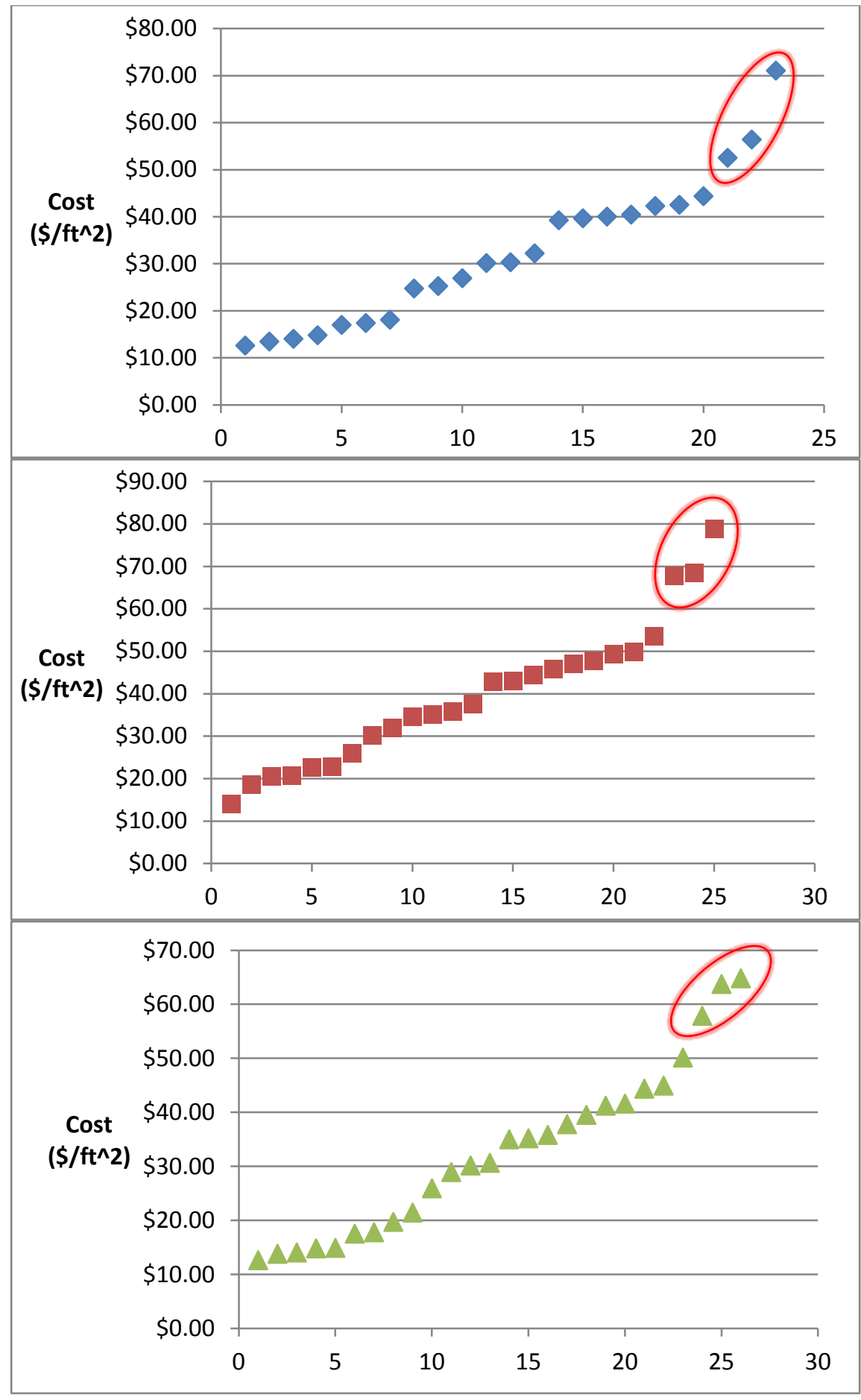

Figure 5.30. Window Cost Data for R-5 Sliders (top), Casements (middle), and Double-Hung (bottom) from the DOE Windows Volume Purchase Program. Red circles indicate outliers assumed to have a high degree of customization that were excluded from the analysis.

Excluding the outliers, the average cost of all the costs data for all three types of R-5 windows is $\$ 31 / \mathrm{ft}^{2}$. All the data also show a similar small break near the average, as indicated in Figure 5.31. To 
arrive at a lower estimate of delivered cost, without installation, the lower half of the data was averaged, yielding an average of $\$ 22 / \mathrm{ft}^{2}$. To arrive at a higher bound the upper half of the data was also averaged, arriving at an average of $\$ 43 / \mathrm{ft}^{2}$. While this reduces some of the extreme variability observed in the window cost data obtained from the Windows Volume Purchase Program, it is thought to be representative of average costs for R-5 windows and sliding glass doors.

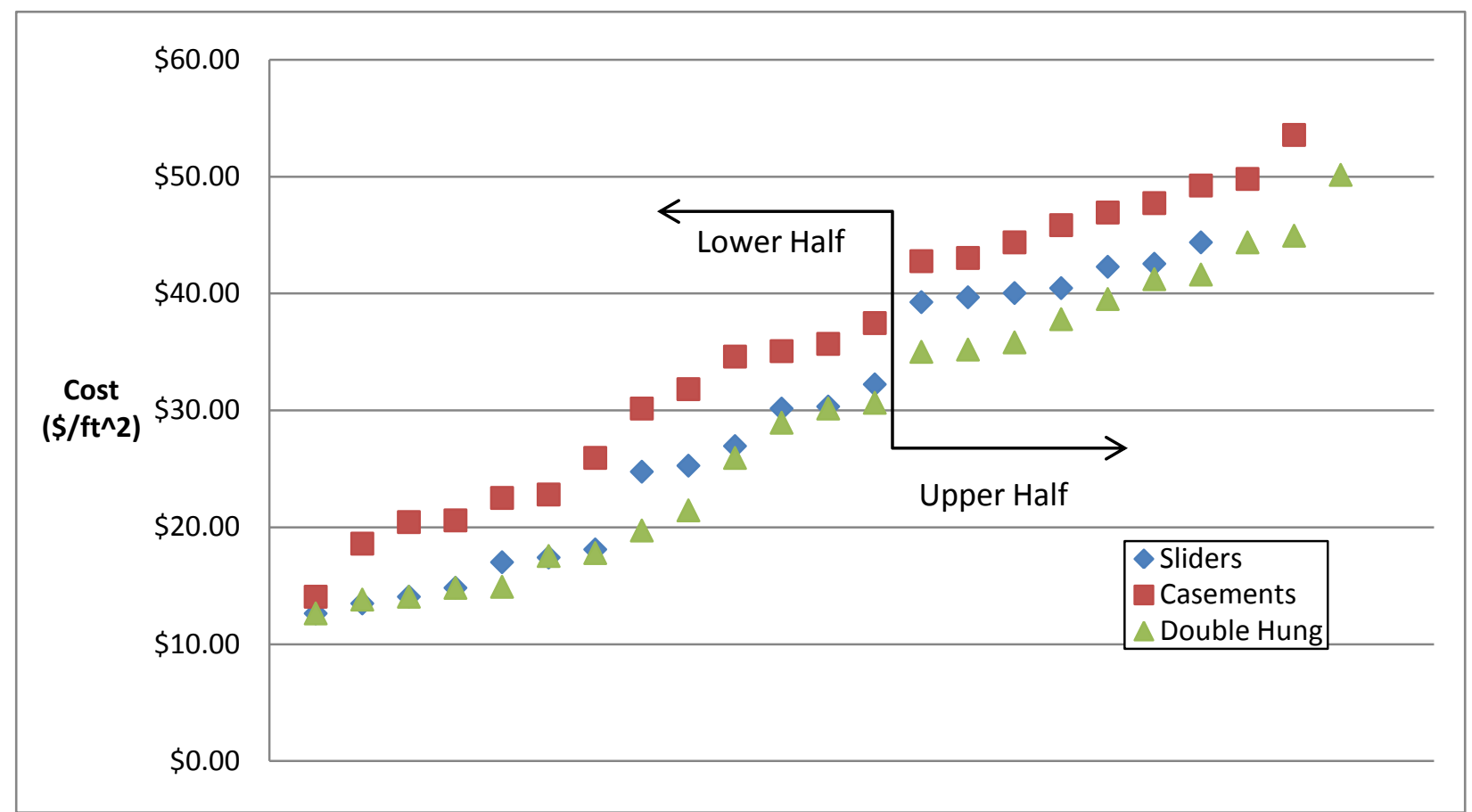

Figure 5.31. Cost Data, Excluding Outliers, for All Window Types from the Windows Volume Purchase Program

In addition to the delivered cost of the window, primary windows must be installed by a qualified contractor. However, costs for installing the highly insulating windows for Lab Home B were not provided as a separate cost to PNNL by the GC because these costs were included in the fixed-price bid for the package of work undertaken by the GC. Installation and materials costs were estimated at $\$ 3 / \mathrm{ft}^{2}$ based on observed retrofitting of the windows by subcontractors at the Lab Homes. Therefore, the total installed cost for the windows and sliding glass doors in Lab Home B was estimated to range from $\$ 4,900$ to $\$ 9,000$ or $\$ 25 / \mathrm{ft}^{2}$ to $\$ 46 / \mathrm{ft}^{2}$ and $\$ 35 / \mathrm{ft}^{2}$ based on the bid for the windows installed in the Lab Homes obtained from windows distributor. This range is consistent with the cost for retrofitting double-pane, clear glass, aluminum-frame windows with triple-pane, low-E, vinyl-framed windows listed in the National Residential Efficiency Measures Database, maintained by the National Renewable Energy Laboratory of $\$ 21 / \mathrm{ft}^{2}$ to $\$ 55 / \mathrm{ft}^{2}$, with an average of $\$ 33 / \mathrm{ft}^{2}$ (NREL 2012).

Based on these costs and a modeled annual savings of 1,370 kWh/yr, the simple PBP ranges from 30 to 55 years, as shown in Figure 5.32. Using, instead, the annual energy savings estimate based on extrapolated measured data of $1,784 \mathrm{kWh} / \mathrm{yr}$, the simple PBP ranges from 23 to 42 years. 


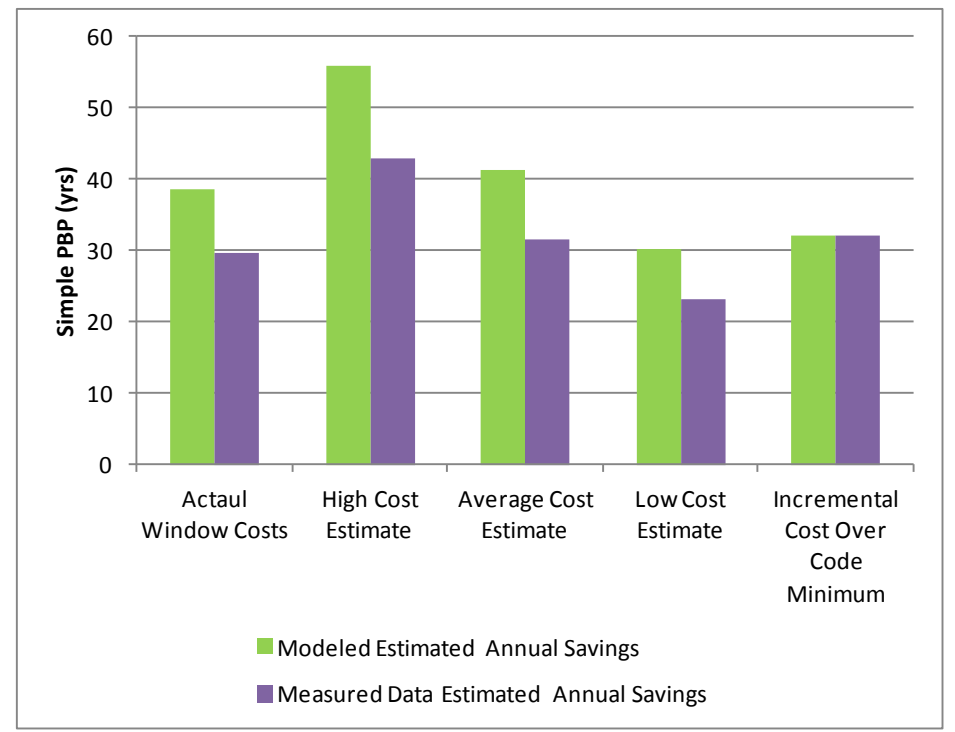

Figure 5.32. Simple PBP for R-5 Windows for a Retrofit or in an Incremental Cost Scenario. Costs considered are the actual windows costs as retrofit in the Lab Homes, a high, average, and low cost estimate based on data in the DOE Windows Volume Purchase Program; and incremental cost over code minimum windows. Modeled and an estimate of annual energy savings are calculated.

These primary window costs are appropriate for a retrofit scenario, but an incremental cost scenario should be considered for new construction or if windows are being replaced for another reason (e.g., safety, functionality, aesthetics). In the incremental cost scenario, installation cost is not included and only the cost difference between code minimum and highly insulating (triple-pane) windows is used. The costs of code minimum windows (as delivered) were obtained from National Residential Efficiency Measures Database (NREL 2012). The incremental cost of highly insulating windows over code minimum windows ranged from $\$ 1.59 / \mathrm{ft}^{2}$ to $\$ 5.84 / \mathrm{ft}^{2}$, with an average of $\$ 3.87 / \mathrm{ft}^{2}$. Installation and material costs were not included in the incremental cost estimate, resulting in total incremental costs for highly insulating windows and sliding glass doors in Lab Home B is estimated to be $\$ 1,372$, based on an average cost of $\$ 27 / \mathrm{ft}^{2}$ and the average cost of R-5 windows of $\$ 34 / \mathrm{ft}^{2}$. Based on a modeled incremental annual energy savings of $363 \mathrm{kWh} / \mathrm{yr}$, the simple PBP is 32 years. 



\subsection{Conclusions}

This experiment used two side-by-side Lab Homes on the PNNL campus to measure the potential energy savings, thermal comfort impacts, and cost effectiveness of highly insulating triple-pane windows (and patio doors) in the experimental home compared to the baseline home equipped with standard double-pane windows (and patio doors), the latter representing windows in many existing homes across the PNW and much of the United States. Testing was conducted during the 2011-2012 winter heating and summer cooling seasons. The design of this field experiment in the Lab Homes was unique to the PNW. The experiment removed as many variables as possible that commonly affect other similar types of field experiments by having a nearly identical pair of homes, as verified by the null testing and by simulating occupancy identically in the two homes. The homes were oriented identically, experienced the same weather, had the same interior furnishings and equipment, and were operated identically during the experiments. Thus, the only differences between the two homes were the windows themselves (their inherent thermal properties) plus any impact from the windows' installation.

To verify similar performance prior to retrofitting the windows, the homes were initially null tested prior to the windows retrofit to verify similar construction and energy performance. Air leakage, duct leakage, ventilation fan flow, and heat pump performance testing was performed on both homes to compare the construction of both homes' envelope and their HVAC performance. This testing found the homes to be statistically the same, with blower door readings of $638.5 \pm 27.8 \mathrm{cfm} 50$ in Lab Home A and $681.1 \pm 26.7 \mathrm{cfm} 50 \mathrm{in} \mathrm{Lab}$ Home B. For additional testing results see Section 1.0. Thermal imaging of the homes' envelopes also revealed similar construction, although some insulation settling had occurred in both homes - slightly more in Lab Home A than Lab Home B. After baseline testing confirmed nearly identical construction of the homes during a null test prior to the winter experiment, the energy use of the two homes was compared to verify similar energy performance. During this null test, no occupancy was simulated and the homes were operated in HP mode with the thermostat set point varied from $50^{\circ} \mathrm{F}$ to $85^{\circ} \mathrm{F}$ on a daily basis. Whole-house energy use was shown to be similar within $0.5 \% \pm 0.5 \%$ during the 6 days of null testing.

The air leakage of both homes was also measured after the windows were retrofitted, to determine the impact of the difference in air leakage inherent to the windows and the quality of the window installation. The blower door measurements after the windows were retrofitted showed an increase of $50.3 \pm 34.1$ cfm50 in air leakage in Lab Home A; this increase in air leakage is attributed to the combined effects of the air leakage of the window and air leakage around the window cavity resulting from the installation of the window. The air leakage of Lab Home B decreased by $46.4 \pm 34.9 \mathrm{cfm} 50$ or $6.9 \%$ after the windows were retrofitted; this decrease in air leakage is primarily due to the quality of the installation because the air leakage of the highly insulating windows is similar to that of the factory-supplied windows, as certified in a laboratory test. This is strong evidence of how important it is to properly install/retrofit windows.

The data from the heating season and cooling season show significant whole-house energy savings and comfort improvement in Lab Home B. The overall whole-house energy savings in Lab Home B with the highly insulating windows are $11.6 \% \pm 1.53 \%$ compared to Lab Home A during the heating season and $18.4 \% \pm 2.06 \%$ during the cooling season. The largest difference in energy performance between the homes was a result of solar insolation (solar heat gain) given the significant difference in SHGC of the windows in Lab Home A (0.7) compared to Lab Home B (0.19). The dependence on solar insolation and 
solar heat gain was observed in the heating season by the lower savings seen in Lab Home B as compared to Lab Home A on sunny days versus cloudy days. On sunny days, for almost any home, solar heat gain through windows contributes enough heat to the home that the heating systems may even turn off, even though the outdoor temperature is well below the thermostat set point for the home. Given that neither home deployed window coverings, this condition was expected and observed more often in Lab Home A (with high SHGC windows); measured average whole-house indoor temperatures often increased 5 to $10^{\circ} \mathrm{F}$ above the set point of the heating system thermostat due to solar heating. In Lab Home B, temperatures remained much more consistent, but the heating system was required to turn on to supply heat much sooner in the evening, while Lab Home A could typically coast well into the late evening before needing to call for heat. Overall, the low SHGC of the windows in Lab Home B showed energy savings on sunny days of $8.9 \% \pm 1.42 \%$ compared to the baseline home Lab Home A.

On cloudy winter days, the difference in the SHGC of the windows, and thus the solar heat gain contribution, is not as evident. Data showed that both homes maintained average interior temperatures near the thermostat set points throughout the day and that the heating systems were operating to maintain that set point throughout the day. The heat pumps in both homes cycle, as would be expected, and they cycle less frequently in the afternoon when outdoor temperatures are the warmest. On overcast days, the average whole-house energy savings from the windows is $14.6 \% \pm 1.86 \%$.

However, due to the frequency of sunny days in the summer experimental period, the energy use and energy savings appeared to be more related to outdoor air temperature, which is a function of the highly insulating windows' lower U-factor. The U-factor of the highly insulating windows and patio doors in the experimental home (Lab Home B) is $\sim 70 \%$ lower than that of the standard windows in the baseline home (Lab Home A) and the SHGC of the highly insulating windows in the experimental home is $77 \%$ compared to the standard windows and patio doors in the baseline home. Due to the high energy savings observed in the summer period, it is assumed that the lower U-factor as well as the low SHGC are both affecting savings. These heating and cooling season savings are reported with no window coverings deployed. A sensitivity analysis deploying interior blinds in both the homes reduced energy savings in Lab Home B compared to Lab Home A by $46 \%$, but did not significantly affect energy use in the homes. However, this could be due to the short period of data collection for sensitivity study resulting in high error about the mean, because visual interpretation of the data suggests lower energy use would be observed.

In addition to significant overall energy savings, the highly insulating windows also reduced the peak load in Lab Home B by $33.9 \%$ during the heating season and $24.7 \%$ during the cooling season during two representative 1-week periods. The heating season peak load in both homes occurred during the evening hours after sunset and thus does not correspond with utility peak loads. However, the cooling season peak occurs in the afternoon and early evening, which corresponds directly with national utility peaks. Thus, energy efficiency measures such as windows can serve as an important peak reduction measure as well in the cooling season. Although there is currently no direct financial benefit to most residential customers of an electric utility for peak load reduction, this significant reduction in peak power can be of benefit to the utility depending upon the time of the utility or system peak.

In addition to the energy savings and peak load reduction potential of highly insulating windows, the thermal comfort implications of more uniform temperature distributions in Lab Home B compared to Lab Home A cannot be discounted. In addition, the highly insulating windows in Lab Home B enabled the maintenance of the average interior temperature near the thermostat set point throughout the day, while 
elevated temperatures were observed in Lab Home A. During the heating season, the high SHGC in the baseline windows resulted in overheating of the interior space despite the cold outdoor air temperatures. In the cooling season, the heat pump was unable to keep up with the cooling load caused by the high outdoor air temperature, high solar heat gain, and limited internal gains. If full occupancy schedules had been used, internal gains would increase, further exaggerating the effects of an undersized heat pump and potentially resulting in uncomfortably warm interior temperatures.

The window surface temperatures also affect the comfort felt by occupants in the home. A window with a colder surface temperature will cause the occupant to feel colder near the window due to the lower window surface temperature than the measured dry bulb room temperature would suggest. This effect is partially illustrated by the dramatically cooler window surface temperatures observed in the baseline home of as low as $50^{\circ} \mathrm{F}$ compared to the experimental home where the window surface temperature never dropped below $60^{\circ} \mathrm{F}$. Overall, the average nighttime MRT in Lab Home B was slightly warmer than the average MRT in Lab Home A. Also, Lab Home A exhibited higher high temperatures and lower low temperatures as measured by the MRT.

Cold interior glass surface temperatures can also affect the health and durability of a home, in addition to its comfort. Cold glass surface temperatures can cause condensation on the inside of the glass and frame, which in time can lead to mold and rot. This experiment did not directly measure the presence of condensation on the windows, nor was additional humidity from occupancy introduced into either home for this experiment. However, window condensation is a common occurrence in most homes during the heating season, and can be of concern to residents. In climates with elevated relative humidity levels such as in the PNW coastal climate, or in residences with significant interior moisture generation, window condensation on interior window surfaces would likely occur. At an average outdoor temperature of $49^{\circ} \mathrm{F}$, an interior window temperature was recorded as low as $50^{\circ} \mathrm{F}$ in Lab Home A, while the lowest interior window temperature recorded was $60^{\circ} \mathrm{F}$ in Lab Home B. ${ }^{1}$ With these temperatures and an average interior room temperature of $75^{\circ} \mathrm{F}$, the relative humidity of the air in Lab Home B would have to exceed $70 \%$ to cause condensation on the highly insulating performance windows, while a $40 \%$ relative humidity would cause condensation on the double-pane windows in Lab Home B. For reference, during the study period, the average relative humidity in Lab Home A was $20.7 \%$ and the maximum was $31.7 \%$; the average relative humidity in Lab Home B was $21.7 \%$ and the maximum was $28.1 \%$.

EnergyPlus models were created to extrapolate measured energy savings during the study period to an entire year. The modeled results generated using EnergyPlus compare fairly well to the measured energy use and savings. The model shows $13.9 \%$ savings over the study period, from February to April and July to August 2012, and predicts $13.15 \%$, or $1,370 \mathrm{kWh}$, annual energy savings. This is as compared to estimated annual savings based on the measured data, extrapolated based on typical annual HDD and $\mathrm{CDD}$, of $1,784 \mathrm{kWh}$ or $12.2 \%$. Future work will involve using real weather data in the energy simulation and matching daily load profiles exactly for the heating and cooling seasons to create a calibrated model that represents the actual observed savings for heating and cooling seasons. This calibrated model can then be used to extrapolate the measured savings to different climate zones to predict performance of the high-performance windows regionally or nationally. Annual measured data and savings will also be

\footnotetext{
${ }^{1}$ The highly insulating windows in Lab Home B have sealed cavities with desiccant material to eliminate any (visible) condensation on inside surfaces of the glass. As noted, the overall insulating properties of the window will minimize the potential for condensation on the interior-facing glass surface even with very cold outdoor temperatures.
} 
compared to other modeling software, particularly the SEEM (Simple Energy Efficiency Model) simulation tool, ${ }^{1}$ which is used in the PNW for determining measure cost and benefits for utility energy efficiency programs.

Measured energy savings of highly insulating windows in the PNNL Lab Homes exhibits significant energy savings. However, the cost of highly insulating windows must be considered when determined the viability of them as an energy efficiency measure. The cost for the highly insulating windows to retrofit these homes is highly variable, so multiple cost scenarios were considered. However, even the low-cost scenario, an installed cost of $\$ 25 / \mathrm{ft}^{2}$, and the extrapolated measured data to estimate annual energy savings, $1,784 \mathrm{kWh} / \mathrm{yr}$, resulted in a PBP of 23 years. The PBP ranged as high as 55 years. This indicates that retrofitting highly insulating windows is still difficult from a cost-effectiveness perspective, due to the high capital cost of windows. However, the study also illustrated that the windows provide additional non-quantifiable benefits, such as increased comfort levels, reduced peak load, and decreased condensation potential.

These data suggest that highly insulating windows are an effective energy-saving measure that should be considered for high-performance new homes and in existing retrofits. However, the cost effectiveness of the measure, as determined by the simple PBP, suggests that highly insulating window costs continue to make windows difficult to justify on a cost basis alone. Additional reductions in costs via improvements in manufacturing and/or market penetration that continue to drive down costs will make highly insulating windows much more viable as a cost-effective energy efficiency measure. In addition, this study illustrates that highly insulating windows have important impacts on peak load, occupant comfort, and condensation potential, which are not captured in the energy savings calculation. More consistent and uniform interior temperature distributions suggest that highly insulated windows, as part of a high performance building envelope, may enable more centralized duct design and downsized HVAC systems. Shorter, more centralized duct systems and smaller HVAC systems could yield additional cost savings, making highly insulating windows more cost effective as part of a package of new construction or retrofit measures which achieve significant reductions in home energy use.

${ }^{1}$ A Simple Energy Efficiency Model. http://www.nwcouncil.org/energy/rtf/measures/support/SEEM/Default.asp 


\subsection{References}

ASTM International. 2010. Standard Test Method for Determining Air Leakage Rate by Fan

Pressurization. ASTM Standard E779-10, West Conshohocken, Pennsylvania.

Energy Information Administration (EIA). 2009. Residential Energy Consumption Survey. Available at: http://www.eia.gov/consumption/residential/index.cfm

Energy Information Administration (EIA). 2012. Electricity Explained: Factors Affecting Electricity

Prices. Available at:

http://www.eia.gov/energyexplained/index.cfm?page=electricity_factors_affecting_prices

Hendron R and C Engebrecht. 2010. Building America House Simulation Protocols. National

Renewable Energy Laboratory. Golden, Colorado. Available at:

http://apps1.eere.energy.gov/buildings/publications/pdfs/building_america/house_simulation_revised.pdf

The Energy Conservatory. 2006. TrueFlow Air Handler Flow Meter Operation Manual. Minneapolis, Minnesota. Available at: http://www.energyconservatory.com/download/tfman.pdf

The Energy Conservatory. 2010. Exhaust Fan Flow Meter Operation Manual. Minneapolis, Minnesota. Available at: http://www.energyconservatory.com/download/boxman.pdf

The Energy Conservatory. 2011. Minneapolis Duct Blaster Operation Manual. Minneapolis, Minnesota. Available at: http://www.energyconservatory.com/download/dbmanual.pdf

The Energy Conservatory. 2012. Minneapolis Blower Door Operation Manual for Model 3 and Model 4 Systems. Minneapolis, Minnesota. Available at:

http://www.energyconservatory.com/download/bdmanual.pdf

National Renewable Energy Laboratory (NREL). 2012. National Residential Efficiency Measures

Database. Available at: http://www.nrel.gov/ap/retrofits/measures.cfm?gId=1\&ctId=47\&scId=558

Parker GP, SH Widder, and NN Bauman. 2012. Field Evaluation of Highly Insulating Windows in the Lab Homes: Winter Experiment. PNNL-21524, Pacific Northwest National Laboratory, Richland, Washington.

Washington State Building Code Council. 2009. 2009 Washington State Energy Code: Chapter 51-11 WAC. Olympia, Washington. Available at: https://fortress.wa.gov/ga/apps/sbcc/File.ashx?cid=1096

U.S. Department of Energy (DOE). 2011. Buildings Energy Data Book. Available at:

http://buildingsdatabook.eren.doe.gov/. 




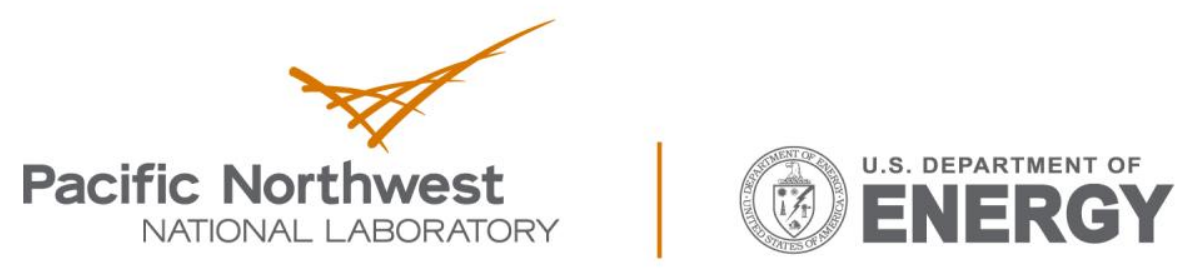

Proudly Operated by Battelle Since 1965

902 Battelle Boulevard

P.O. Box 999

Richland, WA 99352

1-888-375-PNNL (7665)

www.pnnl.gov 